\title{
Literacy knowledge among teachers: Considerations for implementation of the Rtl initiative
}

Amy F. Conner Love

West Virginia University

Follow this and additional works at: https://researchrepository.wvu.edu/etd

\section{Recommended Citation}

Love, Amy F. Conner, "Literacy knowledge among teachers: Considerations for implementation of the Rt। initiative" (2010). Graduate Theses, Dissertations, and Problem Reports. 3527.

https://researchrepository.wvu.edu/etd/3527

This Dissertation is protected by copyright and/or related rights. It has been brought to you by the The Research Repository @ WVU with permission from the rights-holder(s). You are free to use this Dissertation in any way that is permitted by the copyright and related rights legislation that applies to your use. For other uses you must obtain permission from the rights-holder(s) directly, unless additional rights are indicated by a Creative Commons license in the record and/ or on the work itself. This Dissertation has been accepted for inclusion in WVU Graduate Theses, Dissertations, and Problem Reports collection by an authorized administrator of The Research Repository @ WVU.

For more information, please contact researchrepository@mail.wvu.edu. 
Literacy Knowledge Among Teachers: Considerations for Implementation of the RtI Initiative

\author{
Amy F. Conner Love \\ Dissertation submitted to the College of Human Resources and Education \\ at West Virginia University \\ in partial fulfillment of the requirements \\ for the degree of \\ Doctor of Education \\ in \\ Special Education
}

David Hoppey, Ph. D., Committee Co-Chairperson

Elizabeth Dooley, Ed. D., Committee Co-Chairperson

Ann Richards, Ph. D.

Richard Walls, Ph. D.

Diane Yendol-Hoppey, Ph. D.

Department of Special Education

Morgantown, West Virginia
2010

Keywords: response to intervention; literacy knowledge; teaching reading;

professional development; teacher training 


\section{ABSTRACT \\ Literacy Knowledge Among Teachers: Considerations For Implementation Of The RtI Initiative}

\section{Amy F. Conner Love}

A literacy knowledge assessment survey was designed to assess in-service teachers' literacy knowledge and determine the effect of professional training in reading instruction, teaching credentials, and years of experience on their literacy knowledge. This quantitative study used descriptive statistics to examine the relationship between variables of teacher demographics (professional development participation, professional development content, courses taken at a college or university, teaching credentials, and years of experience), comparisons between teachers who teach elementary general education, secondary general education (English/language arts), special education, and those who are reading teachers/reading specialists/literacy coaches, and comparisons between novice and veteran teachers. This study was conducted in one school district in Pennsylvania. Univariate ANOVA analysis demonstrated statistically significant differences in the literacy knowledge of those who were trained in data analysis. Independent t-tests indicated a significant effect for Teaching Certification with those certified in special education receiving higher scores than those certified in English or middle level language arts. There was also a significant effect for Current Teaching Position with those who were a reading teacher/specialist or literacy coach receiving higher scores than those who taught English or middle level language arts. 


\section{Dedication}

The author wishes to dedicate this work to the memory of her grandmother, Dorothy E. Conner, who passed on a love of learning and respect for education. 


\section{Acknowledgements}

I am grateful for all the support I have received while researching and writing this dissertation. Thanks especially go to the following individuals:

My Family, especially my daughters, Julia and Ava, who have endured me throughout the process with unyielding support and love.

Dr. David Hoppey, who has read countless drafts, for his flexibility, patience, words of encouragement, and ability to keep me in the right direction.

Dr. Elizabeth Dooley, for her support and kind words.

Dr. Ann Richards, for her willingness to help.

Dr. Richard Walls, for his humor and impeccable editing skills.

Dr. Diane Yendol-Hoppey, for her ability to "say it with a smile."

Dr. Daniel Trimmer, for his swift response in approving and supporting the study.

Sue Crouse, for her support and link to potential participants.

Daryl Cranston, for listening to my moaning and complaining and trying to support in any way possible every step of the way.

Trina Moore, for lending an ear and her faithful encouragement.

Dr. Richard Sabousky, for his words of wisdom.

Finally, to all my students, past and present, for the inspiration they gave. 


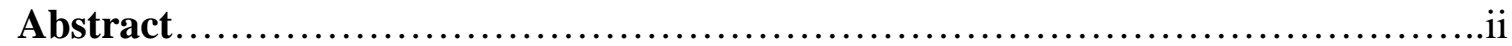

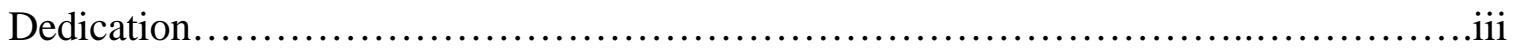

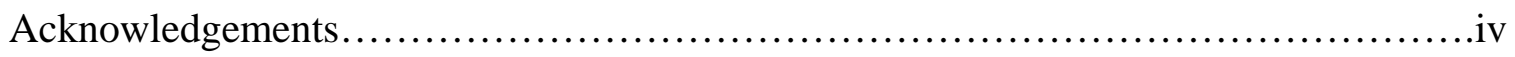

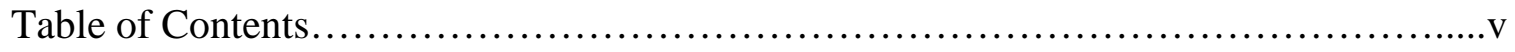

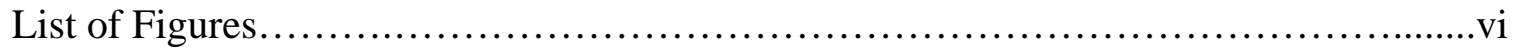

List of Tables........................................................................

Chapter 1: Introduction.........................................................

Statement of the Problem...................................................... 5

Purpose of the Study .......................................................

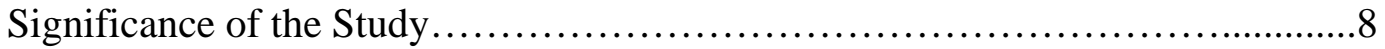

Limitations............................................................. 9

Chapter 2: Review of the Literature............................................ 10

Historical Relevance of Reading Instruction................................10

The Mandate of Scientifically-Based Reading Practices........................15

Response to Intervention.................................................18

Teacher Preparedness....................................................24

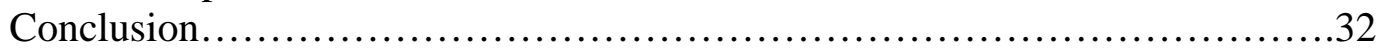

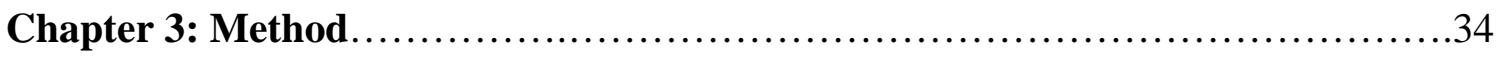

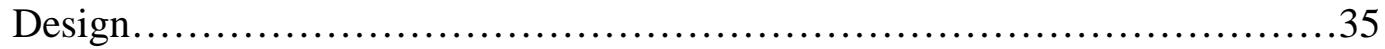

Selection of Participants.................................................. 36

Instrumentation...................................................... 38

Data Collection...........................................................40

Data Analysis........................................................41

Chapter 4: Results.......................................................... 50

Summary of Purpose and Procedures.......................................50

Results of Literacy Knowledge Assessment Survey............................51

Results of the Data Analysis by Research Question............................54

Research Question 1.............................................54

Research Question 2.............................................62

Research Question 3.................................................64

Research Question 4................................................ 71

Summary of Findings..............................................73

Chapter 5: Summary of Findings, Recommendations, and Implications for the Field

................................................................... 74

Summary of Findings................................................. 74

Research Question 1.................................................74

Research Question 2....................................................75

Research Question 3...............................................75

Research Question 4.............................................77

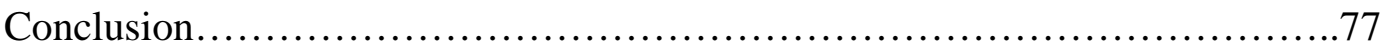

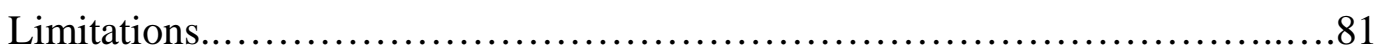

Recommendations.................................................... 82

Implications.......................................................... 84

References..................................................................... 


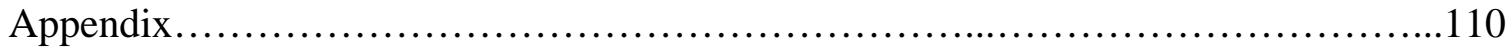

Survey of Teacher Knowledge in Literacy Instruction......................110

Consent Forms.........................................................123

Correct responses on each Literacy Knowledge Assessment item...............129 


\section{LIST OF FIGURES}

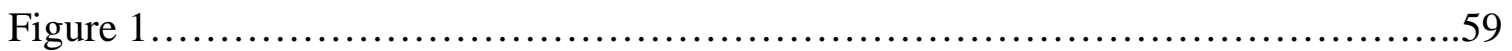

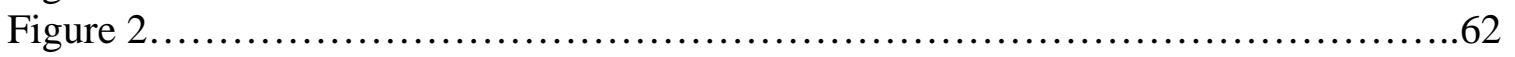

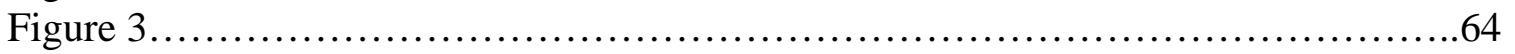

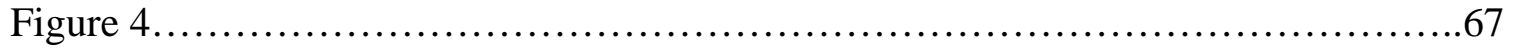

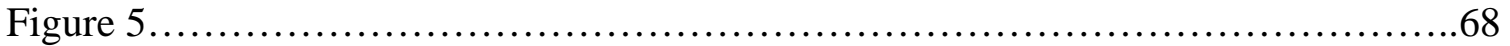

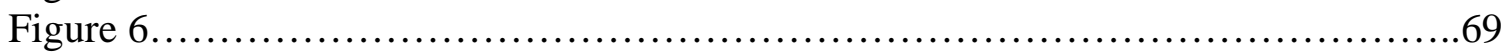

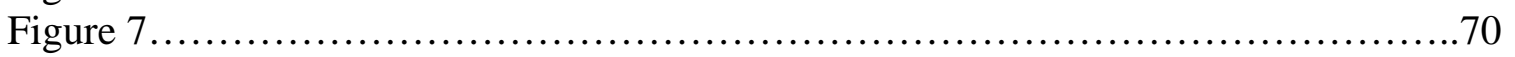

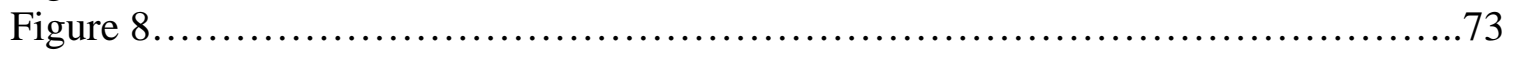




\section{LIST OF GRAPHS}

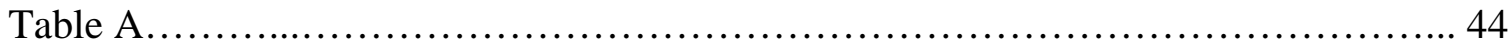

Table B....................................................................45

Table C....................................................................46

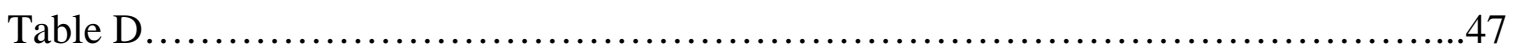

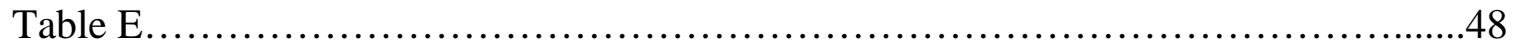

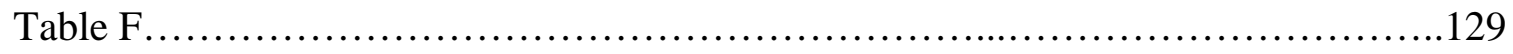

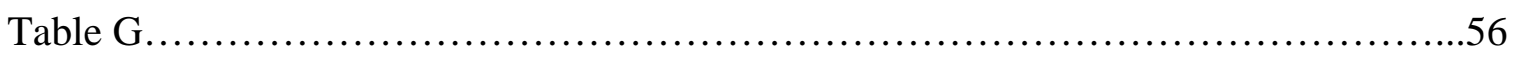

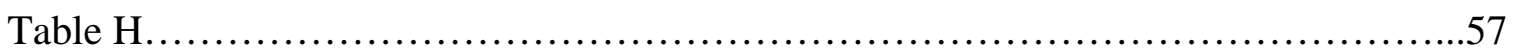

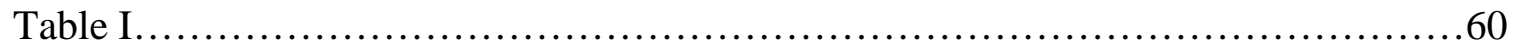

Table J.....................................................................61

Table K.....................................................................63

Table L...................................................................63

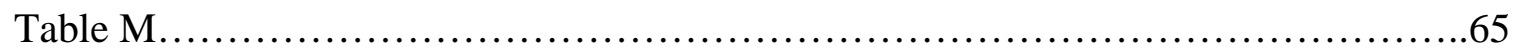

Table N....................................................................66

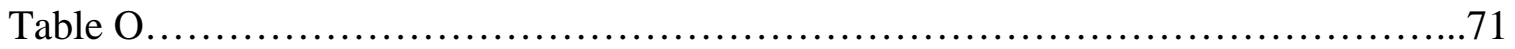

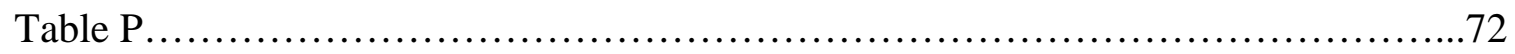

Table Q...................................................................... 72

Table R...................................................................73 


\section{Chapter 1}

\section{Introduction}

The ability to meet the needs of all learners and provide appropriate instruction is an expectation of all teachers. In an era of increased accountability and standards-driven instruction, it is imperative that teachers provide educational opportunities through instruction that facilitate learning. The task is daunting as teachers come into the classroom with varying levels of knowledge, experience, and ability, many unprepared to teach all students, specifically, struggling learners.

Response to Intervention (RtI) is a promising approach in meeting the needs of all learners by encouraging teachers to think about student learning and instructional needs (Roehrig, Duggar, Moats, Glover, \& Mincey, 2008) while incorporating differentiated instructional interventions with frequent assessment to determine student growth and/or needs (Mellard, Deshler, \& Barth, 2004; Mesmer \& Mesmer, 2008). Such responsive, or student-driven, teaching is not new to the field of education (Kashi, 2008). Based on

principles established by B. F. Skinner in the early 1960s, trends in responsive teaching include Direct Instruction, Precision Teaching, and Personalized System of Instruction (Kashi, 2008). Tiering of instruction based on student performance has been used in states such as Pennsylvania's Instructional Support System (Kovaleski \& Glew, 2006) and Iowa's Heartland Problem Solving Model since the 1980s (Jankowski, 2003). However, federal mandates due to underachievement on standardized reading tests of students at-risk from minority groups, low socioeconomic status, and those with disabilities, the underlying premises of responsive teaching has resurfaced nationally using the widely accepted expression "response to intervention." 
According to The Nation's Report Card (2007), reading scores prior to the 2001 mandates requiring scientifically-based reading instruction indicated that the average fourth and eighth grade reader were not considered proficient (U.S. Department of Education, 2007) prompting the passing of the No Child Left Behind Act (NCLB; 2001) and the Reading First initiatives. Since the inception of these mandates, there has been mixed results in improving reading performance for students that struggle, from low socioeconomic status, and/or minority groups. This has occurred despite increasing time spent on reading instruction. On a more positive note though, while improvement has been minimal there has been some overall improvement in reading as evidenced by the rise in decoding skills indicated on some standardized tests (Gamse et al., 2008).

Seemingly, in reaction to the initiatives established by NCLB (2001) and Reading First, the recent reauthorization of the Individuals with Disabilities Education Act (IDEA; 2004) echoes the need for evidence-, or scientifically-, based reading interventions as a way to address the ballooning presence of students with specific learning disabilities (SLD). IDEA also recognizes RtI as a promising practice for early intervention for learners who struggle. In response to these established federal mandates, many states have begun RtI implementation (Berkeley, Bender, Peaster, \& Saunders, 2009) satisfying the NCLB (2001) and Reading First initiatives' scientifically based reading instruction requirement (Bursuck et al., 2004; Whitfield, 2005).

RtI is a multi-tiered reading intervention that includes core instruction provided in general education classrooms (tier one) and depending on student response to instruction, supplemental instruction or intervention for struggling students that is targeted to student areas of need (Bradley, Danielson, \& Doolittle, 2007; Burns \& Ysseldyke, 2005; Fuchs, 
D. \& Fuchs, 2006). Students are provided increasingly intensive intervention(s) (successive tiers) based on analysis of student progress that ultimately could result in special education referral for non-response at the designated final tier (Bradley et al.; Burns \& Ysseldyke, 2005).

While research is inconclusive on specific programs improving student achievement for every child, when properly developed and implemented RtI and scientifically-based reading programs have proven to be effective (Gibbons, n.d.). This has occurred despite many of the curriculum programs being highly prescriptive and rigid (Burns \& Ysseldyke, 2005; Gerstl-Pepin \& Woodside-Jiron, 2005). According to a study conducted by Shinn (2007), more than $90 \%$ of at-risk students responded to interventions imposed within the RtI tiers. While Vaughn, Linan-Thompson, and Hickman (2003) found a majority of at-risk students responded to interventions, they also found it "very concerning that 8 of 24 (about 33\%) were unable to make even minimal progress" (p. 405).

Additionally, some research is beginning to emerge that suggests RtI has resulted in fewer referrals and placements in special education (Burns \& Ysseldyke, 2005; Marston, 2005; Shinn, 2007). Torgesen (2009) indicates significant drops in referrals to special education in schools effectively implementing the RtI process. Emerging studies suggest that students placed in special education at the most intense tier have demonstrated positive outcomes academically as a result of participation in the RtI process (Burns \& Ysseldyke, 2005; Harn, Linan-Thompson, \& Roberts, 2008; Kamps et al., 2008; Stecker, 2007). For instance, Harn et al. found that "students in more intense intervention outperformed students in the less intense intervention" (p. 121) with 
significant effect sizes by outscoring their same-age peers on a standardized measuring device. Furthermore, in a study conducted by Kamps et al. (2008), more than $40 \%$ of students in the most intense instructional tier reached on-grade benchmark levels. Therefore, RtI should be primarily be considered a process of preventing "long-term academic and social failure" (Fuchs, D. \& Fuchs, 2006, p. 621) rather than a method to identify students in need of special education services.

While most RtI program designs acknowledge a general education beginning and depending on response to instruction and intervention efforts ends in possible special education services, there is not a clear definitive point among the multi-tier programs that pinpoints entry into special education (Berkeley et al., 2009; Reschly, 2005). State and/or local educational agencies are typically responsible for setting forth the timeframe or student performance required at each tier as well as an entry point into special education. Moreover, progression through the tiers is often subjective, determined by the teachers' projections based on assessment performance, as measured and compared to peer performance at each tier. This critical phase of the RtI model relies heavily on the expertise of general education teachers in determining appropriate interventions for students who struggle (Dean, Burns, Grialou, \& Varro, 2006; Kratochwill, Volpiansky, Clements, \& Ball, 2007; Stecker, Fuchs, \& Fuchs, 2008). This is problematic as many general educators have not been properly educated in data based decision making, scientifically based reading instruction, and collaborative problem solving required to effectively implement RtI systematically (Armstrong, Cusumano, Todd, \& Cohen, 2008; Bryant, Linan-Thompson, Ugel, Hamff, \& Hougen, 2001;Mather, Bos, \& Babur, 2001; Wiener \& Soodak, 2008). 
Moreover, many teachers lack the knowledge to effectively teach students reading skills (Moats, 1994; Risko et al., 2008) possibly perpetuating the reading problems of struggling students (Fuchs, D. \& Fuchs, 2006; Gersten \& Dimino, 2006). According to a study conducted by the National Center for Education Statistics (2004), while reading specialists have the most training in reading instruction, they comprise less than 3 percent of elementary level teachers. This leaves the majority of reading instruction for the most at need students to general education and special education teachers who lack the expertise needed to design and implemented effective reading methods to meet the diverse learning needs of our most vulnerable students. Effective RtI models of instruction seek to address this dilemma by providing support for teachers and struggling readers alike.

\section{Statement of the Problem}

One way to support students with reading problems and those at risk of developing reading problems is to provide appropriate and effective reading instruction and interventions. While RtI is a model that allows students to receive interventions immediately without having to wait for some sort of classification designation, its effectiveness is dependent on the expertise and knowledge level of teachers. It has been suggested that teachers determine much of the success of RtI implementation and student progression through the tiers, determining the need for remediation and ultimately special education services (Gersten \& Dimino, 2006; Kratochwill et al., 2007). Teachers have shown to be consistent and resolute in the instruction and assessment of student performance provided they are properly educated in the intricacies of the model and curriculum (Meisels, Bickel, Nicholson, Xue, \& Atkins-Burnett, 2001). Empirical 
evidence indicates that student performance is related to the knowledge levels and training of teachers (McCutcheon, Abbott et al., 2002; McCutcheon, Green, Abbott, \& Sanders, 2009; Spear-Swerling \& Brucker, 2004). While students in classrooms where teachers were not exposed to professional development demonstrated some literacy growth, student gains were not as substantial when compared to students whose teachers had expanded their own knowledge through literacy professional development (McCutcheon, Abbott et al.). Further, McCutcheon, Green et al. (2009) found that the more in depth knowledge teachers possessed in literacy instructional concepts, the more effective the teachers were in addressing the needs of struggling readers.

On the other hand, other research indicates that a teacher's motivation and subsequent effort is often in relation to their knowledge of the individual students and ultimately has a significant impact on student success in the classroom (Gerber, 2005; Oortwijn, Boekaerts, \& Vedder, 2008; Sherman, Rasmussen, \& Baydala, 2008). Specifically, a teacher's motivation and effort is in direct relation to their comfort level in their instructional subject knowledge as well as their knowledge of teaching students with diverse needs within the classroom. Therefore, there is a need for continued research and evaluation in understanding the knowledge levels of in-service teachers to determine the specific skills teachers need to learn as they provide appropriate reading instruction for struggling learners. Subsequently, professional development should be designed not only to address the instructional needs of teachers but also take into careful consideration opportunities for teachers to discuss and develop effective RtI models of instruction. Until school systems can identify the specific needs of their teachers based on demonstrated knowledge levels and skills, schools will simply design ineffective 
professional development opportunities limiting potential for fostering systematic acquisition of skills needed to teach students reading.

\section{Purpose of the Study}

The purpose of this study is to investigate the knowledge and skill levels of novice and veteran teachers who provide reading instruction to students in a climate of change as RtI is embraced as a model of instruction. With the implementation of RtI, teachers need to be effective literacy instructors for all students. As local educational agencies and states respond to the mandates of state and national policy shifts and begin to implement RtI as a framework for providing high quality instruction to all students, teachers must be equipped with the knowledge, skills, and strategies to meet these shifts. However, before schools, districts, and states move forward they must accurately assess teachers' knowledge and skills for teaching literacy. Therefore, the overarching research question that guides this study is: Are teachers properly equipped with the knowledge and skills necessary to effectively teach reading to struggling learners? Specifically, the outcome goal is to determine if teachers are sufficiently prepared to implement RtI and possess the capacity to meet the mandates based upon performance on the literacy knowledge assessment. To further understand teacher knowledge of effective reading instruction, this research will also seek to uncover how teachers acquire the necessary skills to become successful reading teachers. These questions include:

1. Is there a relationship between the number of activities/workshops attended by participants and their achievement on the literacy knowledge assessment? 
1a. For those teachers who received a majority of their training through professional development opportunities, is there a relationship between the number of activities/workshops attended and their performance on the literacy knowledge assessment?

1b. For those teachers who received a majority of their training through coursework, is there a relationship between the number of classes taken and performance on the literacy knowledge assessment?

2. Did teaching assignment or role in providing reading instruction affect their achievement on the knowledge assessment?

2a. Is there a significant difference between teachers credentialed in special education and/or reading and those who are only content or general education credentialed teachers performance on the literacy knowledge assessment?

2b. Is there a significant difference between novice (those possessing less than one year to three years of public education teaching experience) and veteran (those possessing more than three years of public education teaching experience) teachers performance on the literacy knowledge assessment?

\section{Significance of Study}

This study seeks to add to the literature by evaluating current teacher's knowledge of effective literacy instruction. Establishing knowledge levels of teachers and 
determining their strengths and weaknesses allows district and school leaders to design and systemically implement appropriate professional development to ultimately improve outcomes for all students. Therefore, a pragmatic outcome of this type of research is to design effective professional development opportunities targeting not only the RtI framework but also explicitly focusing on providing research based literacy instruction in the areas of student need. The structure of RtI has the potential to provide effective literacy instruction to students learning to read if professional development opportunities positively affect the knowledge levels of teachers, and simultaneously facilitate appropriate literacy instruction.

\section{Limitations}

This study has several limitations. First, the sample size disallows for the generalizability of the results. Second, all participants were from one southwestern Pennsylvania school district therefore, responses to questions may not be generalizable to other school systems. Finally, the study was conducted in the midst of preparation for state assessments possibly impacting the number of voluntary participation in the study. 


\section{Chapter 2}

\section{Review of the Literature}

This chapter describes literature relevant to the research purposes of this doctoral dissertation. It is organized into four sections: (1) the historical relevance of reading instruction and identified best practices, (2) the mandates establishing the need for scientifically-based reading practices, (3) an introduction and summary of RtI, and (4) the relationship between teacher preparedness for teaching reading to struggling learners and implementing RtI systemically.

\section{Historical Relevance of Reading Instruction}

While there is very little documentation of literacy history beyond the growth of children's literature prior to the mid-1960s (Moore, Monaghan, \& Hartman, 1997; Kim, 2008), best instructional practices in teaching reading to children historically seem to have fluctuated between phonics instruction and whole language approaches (Adams, 1990; Allington \& McGill-Franzen, 2000; Brown, 2006; Cooper, 2000; Miller, 2000). Between the fifteenth and nineteenth centuries, reading instruction seemingly focused primarily on phonics components (Adams, 1990; Brown, 2006; Hempenstall, 1997). With Pascal's invention of synthetic phonics in the $17^{\text {th }}$ century, phonics became more accessible and alphabetic code-based reading instruction grew as a method for teaching students to read. This system of synthetic phonological coding of the alphabet was further developed and used by Noah Webster whose work focused on syllable mastery as a means for teaching beginning reading skills (Rodgers, 2004).

Starting in the 1820s, whole word methods of teaching reading emerged. This trend was supported by Horace Mann's 1844 "Seventh Annual Report" that viewed whole 
word reading instruction as an efficient means to teaching and acquiring reading skills (Brown, 2006; Urban \& Wagoner, 2009). Whole word methods of instruction emphasized meaning-based reading, promoting focus on the meaning of words and a reliance on context clues and semantics to figure out unfamiliar/unknown words (Rodgers, 2004). Whole word methods of reading instruction were predominant during the time period which lasted through the 1950s and reemerged again in the 1980s and 1990s (Brown, 2006; Pearson, 2004).

Of note is that during the mid-twentieth century, there was a call for a return to phonics instruction based on recent research (Flesch, 1955; Chall, 1967) providing evidence for the superiority of phonics instruction over whole word methods of reading instruction. However, contrary to research findings by Chall (1967) and Flesch (1955) on the effectiveness of phonics instruction and best reading instructional practices for struggling readers, whole language continued to be emphasized and in fact the use of whole language instruction increased in the schools late into the twentieth century (Brown, 2006).

More recently, as results of brain-based research emerged (Brown, 2006; Gray, 2008; Holden, 2004) coupled with the National Reading Panel's (NRP, 2000) in depth study of effective reading instructional methods, phonics-based instruction was once again viewed as best instructional practice. By exploring the impact of reading tasks on patterned brain activity using brain imaging, it was found that students who utilized phonics in decoding unfamiliar words were able to recall the words with relative automaticity creating essential neural pathways in the brain (Hempenstall, 2006). Additional studies indicate that poor readers lack well-developed phonological skills and 
rely on memory to read (Shaywitz et al., 1998; Shaywitz, Mody, \& Shaywitz, 2006). Further, with the aid of brain imaging, intensive phonics instruction with struggling readers is shown effective in developing and honing skills creating neural pathways in the brain enabling more accurate and automatic recognition of words (Gray, 2008;

Hempenstall, 2006). As more brain-based research is conducted, researchers are finding that best instructional practices in reading include explicit and systematic instruction particularly in phonological skills (Shaywitz, Lyon, \& Shaywitz, 2006).

Curriculum materials used during reading instruction made shifts as well to reflect the changing trends over the past two centuries. This was due in part to the ongoing debate that occurred over the best approach to teaching reading skills to children, specifically, phonics, whole language, and balanced literacy approaches (Adams, 1990; Allington \& McGill-Franzen, 2000; Cooper, 2000; Miller, 2000). For example, the fifteenth through the eighteenth century saw phonics instruction provided through such mediums as hornbooks and spellers (Brown, 2006; Urban \& Wagoner, 2009). Hornbooks were simply a single piece of paper pasted onto a paddle that typically contained the alphabet and The Lord's Prayer and was given to beginning readers. The speller was an instructional book embedded in syllabic phonic principles where students read the series of letters making up syllables using basic alphabetic coding. During the nineteenth century a gradual decline in phonics instruction was evident in American schools as phonics-based reading programs and reading series such as the Leigh and McGuffey Readers were being replaced by popular whole language readers such as the Dick and Jane series (Brown, 2006; Urban \& Wagoner, 2009). In the early 1900s, researchers and leaders in the field of education emphasized the need for reading 
curriculum based on controlled, common vocabulary to allow students to glean more meaning from text (Allington \& McGill-Franzen, 2000). Curriculum materials shifted to include common language and situations in which students could identify.

Due to criticism in the early 1960s on the educational programs in reading instruction, Mary Austin and Coleman Morrison (1963) conducted a study that indicated concerns including over-reliance of basal readers as the main tool of instruction, not meeting the needs of all students, and insufficient teacher preparation in teaching students to read. In a similar study conducted 35 years after Austin and Morrison's study Baumann and his colleagues (2000), suggest that while reading instruction had improved, deficits in reading skills and achievement gaps continue to exist. The results of this study concluded with recommendations in which many of them "paralleled more contemporary concerns" (Baumann et al., 2000, p. 341) including differentiating instruction to meet the varied needs of students and effective training of teachers in reading instruction.

In the late 1980s, the trends shifted from the "controlled vocabulary basal reader" to literature-based instruction that indicated a decrease in reliance on the basal readers for reading instruction (Allington \& McGill-Franzen, 2000, p.139). This shift occurred because of the increase in availability of quality, engaging children literature that lent itself readily to teaching beginning readers (Martinez \& McGee, 2000). As a result, literature was emphasized and skills instruction became secondary leading to less reliance on the basal reader (Martinez \& McGee, 2000). Instruction included a heavy emphasis on oral reading strategies and miscue analysis once again (Rasinski \& Hoffman, 2003) while focusing on comprehension skills, and providing explorative, authentic tasks as a way to lead students to engage with the various texts (Quick, 1998). 
During the 1990's, a re-emergence of basal readers in providing core reading instruction has occurred (Kindig, 2006; Whitfield, 2005). However, most basal readers require a scripted approach and have little to no supplemental instruction that targets the needs of struggling readers. This troubling trend inadequately addresses the diverse ways in which children acquire knowledge and develop skills in reading (Kindig, 2006;

Whitfield, 2005). In addition, students who were educated with the more prescriptive or intervention reading programs demonstrated an inability to not only "construct meaning from reading materials“ but, "that NCLB curtailed attention to individual needs because of the overarching group work and recitation" (Whitfield, 2005, p. 45). Moreover, some scholars believe that reading instruction as implied through these mandates reduces the instructional focus to basic skill acquisition, neglecting text and instructional practices that includes all genres of literature, disallowing student exposure to higher order thinking skills (Kindig, 2006; Manzo, 2008).

Despite the pendulum-like swings in reading curriculum and instruction, "elementary school children's reading achievement in the U.S. has remained quite stable over the past 30 years" (Allington \& McGill-Franzen, 2000, p. 142). However, as Moore et al. (1997) point out, "Past forms of pedagogy were not designed to fulfill current aspirations" (p. 91) of attaining 100 percent reading proficiency of the U. S. population. This policy initiative highlights the lack of blanketed success desired from current reading practices and calls for a new method of reading instruction that is research based and meets the challenge of matching instruction to the needs of all learners. 


\section{The Mandate of Scientifically-Based Reading Practices}

During his presidency, George W. Bush signed into law the NCLB Act (2001) and the Reading First initiative in an attempt to ensure that 100 percent of American students reached reading proficiency (Kovaleski, 2007). Because of a history of poor reading performance on standardized reading tests, NCLB required the implementation of research- or scientifically-based reading programs (Bursuck et al., 2006; Manzo, 2008; Whitfield, 2005). NCLB highlights recent reading research that indicated improved outcomes for struggling readers can occur when students are provided scientifically based reading programs (Al Otaiba, Kosanovich-Grek, Torgesen, Hassler, \& Wahl, 2005; Gerstl-Pepin \& Woodside-Jiron, 2005) that specifically include the five key components of reading: phonemic awareness, phonics, reading fluency, vocabulary, and comprehension (Kindig, 2006; Manzo, 2008).

The National Reading Panel's (NRP; National Institute of Child Health and Human Development, 2000) report indicates that effective reading instruction should include and incorporate a balance of systematic and explicit instruction in these components as each has proven to impact reading skill acquisition (National Institute of Child Health and Human Development, 2000). Each component identified by the NRP builds upon the others and are dependent on one another.

Phonemic awareness, the first component, is the ability to hear, identify, and manipulate individual sounds (phonemes) within words (Carnine, Silbert, Kame'enui, Tarver, Jungjohann, 2006; Cooper, 2000; Kindig, 2006; Richek, Caldwell, Jennings, \& Learner, 1996). Students need to demonstrate mastery of phonemic awareness in order to perform phonics tasks. It not only provides a foundation on which to build phonics skills 
and is linked to improved word recognition and spelling skills (Ehri et al., 2001; Kroese, Hynd, Knight, Hiemenz, \& Hall, 2000) as well as increased comprehension skills (Ehri et al.; Engen \& Hoien, 2002).

The second component, phonics skills, allows the reader to attach letters to sounds heard within words and incorporate this knowledge in the decoding of the written words (Carnine et al.2006; Cooper, 2000; Kindig, 2006; Richek et al., 1996). Students with strong phonics skills demonstrate higher word recognition, engage in fluent reading, and have higher comprehension skills (Eldredge, 2005; Foster \& Miller, 2007).

The third component, fluency, is the speed and accuracy at which one reads (Cooper, 2000). Carnine et al. (2006), define fluency as "the ability to read a text quickly and accurately with ease and expression" (p. 141). Reading fluency relies heavily on the reader's strengths in automatically decoding words using phonemic awareness and phonics skills as well as having a well-developed background knowledge and vocabulary.

Vocabulary development is explicitly linked to comprehension (Cooper, 2000; Kindig, 2006), and includes the process of recognizing and identifying words automatically within text (Cooper, 2000) in order to "comprehend and communicate effectively" (Carnine et al., 2006, p. 181). In addition, vocabulary development also aids in the acquisition of phonemic awareness and pre-reading skills (Engen \& Hoien, 2002; McKay \& Thompson, 2009; Wise, Sevcik, Morris, Lovett, \& Wolf, 2007).

The final component, comprehension, relies on the mastery of all prior components (Cooper, 2000) and is "an active and thoughtful interaction with the text" (Kindig, 2006, p. 30) allowing the reader to demonstrate understanding. Studies have 
indicated that explicit instruction in comprehension strategies correlated to increased student achievement (Connor, Jakobsons, Crowe, \& Meadows, 2009).

In order for districts and schools to receive federal funding through the Reading First initiative, specific criteria must be met including below-state-average fourth grade reading scores and having more than 50 percent of the student population qualifying for free or reduced lunch (Al Otaiba et al., 2005). The reading programs implemented in the schools receiving Reading First monies must have "90 minutes of sustained reading instruction daily, including instruction and assessment techniques that reflect Scientifically Based Reading Research (SBRR) and cover five building blocks of reading..." (Hines et al., 2007, pp. 76-77). According to Whitfield (2005), Reading First created a "one size fits all element for schools that have traditionally responded to local needs and concerns" (p. 50). However, despite dwindling funding to meet the requirements of this initiative, data suggest that schools involved in Reading First demonstrated higher comprehension scores (Manzo, 2008).

In 2004, the reauthorization of the Individuals with Disabilities Education Act (IDEA) echoed the need for scientifically based instructional programs (Harn et al., 2008). In fact, IDEA (2004) allows general education to use 15 percent of special education funding for early intervention services using scientifically based instructional programs in an attempt to reduce the need for special education services (Fuchs \& Deshler, 2007; Fuchs, L. \& Fuchs, 2006; Lose, 2007). In addition, IDEA (2004), gives states the ability to use RtI, an instructional framework that matches reading instruction and interventions to student needs as an alternative for identification of students with 
specific learning disabilities (Berkeley et al., 2009; Johnson, Mellard, \& Byrd, 2006; Zirkel, 2007).

\section{Response to Intervention}

RtI is a proposed framework of instruction and intervention based upon student needs (Deshler, Mellard, Tollefson, \& Byrd, 2005; Mellard et al., 2004; Reutebuch, 2008) that allows intervention to begin immediately in a less invasive atmosphere at the first indication of problems in reading performance (Bradley et al., 2007). It is a multitiered intervention model currently in various stages of implementation in many states in response to NCLB (2001), Reading First, and IDEA (2004) mandates. The RtI process begins with reading instruction in the general education setting and depending upon student response to instruction and/or interventions can lead to the eventual need for special education services for some students (Bradley et al.; Burns \& Ysseldyke, 2005).

Fundamental to the success of the RtI process are the following six components as identified by Palenchar and Boyer (2008):

- Tiered instruction and intervention models

- Universal screening

- Research based instruction

- Progress monitoring

- Teaming and collaboration

- Data-based decision making (p. 20).

Tiered Instruction and Intervention Models. Instruction and intervention models are considered tiered if they possess increasingly intense levels of instruction based upon student performance (Fuchs, D. \& Fuchs, 2006). Instruction begins with a 
"population focus" (Mellard, Byrd, Johnson, Tollefson, \& Boesche, 2004, p. 245) through general education (Berkeley et al., 2009; Fuchs, L. \& Fuchs, 2006). When student performance is not commensurate with peers, students are placed into a group-focused preventative skills-based intervention (Xu \& Drame, 2008). Based upon student response to this preventative intervention, an "individually directed" (Mellard et al., p. 245) skillsbased approach may be utilized (Berkeley et al.).

Most of the existing literature indicates at least three tiers within an RtI model of reading instruction. Tier 1 instruction occurs in the general education setting with all students receiving reading instruction using a core reading program (Kovaleski \& Glew, 2006). While most of the research about RtI has been conducted at tiers 2 and 3, the goal of RtI should be increasing proficiency in the core curriculum (Kovaleski, 2007; Kovaleski \& Glew, 2006). Tier 2 instruction occurs when a student, through universal screening, demonstrates weaknesses within the core reading program that require additional learning opportunities in the form of small group skills-based intervention. During tier 2, daily instruction targeting student deficit areas are designed and progress monitoring of student growth occurs at least every two weeks (Palenchar \& Boyer, 2008). Tier 3 instruction occurs when the student, despite given additional learning opportunities in tier 2, continues to display deficits in reading performance. Intervention efforts in this tier tend to be more individualized and prescriptive in nature. Referral to special education occurs at this final tier (Reschley, 2005) and only if all other implemented measures have been unsuccessful (Bradley et al., 2007).

The essential proactive principles of RtI should look comparable across varied settings promoting favorable academic gains through quality instruction, appropriate 
assessment and monitoring, and a student-driven intervention despite varied features (Barnes \& Harlacher, 2008) such as specific core reading programs, prescriptive interventions, and assessment tools. Kratochwill et al. (2007) states that "a major issue in the implementation of RTI is the limited research base to support the various practices currently being recommended" (p. 619) and despite interventions, many students will continue to demonstrate reading deficits (Chard et al., 2008; Vaughn et al., 2009). For example, research indicates that there is not one program where research has proved conclusively that it works with every child (Gerstl-Pepin \& Woodside-Jiron, 2005). Furthermore, while a majority of students provided an RtI program demonstrate academic gains (Burns \& Ysseldyke, 2005; Bursuck et al., 2006; Gerstl-Pepin \& Woodside-Jiron, 2005), some students continue to struggle and "have a slim chance of meeting standards on state high-stakes tests" (Bursuck et al., p. 311).

Assessment in RtI. Assessment is an important component in the RtI model of reading instruction requiring frequent monitoring to determine student growth and/or needs in delivered services (Mellard et al., 2004; Mesmer \& Mesmer, 2008; Roehrig et al., 2008; Speece, 2005; Stecker et al., 2008). Reliable universal screening as well as informative progress monitoring allows for ongoing assessment that ensures students are not only matched to instruction based on need but simultaneously gathering student data that allow for accurate identification of at-risk students (Danielson, Doolittle, \& Bradley, 2007; Kamps \& Greenwood, 2005; Stecker et al.). Universal screening is a process in which all students are formally assessed on reading skills several times a year. The purpose of universal screening is to identify students who are at-risk for reading disabilities or difficulties providing a baseline for measuring student achievement (Deno 
et al., 2009; Fuchs, D. \& Fuchs, 2006; Stecker et al.). Progress monitoring is best characterized as being brief, frequent, on-going assessments of reading skills using such tools as curriculum-based measurements to determine effectiveness of instruction as evidenced by student growth (Deno et al., Fuchs, D. \& Fuchs, 2006; Stecker et al.).

Hence, the determination of progress in reading based on assessment performance requires "data-based decision making derived from observable and measurable outcomes, not unseen etiologies" (Hale, Kauffman, Naglieri, \& Kavale, 2006, p. 754). As a result, data analysis is imperative for successful implementation of best practices instruction (Roehrig et al.). However, while many teachers are adept at gathering data regarding student progress, many teachers are unable and struggle to interpret the data (Mokhtari, Rosemary, and Edwards, 2007).

Data-based decision making. Core to RtI is the ability to use results from universal screening and progress monitoring assessments to determine effectiveness of instruction at each tier on student progress (Roehrig et al., 2008; Stecker et al., 2008). This analysis of student data can indicate what instructional and intervention strategies work or do not work with a student (Holdnack \& Weiss, 2006) and is essential in reflecting upon the need for increased intervention and/or additional resource allocation (Speece, 2005). Teacher ability to respond to each student's performance on assessments and make instructional decisions is dependent upon their professional knowledge (Jacobs, Gregory, Hoppey, \& Yendol-Hoppey, 2009) and requires analysis of student work to include not only curriculum based measurements but also informal assessments, daily work, and writing samples (Jacobs et al.; Mokhtari et al., 2007). Traditionally, data have been attributed with accountability (Shen \& Cooley, 2008), but it is more important than 
ever that teachers learn to use such data to inform instruction (Shen \& Cooley, 2008; Smith, Fien, Basaraba, \& Travers, 2009) and collaborate with other professionals (Barnes \& Harlacher, 2008).

Research based instruction. In 1997, the NRP was organized to conduct an in depth study to determine the most effective instructional approaches in teaching children to read. This panel collected and analyzed thousands of research dating from the 1960s forward to gather this information (National Institute of Child Health and Human Development, 2000). It is highly recommended that instructional programming be comprised of research based or proven strategies as outlined in recently passed legislation (i.e., NCLB, Reading First, and IDEA) (Crawford \& Torgesen, n.d.; Fuchs \& Deshler, 2007; Kovaleski, 2007).

According to the NRP's in depth study, a balanced literacy program should include five literacy components as recommended in the instructional process to comply with NCLB (2001) mandates and the Reading First initiative (Al Otaiba et al., 2005; Hines et al., 2007; Manzo, 2008): Phonemic awareness, phonics, vocabulary, fluency, and comprehension. In order for prescribed scientifically based reading instruction to be effective, core instructional and supplemental intervention programming must align and contain all five components (Al Otaiba et al.). The goal is for teachers to infuse these five components into their literacy instruction systematically while simultaneously differentiating instruction.

RtI is a widely adopted model meeting the NCLB (2001) requirements of "effective instruction and early intervention..." (Kamps et al., 2008, p. 111). However, for an RtI model to be considered scientifically based, the program must have gone 
through "a process of experimentation by which the importance of an instructional procedure or curriculum has been tested" (Fuchs \& Deshler, 2007, p. 131). While programs not considered scientifically based are not necessarily ineffective, they should be avoided, as "they are not good bets" (Fuchs \& Deshler, 2007, p. 132). Kovaleski (2007) backs this assertion by stating that to address nonresponse to instruction or intervention, evidence-based practices "that have been shown to work with large percentages of students who have similar needs" (p. 642) should be utilized. When selecting the various components to use within the RtI framework, a plethora of scientifically based instructional programs and materials are available that allow state and/or local educational agencies to match their framework to the needs of students (Reutebuch, 2008). Therefore, program selection requires careful consideration of local school-wide needs and ongoing support for teachers to successfully implement RtI (Bergstrom, 2008; Bursuck et al., 2006). Furthermore, scholars stress the importance of attending to the diversity present in schools when considering RtI materials and interventions (Hale et al., 2006; Gerstl-Pepin \& Wooside-Jiron, 2006; Stecker et al., 2008). By considering diversity upfront, schools can also begin to address the multitude of concerns regarding disproportionality that currently plagues special education (Klingner \& Edwards, 2006).

Teaming and collaboration. Roles of teachers and staff are likely to change using an RtI model of instruction, requiring open communication and shared resources and knowledge through increased interdisciplinary teaming and collaborative efforts (Hawkins, Kroeger, Musti-Rao, Barnett, \& Ward, 2008; Moore \& Whitfield, 2009) since students will be moving between tiers and professionals. For example, more than ever 
general educators are held responsible for instructional and intervention decisions in their classrooms requiring collaboration with experts on effective strategy and instructional delivery to meet the increasingly diverse needs in the classroom (Murawski \& Hughes, 2009). Mahdavi and Beebe-Frankenberger (2009) conducted a study exploring collaboration in the implementation of RtI with results implying that increased collaboration between teachers, administration, and community had a positive impact on student reading performance.

Mastropieri and Scruggs (2010) define collaboration as "working jointly with others, willingly cooperating with others, and sharing in goal setting, problem solving, and goal achievement" (p. 27). Traditionally, collaborative roles within inclusive settings have been the general education teacher providing core instruction in reading and the special education teacher providing interventions to struggling readers or students who have disabilities with general education teachers viewing struggling students as the special educator's responsibility (Smith \& Leonard, 2005). Roles will obviously change with implementation of RtI with general education taking on roles that have traditionally been considered a special educator's role by providing instruction and even interventions within the context of the general education classroom (Mastropieri \& Scruggs, 2005).

\section{Teacher Preparedness}

RtI as a process for delivering instruction is relatively new for many school systems. While RtI has promise, it "introduces the immense challenge of preparing all teachers... to deal with the wide-ranging and differentiated needs of students" (Brozo, 2010, p. 280). According to Fuchs and Fuchs (2009), RtI is 
complex in terms of structure (multiple levels) and because various kinds of assessments (screening and progress monitoring) must be integrated meaningfully with different kinds of instruction (core, small group, and individualized)... It requires close coordination of services delivered by different personnel at different prevention levels (p. 251).

Therefore, intervention effectiveness, and movement through the tiers, is a multi-faceted process involving the ability for teachers to "refine teaching decisions" (Lose, 2007, p. 277) in regards to the duration, intensity, and relevance of instruction at each tier (Danielson et al., 2007; Fuchs, L. \& Fuchs, 2006) utilizing assessment procedures to inform instructional decision making (Danielson, Doolittle, \& Bradley, 2005). Successful implementation of RtI components is dependent on the level of experience and knowledge a teacher possesses in literacy instruction (Brabham \& Villaume, 2003) as instructional fidelity and monitoring through assessments is "necessary... to assessing effectiveness of the intervention" (Reynolds \& Shaywitz, 2009, p. 131).

Administrators indicate concerns over teacher preparedness to implement the components of RtI and provide appropriate reading instruction to struggling learners given the lack of specific guidance in appropriate implementation (Wiener \& Soodak, 2008). Currently these professionals are insufficiently prepared to provide reading instruction and support (Al Otaiba \& Lake, 2007; Risko et al., 2008). Many teachers may have had sufficient preparation but lack the ability to apply the knowledge in the classroom (Risko et al.) while other teachers lack the specific training and foundational knowledge needed to teach struggling learners (Al-Hazza, Fleener, \& Hagen, 2008; Bos, Mather, Dickson, Podhajski, \& Chard, 2001; Crim et al., 2008; Cunningham, Perry, 
Stanovich, \& Stanovich, 2004; Mahar \& Richdale, 2008; Mather et al., 2001; Moats \& Foorman, 2003). In a study conducted by Risko et al., despite many in-service teachers having had specific coursework in reading instruction and strategies, they did not infuse the strategies learned into practice. In addition, beginning teachers while being aware of best practices in reading were unable to implement them effectively in their classrooms (Roehrig, Turner, Grove, Schneider, \& Liu, 2009). Further, these teachers not only held negative views of their teaching ability (Roehrig et al.), and toward providing literacybased strategies (Risko et al.), but also toward struggling students (Roehrig et al.).

In studies conducted by Al-Hazza et al. (2008), Cunningham et al. (2004), and Bos et al. (2001), while many in-service teachers perceived themselves as having the ability and confidence in teaching literacy skills, their self-perceived knowledge of teaching literacy skills was overestimated as teacher demonstrated lack of specific knowledge in foundational skills. In addition, many pre-service teachers also indicated preparedness to teach reading but they too did not demonstrate the requisite knowledge needed to teach struggling readers (Bos et al.), nor were they often able to identify effective reading instruction in classrooms of in-service teachers (Roehrig, Guidry et al., 2008).

It is critical for both in-service and pre-service teachers to be responsive to changing trends and be provided opportunities in the area of effective reading programs and effectively implementing RtI frameworks (Brabham \& Villaume, 2003; Mercer, Campbell, Miller, Mercer, \& Lane, 2000). Increased knowledge in reading instruction in the field is imperative to implement effective reading instruction required for informed decision-making (Foorman \& Moats, 2004). Therefore, proper implementation of RtI 
includes "extensive training and careful implementation" (Burns \& Ysseldyke, 2005, p. 17) of the key components outlined above. Teachers are the first line of defense in keeping students out of special education due to reading problems (Al Otaiba \& Lake, 2007). Professional development is the key to the successful implementation of RtI (Bergstrom, 2008; Gersten \& Dimino, 2006) as an early intervening service (Gersten \& Dimino, 2006).

Identified skills needed. For students to have continued opportunities to practice and hone their reading skills and access content curriculum, all teachers regardless of content area need to be aware of, facilitate, and teach literacy instructional strategies within the context of their classes (Boling \& Evans, 2008; Freedman \& Carver, 2007; Kozen, Murray, \& Windell, 2006; Moje, 2008). Teachers increased knowledge in reading instruction is imperative to implement effective reading instruction and required for informed decision-making when selecting instructional and intervention programming and differentiation of instruction (Baker, 2007; Foorman \& Moats, 2004; Spear-Swerling \& Brucker, 2004). Research suggests that increased teacher skill and knowledge of best reading practices has increased reading performance for students (Spear-Swerling \& Brucker, 2004). Specifically, research indicates that teachers need to be able to help students acquire and develop reading skills in particular in the areas of structural analysis of words that includes grapheme and phoneme analysis (Baker, 2007; Malmgren \& Trezek, 2009; Palumbo \& Sanacore, 2009; Phelps, 2009).

Moreover, the ability to meet and tailor instruction is dependent upon the teacher's ability to identify the reading problem of the student(s) and provide appropriate intervention or differentiated instructional strategies that are highly reliant on this teacher 
knowledge (Moats, 2009). Teachers of reading need to implement interventions with fidelity as well as using assessment data to modify interventions to meet the needs of students with substantial reading problems who are not responding to an intervention (Al Otaiba \& Lake, 2007; Jackson, Paratore, Chard, \& Garnick, 1999; Reynolds \& Shaywitz, 2009) and "relies most often on teacher self-reports" (Reynolds \& Shaywitz, 2009, p.

131). The ability to adopt and implement multiple practices at the same time can be an overwhelming and compromise effectiveness of instruction and intervention (Murawski \& Hughes, 2009). In order to effectively implement strategies and interventions, teacher education programs and in-service professional development must focus on scientifically based reading research, data-based decision making, and intervening early on targeted reading deficits skills to help inform the field of appropriate processes, strategies, and instructional materials (Connor et al., 2009).

In studies investigating the teaching practices of effective teachers of reading, instructional grouping, knowledge of reading materials, modeling of skills, understanding the needs of students, and experience with a variety of reading strategies are important facilitators for effective literacy instruction (Pressley, Yokoi, Rankin, WhartonMcDonald, \& Mistretta, 1997; Rankin-Erickson \& Pressley, 2001). More specifically, it is essential that teachers possess the knowledge of how to teach phonological awareness skills as most students who have reading problems have problems in this area (Adams, 1990; Crim et al., 2008; Moats, 1994). Moats (1994) measured teachers' foundational knowledge in language - phonemic awareness skills, finding that teachers lacked specific knowledge in phonological awareness. Similar research has echoed these same findings (Crim et al.; Mahar \& Richdale, 2008; Mather et al., 2001; Moats \& Foorman, 2003), 
each contending that this lack of knowledge disallows teachers to effectively teach foundational skills to struggling readers.

According to a study conducted by Spear-Swerling et al. (2005), the teachers' ability to teach reading related to the level of preparation and experience, resulting in higher knowledge levels. Further, "with limited or no formal preparation in a specific area, experience might become the primary avenue for acquiring knowledge in that area, to the extent that the knowledge is acquired at all" (Spear-Swerling et al., p. 287).

Because teacher beliefs and confidence levels impact classroom teaching (Westwood, Knight, \& Redden, 1997) the more knowledge a teacher possesses in literacy instruction, the better prepared they feel in providing effective reading instruction (Al Otaiba \& Lake, 2007; Mahar \& Richdale, 2008). Teachers express the less knowledge they possess in reading instruction, the more concerned they are in their ability to effectively meet students' needs (Mather et al., 2001). According to Soodak and Podell (1994), teachers who often felt ill-prepared to teach struggling or difficult learners had the tendency to refer to them to special education in lieu of applying alternative strategies or using consultative services. In addition, teachers who were less familiar with explicit instructional practices felt less prepared to teach struggling readers; those who were more knowledgeable indicated they felt better prepared to teach all children (Bos et al., 2001). Of additional concern is the lack of self-awareness of some teachers in their teaching ability. Many teachers believe that they are sufficiently prepared to meet the needs of students despite poor performance on literacy knowledge assessments (Cunningham et al., 2004; Bos et al.). 
In-service professional development opportunities. Professional development opportunities that provide teachers with up-to-date knowledge on research-proven strategies and interventions are imperative in preparing teachers to teach reading to struggling learners. However, many professionals acknowledge a disconnection between research and classroom practice (Bondy \& Brownell, 2004). Cochran-Smith and Lytle (1999) identified three relationships pertaining to the generation of knowledge that exists between research and practice: knowledge for practice, knowledge in practice, and knowledge of practice. Seemingly, each relationship has a legitimate place in the professional development of teachers moving from the generation of content area and pedagogical knowledge to eventual collaborative global exchanges of knowledge within the field. Seemingly, each relationship narrows the gap between research and practice as it changes the role of the teacher significantly.

Knowledge for practice is considered the acquisition of a formal knowledge base (Cochran-Smith \& Lytle, 1999) where teachers are "consumers of knowledge that is largely produced by others..." (McLeskey \& Waldron, 2004, p. 5) and is typically accomplished with in-service teachers through traditional professional development activities such as workshops (Cochran-Smith \& Lytle, 1999; McLeskey \& Waldron, 2004). Knowledge in practice is related to practical or craft knowledge that teachers construct through day-to-day classroom activities by engaging in self-reflection and instructional decision-making (Cochran-Smith \& Lytle, 1999). Various types of professional development activities focus on learning with expert teachers through such avenues as mentoring (Cochran-Smith \& Lytle, 1999) and teacher book clubs and study groups (Frey \& Fisher, 2004). Cochran-Smith and Lytle (1999) view the final 
relationship, knowledge of practice, as a collaborative, reciprocal sharing and generation of knowledge among all stakeholders. "From the knowledge-of-practice perspective, one type of knowledge does not govern the other. Knowledge is developed collectively; and hence, research cannot be separated from practice" (Bondy \& Brownell, 2004, p. 50). Professional development activities are inquiry-based and include professional learning communities often with university-school system partnering that leads to changes in teacher practice and school cultures (Cochran-Smith \& Lytle, 1999).

The driving force behind any type of professional development should be student performance (Guskey, 2003; McLeskey \& Waldron, 2004; Munoz, Guskey, \& Aberli, 2009). "Professional development activities that cannot be shown to have an impact on students' academic performance probably should be restructured or redefined" (Munoz et al., p. 76). When looking at professional development opportunities for in-service teachers, the most effective types of professional development are those activities within the knowledge in or of practice that allow stakeholders to converse with one another, reflect, expand their knowledge through an inquiry process driven by student performance (Cochran-Smith \& Lytle, 1999), and participating in a continual redefinition of knowledge (Ross \& Blanton, 2004). From the knowledge of practice perspective, preservice, in-service, and teacher educators alike are collaboratively regenerating knowledge through a cycle of critical analysis of classroom practice using student data (Bondy \& Brownell, 2004) making adjustments accordingly dependent upon each school's unique culture (Frey \& Fisher, 2004). According to Frey and Fisher (2004), school systems implementing a continuum of professional development opportunities using perspectives from knowledge for practice, knowledge in practice, and knowledge of 
practice as outlined by Cochran-Smith and Lytle (1999) demonstrated not only an increase in student achievement but also an increase in teacher participation in professional development opportunities with many earning master degrees.

Keeping teachers abreast of reading research and effective instructional reading strategies requires continual opportunities for professional development and job embedded training in reading instruction, progress monitoring, using data to drive instruction, and reading interventions (Armstrong et al., 2008; Crawford \& Torgeson, n.d.). Ongoing professional development is necessary for adequate acquisition of research based literacy instruction and skills to more effectively meet the diverse to students (Crim et al., 2008; McCutcheon et al., 2002; McCutcheon, Green, Abbott, \& Sanders, 2009; Spear-Swerling \& Brucker, 2004). Since teacher attitudes toward professional development impact knowledge gained (Brady et al., 2009), professional development opportunities based on the knowledge levels of teachers allowing for strategy training and modeling of strategies for use in the classroom is essential in preparing teachers for literacy instruction (Parris \& Block, 2007) and RtI implementation as "teachers are not only critical to creating school change, but are essential in the more difficult work of sustaining school change" (Frey \& Fisher, 2004, p. 61).

\section{Conclusion}

In a study conducted by Simmons et al. (2008), effective early reading interventions aided in "later reading proficiency" (p. 171). In addition, teacher efficacy improved when teachers felt RtI was effective (Nunn, Jantz, \& Buitikofer, 2009). Therefore, RtI should not be considered a special education identification process but instead viewed as prevention for "long-term academic and social failure" (Fuchs, L. \& 
Fuchs, 2006, p. 621). While RtI has promise in meeting the diverse literacy needs of a wide range of students, it may not be sufficient to address the needs of all students (Kavale, Holdnack, \& Mostert, 2006). In addition the lack of resource availability, coupled with inadequately designed reading professional development may result in inadequate instruction for struggling readers while also having the potential to negatively influence the identification process for students with specific learning disabilities (Johnson et al., 2006; Fuchs, D. \& Fuchs, 2006; Gersten \& Dimino, 2006). Furthermore, appropriate instruction, intervention, and assessment should be provided to all students regardless of disability (Sabornie, Evans, \& Cullinan, 2006). Since IDEA (2004) has brought the RtI process to the forefront in special education through funding opportunities and allowing states to use RtI during the identification process for students with learning disabilities, it is more important than ever to try and understanding how the various factors outlined above influence teachers knowledge of reading instruction. In short, RtI has the potential to promote favorable gains through quality instruction, appropriate assessment and monitoring, and interventions driven by student need (Barnes \& Harlacher, 2008). Therefore, the question that guides this study as schools begin to implement RtI and meet the mandates is: Are teachers properly equipped with the knowledge and skills necessary to effectively teach reading to struggling learners? 


\section{Chapter 3}

\section{Method}

The purpose of this study is to explore the necessary knowledge and skills teachers possess to effectively teach reading to struggling learners as schools prepare to implement RtI. The research questions were developed to assess the literacy knowledge of elementary general education teachers, secondary English/language arts teachers, special education teachers, reading teachers, reading specialists, literacy coaches, and teachers of English language learners, including the similarities and differences in the training of these teachers. To answer the two overarching questions, two research questions were generated for each. These research questions were as follows:

1. Is there a relationship between the number of activities/workshops attended by participants and their achievement on the literacy knowledge assessment?

1a. For those teachers who received a majority of their training through professional development opportunities, is there a relationship between the number of activities/workshops attended and their performance on the literacy knowledge assessment?

1b. For those teachers who received a majority of their training through coursework, is there a relationship between the number of classes taken and performance on the literacy knowledge assessment?

2. Did teaching assignment or role in providing reading instruction affect their achievement on the knowledge assessment? 
2a. Is there a significant difference between teachers credentialed in special education and/or reading and those who are only content or general education credentialed teachers performance on the literacy knowledge assessment?

2b. Is there a significant difference between novice (those possessing less than one year to three years of public education teaching experience) and veteran (those possessing more than three years of public education teaching experience) teachers performance on the literacy knowledge assessment?

The chapter is organized into five sections: (a) Design, (b) Selection of Participants, (c) Instrumentation, (d) Data Collection, and (e) Data Analysis.

\section{Design}

A causal-comparative research design was employed in this study. The causalcomparative research design compares two or more groups in attempts to identify a relationship between existing variables to explain the difference in performance (Charles \& Mertler, 2002; Mertens \& McLaughlin, 2004) on the literacy knowledge assessment. Each of the above research questions compared at least two groups of teachers. No variables were manipulated in each of the research questions. Instead, the characteristics within the groups and their performance on the literacy knowledge assessment were examined.

For the first research question, the independent variable was participation in professional development activities and the dependent variable was performance on the literacy knowledge assessment. For the second research question, the independent 
variable was the number of courses taken at a college or university and the dependent variable was performance on the literacy knowledge assessment. For the third research question, the independent variable was teacher credentials (e.g., general education versus special education and/or reading, certification areas) and the dependent variable was

performance on the literacy knowledge assessment. For the fourth research question, the independent variable was years of teaching experience and the dependent variable was performance on the literacy knowledge assessment.

\section{Selection of Participants}

In-service teachers from three elementary schools and two secondary schools in south central Pennsylvania were recruited to participate in this study. The school district in which this study was conducted is considered an urban school district by the state of Pennsylvania (The Center for Rural Pennsylvania, n.d.). In 2008, it had an enrollment of 3,858 students in grades $\mathrm{K}-12$ with white students comprising $86.9 \%$, Hispanic students 10.3\%, African American students 2.2\%, and Asian students 0.6\% (Federal Education Budget Project, n.d.). In addition, students receiving special education services was $14.1 \%$ and $3.1 \%$ of the student population were considered learners of English language (Federal Education Budget Project, n.d.). The school had a poverty rate of 8.5\% in 2008 (Federal Education Budget Project, n.d.) with 25\% of students enrolled in the free and reduced priced lunch program (Pennsylvania Department of Education, 2010). According to recent state assessment data for the 2008-09 academic school year, the following reading proficiency rates were achieved: Third grade $-67.2 \%$, fourth grade $69.3 \%$, fifth grade $-62.8 \%$, sixth grade $-68.9 \%$, seventh grade $-70.2 \%$, eighth grade 81.5\%, and eleventh grade $-60.2 \%$ (Fenton, n.d). 
After receiving permission from the school district administrator, as well as building principals (see Appendix B), and subsequent approval by the dissertation committee and the West Virginia University Institutional Review Board (IRB), a survey was distributed to 143 teachers. Participants were recruited through school email solicitation where teachers who were willing to voluntarily participate in the study were provided a link to SurveyMonkey. The sample of participants identified for inclusion in the study included elementary general education teachers, secondary English/language arts, special education teachers, reading teachers, reading specialists, literacy coaches, and teachers of English language learners identified on the individual schools' websites. The goal was to recruit at least $30 \%$ of identified teachers from the school district or a total of 43 teachers. Initial email solicitation was sent to all participants after IRB approval. A second email solicitation was sent to participants two weeks following initial email solicitation due to a low response rate. In addition, the researcher sent an email to the building-level administrators to ask that they encourage their teachers to participate in the survey. After three weeks, the desired sample size had not yet been reached, so the building level administrators received an email from the researcher containing a link to the survey on SurveyMonkey for them to forward to their teachers and prompt participation. The researcher also inquired as to the possibility of site visits to provide paper-and-pencil surveys to the teachers as a way to solicit more participation. One principal agreed to a site visit but the site visit solicited no additional responses to the survey.

From the five schools, 35 participants volunteered to complete the survey. Of those 35 participants, 24 identified themselves as being general education teachers (13 at 
the elementary level and 11 at the secondary level), 6 teachers indicated that they were special education teachers, and 5 identified themselves as being a reading

teacher/specialist or literacy coach. The desired sample size was not achieved because of a variety of factors (e.g., preparation for state assessments, principals did not send link to teachers). The overall response rate for this study was $24.4 \%$. While this response rate was not the response desired by the researcher, many studies using online surveys have indicated response rates significantly less (Grannello \& Wheaton, 2006; Manning, Bullock, \& Gable, 2009; Sax, Gilmartin, \& Bryant, 2003). According to Nulty (2008) for a sample size of at least 100 individuals, a 15\% response rate using online surveys is required to obtain a $10 \%$ sampling error and an $80 \%$ confidence level.

\section{Instrumentation}

Data was collected using an untimed comprehensive survey to assess teachers' knowledge in literacy and reading instruction as well as obtaining demographic information on participants. In order to maintain confidentiality, an online survey was used. Participants using this survey were assured anonymity in their responses and consent was assumed upon completion of the online survey as responses cannot be tracked to any individual participant. Part I of the survey was comprised of a demographic questionnaire adapted from Mahar and Richdale (2008) and included information such as gender, degree, years of experience, reading courses taken at a college or university, and professional development opportunities, and area(s) of certification/expertise. Part II was designed to collect information on teachers' professional development experiences related specifically to RtI training and readiness of implementation. Part III assessed the participants' ability to identify definitions, identify 
sounds within words, morphemes, syllable structure, and demonstrate understanding of reading skill development by using an adapted version of a survey first used by Moats and Foorman (2003) and recently redesigned by Moats (2009) that was originally developed as the Survey of Linguistic Knowledge (Moats,1994). This survey consisted of 54 multiple-choice questions and 6 true/false questions (see Appendix A). In the initial study (Moats, 1994) included open-ended responses in terminology, demonstrating phonic, syllabic, and morphemic knowledge, as well as word analysis. Subsequent uses of the survey (Moats and Foorman, 2003; Moats, 2009) improved the Survey of Linguistic Knowledge (Moats, 1994) to include survey items on participants knowledge of phoneme identification, syllabication, spelling, regular and irregular words, affixes, word types, and reading skill development. According to study conducted by McCutchen, Harry, et al. (as cited in McCutchen et al., 2009), the Moats survey had internal consistency reliability coefficients ranging from .70 to .84 and reliability coefficients ranging from .79 to .84 in a similar study conducted by McCutchen, Abbot et al. (2002). The Moats' survey has become an important instrument of teacher knowledge as it measures teacher knowledge and skills primarily in the specific areas of structural analysis of words - the exact areas teachers need to assist students in acquiring. Therefore, the Moats' survey has been used in many studies exploring teacher literacy knowledge (McCutchen et al., 2002; McCutchen et al., 2009) and with some studies modeling their own assessment of literacy knowledge after the Moats' survey (Carlisle, Correnti, Phelps \& Zeng, 2009; Crim et al., 2008; Cunningham et al., 2004; Mahar \& Richdale, 2008; McIntyre \& Hellsten, 2008; Moats \& Foorman, 2003; Spear-Swerling et 
al., 2005) and was recommended for use in this study (P. Pullen, personal communication, October 18, 2009).

\section{Data Collection}

Data were collected by the administration of an adapted version of the Survey of Linguistic Knowledge (Moats, 1994) and Teacher Knowledge Survey (Moats \& Foorman, 2003; Moats, 2009). While many participants had the option of participating in the survey using an online survey form that was emailed to each teacher or to complete a paper version of the survey at each individual school, all participants used the online survey form. Therefore, the participants were able to select their own setting to respond to the survey. The first method consisted of distributing the survey utilizing email and SurveyMonkey. This strategy incorporated sending the consent form to the participants through electronic mail. Within the message, a universal resource locator (URL) address of the online survey form was provided. The participants provided consent by visiting the specified URL and completing the online survey. The second method consisted of handing out survey packets to targeted participants in a faculty meeting at one school as a follow-up to the online survey in hopes of soliciting additional volunteers. The survey packets included the survey form and a cover letter explaining the study with a stamped, return addressed envelope. While using both web-based and paper-based surveys has shown to increase response rates (Greenlaw \& Brown-Welty, 2009), none of the participants in this study took advantage of the paper-based survey.

There were three parts to the survey. Part I of the survey asked participants to answer demographic questions. Part II of the survey asked participants to answer questions related to professional development experiences related specifically to RtI and 
their perceived readiness of RtI implementation. The final section of the survey, Part III, asked participants to respond to questions assessing their knowledge of literacy.

Teachers were instructed to answer questions without referring to any resources or in collaboration with other participants and were told that they could quit the study at any time without penalty and would have the capability to skip questions. Scoring included an item analysis report that indicated the percentage of correct and incorrect responses for each item in Part III of the survey. Non-responses were marked incorrect. After this process was completed, data were compiled into a Microsoft Excel spreadsheet and uploaded into a SPSS file for data analysis.

\section{Data Analysis}

Quantitative analysis was conducted using the responses from items on the Survey of Teacher Knowledge in Literacy Instruction. Items in Parts I and II of the survey were responses to demographic questions that served as independent variables. Items in Part III of the survey comprised an assessment of teachers' specific knowledge in early literacy skills that served as dependent variables. Correct and incorrect answers on Part III of the survey were tabulated by the author and verified by the co-investigator of the study as well as being scored by the computer. Demographic data from Parts I and II and the raw score (number of items answered correctly) from Part III of the Survey of Teacher Knowledge in Literacy Instruction were entered into SPSS-Version 18.0 for each of the participants. This allowed the researcher to compare scores on the literacy knowledge assessment to determine (1) the impact of professional development opportunities, (2) the impact of specific coursework in reading instruction, (3) similarities and differences between teacher classification (e.g., special education teacher versus 
general education teacher), and (4) similarities and differences between novice and veteran teachers. Frequencies and percentages of the responses are presented in a table, comparisons are displayed in graphs, and statistical analyses findings are presented in tables as well as explained in narrative form.

Professional development and coursework. To answer the first research question and determine the possible impact of professional development participation on the literacy knowledge of teachers, data from questions 9-17 from Part I and participants' raw score from Part III were used (See Table A). The independent variables were types of professional development opportunities that the participants participated specific to reading instruction - institutes, workshops, seminars, study/book groups, mentoring, peer coaching, action research, professional learning communities - and time spent in each type of professional development that ranged from one hour to more than four days. According to Guskey (2000), professional development is the "process and activities designed to enhance the professional knowledge, skills, and attitudes of educators..." (p. 16). These activities might include training sessions, workshops, seminars, study groups, mentoring, peer-coaching, and action research (Gordon, 2004; Guskey, 2000). Institutes are "intensive [one to three weeks] learning experiences in a specific area of study" (Gordon, 2004, p. 32). Workshops focus on teaching educators' specific skills and strategies for use in the classroom and are typically spaced several weeks apart with the expectation of teachers practicing learned skills between workshop sessions (Gordon, 2004). "Seminars are small groups working closely with acknowledged experts in the field. Participants meet regularly to receive training..." (Gordon, 2004, p. 32). Study groups are comprised of teachers and professionals who 
collectively meet in a small group to discuss and share new information and ideas from the field to be used in the classroom to enhance student performance (Murphy \& Murphy, 2008). Mentoring is defined as activities (e.g., co-planning, co-teaching, problemsolving, observations) occurring between a veteran teacher and a novice teacher to help with acclimation to the school or subject area (Robbins, 2008). McNeil and Klink (2008) define a coach as "a person who helps others move from where they are to where they want to be" (p. 210) in terms of facilitating problem solving in the classroom. Action research is defined as engaging in data collection of student performance and using this information to analyze your teaching practices and make changes as appropriate (CaroBruce, 2008). Finally, professional learning communities are collaborative groups of professionals and stakeholders who meet regularly to plan and analyze curriculum and assessment results (Servage, 2008). 
Table A

Variables and Analysis for Research Question 1:

Professional Development Types and Participation

\begin{tabular}{|c|c|c|}
\hline $\begin{array}{l}\text { Survey } \\
\text { Item }\end{array}$ & Independent Variables & Response Choice \\
\hline 9, Part I & Institutes & $\begin{array}{l}1-3 \text { hours, } 1 / 2 \text { to } 1 \text { day, } 2-3 \text { days, } 4 \\
\text { or more days }\end{array}$ \\
\hline 10, Part I & Workshops & $\begin{array}{l}1-3 \text { hours, } 1 / 2 \text { to } 1 \text { day, } 2-3 \text { days, } 4 \\
\text { or more days }\end{array}$ \\
\hline 11, Part I & Seminars & $\begin{array}{l}1-3 \text { hours, } 1 / 2 \text { to } 1 \text { day, } 2-3 \text { days, } 4 \\
\text { or more days }\end{array}$ \\
\hline 12, Part I & Study/Book Groups & $\begin{array}{l}1-3 \text { hours, } 1 / 2 \text { to } 1 \text { day, } 2-3 \text { days, } 4 \\
\text { or more days }\end{array}$ \\
\hline 13, Part I & Mentoring & $\begin{array}{l}1-3 \text { hours, } 1 / 2 \text { to } 1 \text { day, } 2-3 \text { days, } 4 \\
\text { or more days }\end{array}$ \\
\hline 14, Part I & Peer Coaching & $\begin{array}{l}1-3 \text { hours, } 1 / 2 \text { to } 1 \text { day, } 2-3 \text { days, } 4 \\
\text { or more days }\end{array}$ \\
\hline 15, Part I & Action Research & $\begin{array}{l}1-3 \text { hours, } 1 / 2 \text { to } 1 \text { day, } 2-3 \text { days, } 4 \\
\text { or more days }\end{array}$ \\
\hline 16, Part I & Professional Learning Communities & $\begin{array}{l}1-3 \text { hours, } 1 / 2 \text { to } 1 \text { day, } 2-3 \text { days, } 4 \\
\text { or more days }\end{array}$ \\
\hline \multirow[t]{2}{*}{ 17, Part I } & Other & $\begin{array}{l}1-3 \text { hours, } 1 / 2 \text { to } 1 \text { day, } 2-3 \text { days, } 4 \\
\text { or more days }\end{array}$ \\
\hline & Dependent Variable & Raw Scores of: \\
\hline $\begin{array}{l}\text { 1-60, Part } \\
\text { III }\end{array}$ & Raw score of items answered correctly & $0-60$ \\
\hline
\end{tabular}

\section{Analysis}

Standardized scores for each independent variable and Univariate ANOVA and Multiple Comparisons were used with each independent variable to assess relationships to the dependent variable.

Note. Survey items for questions 1, 18-22 in Part I and questions`1, 11-16 in Part II were not analyzed because they were put into the survey for future analysis.

In addition, to determine the impact content of professional development related to RtI implementation on teacher knowledge in literacy, data from questions 2-10 from Part II and participants' raw score from Part III were used (See Table B). Additional independent variables included content of professional development opportunities preparing teachers for teaching reading and implementing RtI and including the 
following components of RtI: core reading program, data analysis, interventions, universal screening, progress monitoring, collaboration, professional learning communities, and coaching. The dependent variable was the literacy knowledge assessment raw score determined by questions asked in Part III of the survey.

Table B

Variables and Analysis for Research Question 1:

Professional Development Content Related to Implementation of RtI Components

\begin{tabular}{lll}
\hline $\begin{array}{c}\text { Survey } \\
\text { Item }\end{array}$ & \multicolumn{1}{c}{ Independent Variables } & \multicolumn{1}{c}{ Response Choice } \\
\hline 2, Part II & Core reading program & Yes, No \\
3, Part II & Data Analysis & Yes, No \\
4, Part II & Interventions & Yes, No \\
5, Part II & Universal Screening & Yes, No \\
6, Part II & Progress Monitoring & Yes, No \\
7, Part II & Collaboration/Problem Solving & Yes, No \\
8, Part II & Professional Learning Communities & Yes, No \\
9, Part II & Coaching & Yes, No \\
10, Part II & No RtI Professional Development & \\
\hline
\end{tabular}

$\begin{array}{cc}\text { Dependent Variable } & \text { Raw Scores of: }\end{array}$

1-60, Part Raw score of items answered correctly $\quad 0-60$

III

Analysis

Standardized scores for each independent variable and Univariate ANOVA and Multiple Comparisons were used with each independent variable to assess relationships to the dependent variable.

Note. Survey items for questions 1, 18-22 in Part I and questions 1, 11-16 in Part II were not analyzed because they were put into the survey for future analysis.

To answer the second research question and determine the possible impact of coursework taken at a college or university on the literacy knowledge of teachers, data from question 8 from Part I and participants' raw score from Part III were used (See Table C). The independent variables were the number of courses specific to reading instruction taken at a college and/or university. The dependent variable was the literacy knowledge assessment raw score determined by questions asked in Part III of the survey. 
Table C

Variables and Analysis for Research Question 2:

Reading Instruction Courses Taken at a College and/or University

\begin{tabular}{lcc}
\hline $\begin{array}{c}\text { Survey } \\
\text { Item }\end{array}$ & \multicolumn{1}{c}{ Independent Variables } & \multicolumn{1}{c}{ Response Choice } \\
\hline 8, Part I & Courses & $\begin{array}{l}\text { 1 course, 2-3 courses, } 4 \text { or more } \\
\text { courses, None }\end{array}$ \\
\hline \multicolumn{2}{c}{ Dependent Variable } & Raw Scores of: \\
\hline $\begin{array}{l}\text { 1-60, Part } \\
\text { III }\end{array}$ & Raw score of items answered correctly & $0-60$ \\
\hline
\end{tabular}

\section{Analysis}

Standardized scores for each independent variable and Univariate ANOVA and Multiple Comparisons were used with each independent variable to assess relationships to the dependent variable.

Note. Survey items for questions 1, 18-22 in Part I and questions 1, 11-16 in Part II were not analyzed because they were put into the survey for future analysis.

Teaching assignment and role. To answer the third research question and determine if teachers in specific certification areas and teacher-designated roles performed similarly or differently on the literacy knowledge assessment, data from questions 2 - 5 from Part I and participants' raw score from Part III were used (See Table D). The independent variables were the participants' primary teaching role (e.g., special education versus general education), level of education (e.g., bachelor degree, master degree), when highest degree was earned, and certification areas (e.g., reading, elementary education). The dependent variable was the literacy knowledge assessment raw score determined by questions asked in Part III of the survey. 
Table D

Variables and Analysis for Research Question 3:

Teacher Credentials

\begin{tabular}{|c|c|c|}
\hline $\begin{array}{l}\text { Survey } \\
\text { Item }\end{array}$ & Independent Variables & Response Choice \\
\hline 2, Part I & Primary Teaching Role & $\begin{array}{l}\text { General Education Teacher - K-3, } \\
\text { General Education Teacher - 4-6, } \\
\text { Secondary English Teacher - 7-12, } \\
\text { Special Education Teacher - K-3, } \\
\text { Special Education Teacher - 4-6, } \\
\text { Special Education Teacher - 7-12, } \\
\text { Reading Teacher/Specialist or } \\
\text { Literacy Coach, English Language } \\
\text { Learner Teacher, Other }\end{array}$ \\
\hline 3, Part I & Level of Education & $\begin{array}{l}\text { Doctoral degree, Master's degree } \\
\text { plus additional coursework, } \\
\text { Master's degree, Master's } \\
\text { equivalency, Bachelor's degree plus } \\
\text { master's level coursework, } \\
\text { Bachelor's degree. }\end{array}$ \\
\hline 4, Part I & When Highest Degree was Earned & $\begin{array}{l}5-10 \text { years ago, } 11-15 \text { years ago, } \\
16 \text { or more years ago }\end{array}$ \\
\hline \multirow[t]{2}{*}{ 5, Part I } & Certification Area(s) & $\begin{array}{l}\text { Elementary education, Special } \\
\text { education, Reading, Middle level } \\
\text { or secondary English/Language } \\
\text { Arts, Emergency permit/certified in } \\
\text { another area of education, } \\
\text { Emergency permit/not certified in } \\
\text { any other area of education. }\end{array}$ \\
\hline & Dependent Variable & Raw Scores of: \\
\hline $\begin{array}{l}\text { 1-60, Part } \\
\text { III }\end{array}$ & Raw score of items answered correctly & $0-60$ \\
\hline
\end{tabular}

Analysis

Standardized scores for each independent variable and Univariate ANOVA and Multiple Comparisons were used with each independent variable to assess relationships to the dependent variable. Independent t-tests were conducted to determine whether the means of two comparison groups were statistically different from one another.

Note. Survey items for questions 1, 18-22 in Part I and questions 1, 11-16 in Part II were not analyzed because they were put into the survey for future analysis.

To answer the final research question and determine if years of teaching experience impacted literacy knowledge of teachers, data from questions 6 and 7 from 
Part I and participants' raw score from Part III were used (See Table E). The independent variables were the participants' years of experience in their current role and years of overall teaching experience. The dependent variable was the literacy knowledge assessment raw score determined by questions asked in Part III of the survey.

Table E

Variables and Analysis for Research Question 4: Years of Experience

\begin{tabular}{|c|c|c|}
\hline $\begin{array}{l}\text { Survey } \\
\text { Item }\end{array}$ & Independent Variables & Response Choice \\
\hline 6, Part I & Years in Current Position & $\begin{array}{l}\text { Over } 20 \text { years, } 10-19 \text { years, } 4-9 \\
\text { years, } 1-3 \text { years }\end{array}$ \\
\hline 7, Part I & Years of Overall Teaching Experience & $\begin{array}{l}\text { Over } 20 \text { years. } 10-19 \text { years, } 4-9 \\
\text { years, } 1-3 \text { years }\end{array}$ \\
\hline & Dependent Variable & Raw Scores of: \\
\hline $\begin{array}{l}\text { 1-60, Part } \\
\text { III }\end{array}$ & Raw score of items answered correctly & $0-60$ \\
\hline
\end{tabular}

\section{Analysis}

Standardized scores for each independent variable and Univariate ANOVA and Multiple Comparisons were used with each independent variable to assess relationships to the dependent variable. Independent t-tests were conducted to determine whether the means of two comparison groups were statistically different from one another.

Note. Survey items for questions 1, 18-22 in Part I and questions 1, 11-16 in Part II were not analyzed because they were put into the survey for future analysis.

Descriptive data analysis were conducted using SPSS-Version 18.0 (e.g., frequencies, means, and standard deviations). Descriptive data describing teachers' professional development in reading instruction and RtI components using frequency, mean, and standard deviation was analyzed. In addition, descriptive data broken out by teaching characteristics to include professional training in reading, years of teaching 
experience, area(s) of certification, education level, and current teaching role are placed in tables and explained in text.

Tests of statistical significance were conducted for the independent variables to include professional development participation, coursework, and teaching credentials. To investigate relationships in the levels of professional training in reading instruction a univariate analysis of variance (ANOVA) was used to conduct multiple comparisons between the independent variables. A univariate ANOVA was used to investigate the relationships and to conduct multiple comparisons between the following variables: (1) primary teaching role; (2) level of education; (3) when highest degree was earned; (4) area of certification; (5) years of teaching experience; and (6) reading knowledge. Independent samples t-tests were conducted in order to determine whether teachers credentialed in special education or reading differed from those credentialed in general education on the mean scores calculated for Part III of the survey. Results of the tests of statistical significance for each of the independent variables are explained in text as well as placed in tables. 


\section{Chapter Four}

\section{Results}

The purpose of this chapter is to report the findings of this study. The purpose of this study was to explore the knowledge and skills teachers possess as schools prepare to effectively implement RtI. The chapter is organized into four sections: (a) Summary of Purpose and Procedures, (b) Results of the Literacy Knowledge Assessment, (c) Results of the Data Analysis by Research Question, and (c) Summary of Findings.

\section{Summary of Purpose and Procedures}

The primary purpose of this study was to examine the literacy knowledge of inservice teachers who provide reading instruction. The secondary purpose was to examine the similarities and differences between teacher training specific to reading instruction (e.g., through professional development participation, coursework) and teacher classification and role (e.g., general education versus special education, years of experience). The objective was to aid stakeholders in determining appropriate professional development needs of teachers expected to teach struggling readers.

A quantitative analysis was conducted using data collected from the Survey of Teacher Knowledge in Literacy Instruction to measure teachers’ literacy knowledge. Thirty-five teachers of 143 surveyed (25\% return rate) from one urban south central Pennsylvania school district completed the online survey. Of those 35 teachers, 6 (17\%) taught special education, 5 (14\%) were reading teachers/specialists or literacy coaches, and 24 (69\%) taught general education. Responses to questions 2-17 from Part I and questions 2-10 from Part II served as independent variables. The raw score determined by the number of correct responses to the questions from Part III of the survey served as 
the dependent variable. Questions 1 and 18-22 in Part I and questions 1 and 11-16 in Part II were included in the survey but not analyzed in this study. Independent variable and dependent variable data were entered into SPSS 18.0 for each of the participants.

The analysis strategy for research questions 1 and 2 were similar. Frequencies and percentages of participants' responses were determined and descriptive statistical analysis was performed. In addition, a univariate ANOVA was performed to conduct multiple comparisons between the independent variables. Results were graphed to determine differences.

The analysis strategy for research questions 3 and 4 were similar. Frequencies and percentages of participants' responses were determined, and a descriptive statistical analysis was performed. A univariate ANOVA analysis was performed to conduct multiple comparisons between the independent variables, this was followed by a series of independent t-tests performed to determine whether teachers credentialed in special education or reading differed from those credentialed in general education and to determine whether novice or veteran teachers differed.

\section{Results of the Literacy Knowledge Assessment Survey}

A total knowledge assessment score was computed for each participant by adding the number of correct answers. Table F located in Appendix C shows the number and percentage of correct responses to each of the 60 items in the literacy knowledge assessment.

Phoneme and morpheme awareness. While more than $50 \%$ of teachers were able to accurately identify phonemes in 9 out of 11 words, only $3 \%$ of this group of teachers knew that the word "fix" is comprised of four speech sounds although it has only 
three letters (x corresponds to /k/ and /s/). Participants had few difficulties with phoneme matching. The vowel match between "knew" and "igloo" was recognized by $80 \%$ of the teachers; the vowel match between "push" and "sugar" was recognized by 91\%; and the vowel match between "weigh" and "raid" was recognized by 91percent. The /t/ phoneme on the end of "coached" and "trapped" was recognized by 77 percent; the /k/ phoneme on the end of "shrink" and "antique" was recognized by 86 percent; the /t/ phoneme was recognized in "intend" and "baked" by 80 percent; and 91\% of the teachers were able to match the r-controlled vowel sounds in "stir" and "burr." More than half of the teachers were unable to identify the /z/ phoneme on the end of "dogs" and "his" and 34\% were unable to identify the /z/ phoneme on the end of "was" and "nose." In addition, $66 \%$ of the teachers were unable to recognize the nasal /n/ in the final sound in "ring" and match it to "sink."

In addition, participants struggled with determining the number of morphemes with more than half of the respondents counting syllables instead of the meaningful units within the words: Thirty-one percent correctly counted the number of morphemes in "salamander" and "crocodile," 29\% correctly counted the number of morphemes in "attached," and 37\% correctly counted the number of morphemes in "unbelievable" and "finger."

Syllable conventions. Seventy-four percent of participants were able to provide the correct definition of a syllable. Counting syllables did not seem to pose much of a problem for participants with more than $70 \%$ of participants responding accurately to these items in the literacy knowledge assessment and 89\% of participants correctly identifying the word that began with a long vowel, open syllable. More than $80 \%$ of the 
teachers were able to identify the magic-e syllable, knew the spelling rule associated with adding a suffix that begins with a vowel to a word that contains the silent e, and could provide an example of the "y rule" for adding endings. And, more than half of the participants were able to indicate that there is a double " $n$ " in "stunning" because the words ends in a single consonant preceded by a single vowel and the ending begins with a vowel.

However, nearly $70 \%$ of participants were unable to provide an example of a closed syllable; $60 \%$ erroneously believed that a closed syllable always begins with a consonant; and 63\% did not know that a double "d" resulted from joining a closed syllable (pud) with a consonant -le syllable (dle) in the word "puddle." In addition, teachers struggled with identifying affixes in multi-syllabic words: only $17 \%$ were able to indicate that "commit" contained a prefix; less than half recognized that "requirement" contained both a prefix and suffix and that "natural" possesses an adjective suffix.

Knowledge of phonics and linguistic awareness. While two-thirds of the participants could explain why "ck" is used in spelling, less than half could identify the reduced vowel schwa. Consonant blends and digraphs posed a problem for teachers: only $29 \%$ of the teachers could identify a consonant blend and $80 \%$ of teachers were unable to identify a consonant digraph. Sixty percent of the participants were able to recognize irregular words "does," "were," and "said."

Eighty percent of teachers knew that a kernel or "bare bones" sentence is made of a subject and a predicate and more than $70 \%$ were able to recognize the orthographic pattern violation in the nonsense word "toyn." Additionally more than $90 \%$ of 
participants identified compound nouns with accuracy. However, only $11 \%$ recognized that one feature of English spelling is that words never end in the letters "j" and "v."

Instructional interpretation. A series of questions asked participants to interpret writing and oral reading samples and indicate instructional best practices in reading. Sixty-nine percent were not aware that the spelling "f-i-n-e-l-y" for "finally" indicates that the student has not matched spelling to the morphemes of the word. In addition, more than half were not aware that the spelling "e-l-e-k-t-r-i-s-u-t-y" for "electricity" indicates that the student does not know the base word and suffix from which the word "electricity" was constructed. More than two-thirds of the participants correctly responded to questions pertaining to listing and reading comprehension and nonsense word reading. While 74\% indicated that students should not be discouraged from spending time to decode, 57\% were unable to indicate ways to increase reading fluency. Only between 37\% and 57\% demonstrated knowledge pertaining to screening and progress monitoring assessments. Nearly half of the participants were unable to identify phonological awareness skills and instructional strategies needed for struggling or beginning readers.

\section{Results of the Data Analysis by Research Question}

Results in this section are organized by research question. A summary of the results for each question are presented in tables and data are displayed in figures and/or graphs as well as discussed in text. The percentage table for each item answered correctly on the literacy knowledge assessment is found in Appendix C.

Research question 1: For those teachers who received a majority of their training through professional development opportunities, is there a relationship 


\section{between the number of activities/workshops attended and their performance on the}

literacy knowledge assessment? To answer the first research question, a summary of the descriptive analysis results pertaining to professional development types are presented in Table G and a summary of the descriptive analysis results pertaining to professional development content are presented in Table I. The independent variables are identified as well as the dependent variable. The results from the univariate ANOVA analysis conducted on the types of professional development are presented in Table $\mathrm{H}$ and the results from the univariate ANOVA analysis conducted on the content of professional development are presented in Table J. Findings are discussed and followed by tables and graphs to visually display the results.

Professional development participation. According to Table G, while all participants indicated having participated in various types of professional development opportunities pertaining to reading instruction, a majority indicated having spent time participating in workshops (86\%) and professional learning communities (74\%); more than half participated in mentoring (69\%), action research (57\%), and study/book groups (51\%). Forty-six percent of participants indicated participating in institutes and 26\% in seminars. One participant indicated having participated in "Other" but did not provide a response as to what kind of professional development in which he or she had participated. While peer coaching in reading instruction was experienced at some level in less than half of the participants (43\%), those who reported participating in $1-3$ hours of peer coaching had the highest mean score of all other participants. As Table H demonstrates, data indicate no meaningful pattern in the type of professional development or in time 
spent in each. Analysis yielded no statistically significant findings between professional development participation types or time spent in each type.

Table G

Standardized Literacy Knowledge Assessment Scores by Teacher Training-Professional Development Participation

Dependent Variable: Raw score of items answered correctly on Items 1-60, Part III

\begin{tabular}{|c|c|c|c|}
\hline & $N$ & $M$ & $S D$ \\
\hline \multicolumn{4}{|l|}{ Institutes } \\
\hline $1-3$ hours & - & - & - \\
\hline $1 / 2$ to 1 day & - & - & - \\
\hline 2 - 3 days & 7 & 37.86 & 5.956 \\
\hline 4 plus days & 9 & 37.67 & 5.545 \\
\hline \multicolumn{4}{|l|}{ Workshops } \\
\hline $1-3$ hours & 3 & 37.33 & 9.504 \\
\hline $1 / 2$ to 1 day & 7 & 37.86 & 5.640 \\
\hline 2 - 3 days & 8 & 37.13 & 5.866 \\
\hline 4 plus days & 12 & 35.42 & 6.007 \\
\hline \multicolumn{4}{|l|}{ Seminars } \\
\hline $1-3$ hours & - & - & - \\
\hline $1 / 2$ to 1 day & - & - & - \\
\hline 2 - 3 days & 2 & 36.50 & 6.364 \\
\hline 4 plus days & 7 & 35.57 & 7.277 \\
\hline \multicolumn{4}{|c|}{ Study/Book groups } \\
\hline $1-3$ hours & 3 & 36.00 & 6.928 \\
\hline $1 / 2$ to 1 day & 5 & 35.80 & 7.823 \\
\hline 2 - 3 days & 2 & 30.00 & 1.414 \\
\hline 4 plus days & 8 & 37.38 & 4.897 \\
\hline \multicolumn{4}{|l|}{ Mentoring } \\
\hline $1-3$ hours & 3 & 40.33 & 7.371 \\
\hline $1 / 2$ to 1 day & 1 & 31.00 & \\
\hline 2 - 3 days & . & - & - \\
\hline 4 plus days & 20 & 36.05 & 6.362 \\
\hline \multicolumn{4}{|l|}{ Peer-coaching } \\
\hline $1-3$ hours & 4 & 42.25 & 6.397 \\
\hline $1 / 2$ to 1 day & - & - & - \\
\hline 2 - 3 days & 3 & 31.00 & 8.000 \\
\hline 4 plus days & 8 & 36.38 & 5.528 \\
\hline \multicolumn{4}{|l|}{ Action Research } \\
\hline $1-3$ hours & 2 & 39.00 & 9.899 \\
\hline $1 / 2$ to 1 day & - & - & - \\
\hline 2 - 3 days & 4 & 32.00 & 6.831 \\
\hline 4 plus days & 14 & 37.29 & $\begin{array}{c}6.005 \\
\text { (continued) }\end{array}$ \\
\hline
\end{tabular}




\begin{tabular}{lccc}
\hline & $N$ & $M$ & $S D$ \\
\hline Professional Learning & & & \\
Communities & 2 & 36.00 & 5.657 \\
1 - 3 hours & - & - & - \\
$1 / 2$ to 1 day & 6 & 36.17 & 8.472 \\
2 - 3 days & 18 & 35.89 & 5.697 \\
4 plus days & & & - \\
Other & - & - & - \\
1 - 3 hours & - & - & - \\
$1 / 2$ to 1 day & - & - & \\
2 - 3 days & 13 & 37.00 & \\
4 plus days & &
\end{tabular}

Table H

Univariate ANOVA and Multiple Comparison Results

Teacher Training - Professional Development Participation

Dependent Variable: Raw score of items answered correctly on Items 1-60, Part III

$$
\text { F-value } d f \quad p \quad \text { Multiple Comparisons }
$$

$$
\begin{gathered}
\hline \text { Institutes } \\
1 \text { - } 3 \text { hours } \\
1 / 2 \text { to } 1 \text { day } \\
2 \text { - } 3 \text { days } \\
4 \text { plus days } \\
\text { Workshops } \\
1 \text { - } 3 \text { hours } \\
1 / 2 \text { to } 1 \text { day } \\
2 \text { - } 3 \text { days } \\
4 \text { plus days }
\end{gathered}
$$

Seminars

1 - 3 hours

$1 / 2$ to 1 day

2 - 3 days

4 plus days

Study/Book groups

1 - 3 hours

$1 / 2$ to 1 day

2 - 3 days

4 plus days

$.454 \quad 1 \quad .639 \quad 2-3$ days $>4$ plus days

$.204 \quad 3 \quad 934 \quad 1 / 2-1$ day $>1-3$ hours $>$

2 - 3 days $>4$ plus days

$\begin{array}{llll}.151 & 1 & .861 & 2\end{array}-3$ days $>4$ plus days

$\begin{array}{llll}.751 & 3 & .565 & 4 \text { plus days }>1-3 \text { hours }\end{array}$

$>1 / 2-1$ day $>2-3$ days

(continued) 


\begin{tabular}{|c|c|c|c|c|}
\hline & F-value & $d f$ & $p$ & Multiple Comparisons \\
\hline $\begin{array}{l}\text { Mentoring } \\
1 \text { - } 3 \text { hours } \\
1 / 2 \text { to } 1 \text { day } \\
2 \text { - } 3 \text { days } \\
4 \text { plus days }\end{array}$ & .781 & 2 & .514 & $\begin{array}{c}1-3 \text { hours }>4 \text { plus days } \\
>1 / 2-1 \text { day }\end{array}$ \\
\hline $\begin{array}{c}\text { Peer-coaching } \\
1 \text { - } 3 \text { hours } \\
1 / 2 \text { to } 1 \text { day } \\
2 \text { - } 3 \text { days } \\
4 \text { plus days }\end{array}$ & 2.308 & 2 & .096 & $\begin{array}{c}1-3 \text { hours }>4 \text { plus days } \\
>2-3 \text { days }\end{array}$ \\
\hline $\begin{array}{c}\text { Action Research } \\
1-3 \text { hours } \\
1 / 2 \text { to } 1 \text { day } \\
2-3 \text { days } \\
4 \text { plus days }\end{array}$ & .985 & 2 & .413 & $\begin{array}{c}1 \text { - } 3 \text { hours }>4 \text { plus days } \\
>2-3 \text { days }\end{array}$ \\
\hline $\begin{array}{l}\text { Professional Learning } \\
\text { Community } \\
1 \text { - } 3 \text { hours } \\
1 / 2 \text { to } 1 \text { day } \\
2 \text { - } 3 \text { days } \\
4 \text { plus days }\end{array}$ & .475 & 2 & .702 & $\begin{array}{c}2-3 \text { days }>4 \text { plus days }> \\
1-3 \text { hours }\end{array}$ \\
\hline $\begin{array}{l}\text { Other } \\
1-3 \text { hours } \\
1 / 2 \text { to } 1 \text { day } \\
2-3 \text { days } \\
4 \text { plus days }\end{array}$ & .003 & - & .958 & \\
\hline
\end{tabular}

However, Figure 1 shows that those who participated in institutes had the highest mean score $(M=37.5, S D=5.532)$ followed by other $(M=37.00$, no $S D)$, peer coaching $(M=36.87, S D=6.999)$, workshops $(M=36.63, S D=5.991)$, action research $(M=$ 36.40, $S D=6.524)$, mentoring $(M=36.38, S D=6.446)$, professional learning communities $(M=35.96, S D=6.142)$, study/book groups $(M=35.89, S D=5.93)$, and seminars $(M=35.78, S D=6.704)$. This research suggests that providing consecutive 
multiple days of professional development such as through institutes was beneficial in the knowledge levels of teachers.

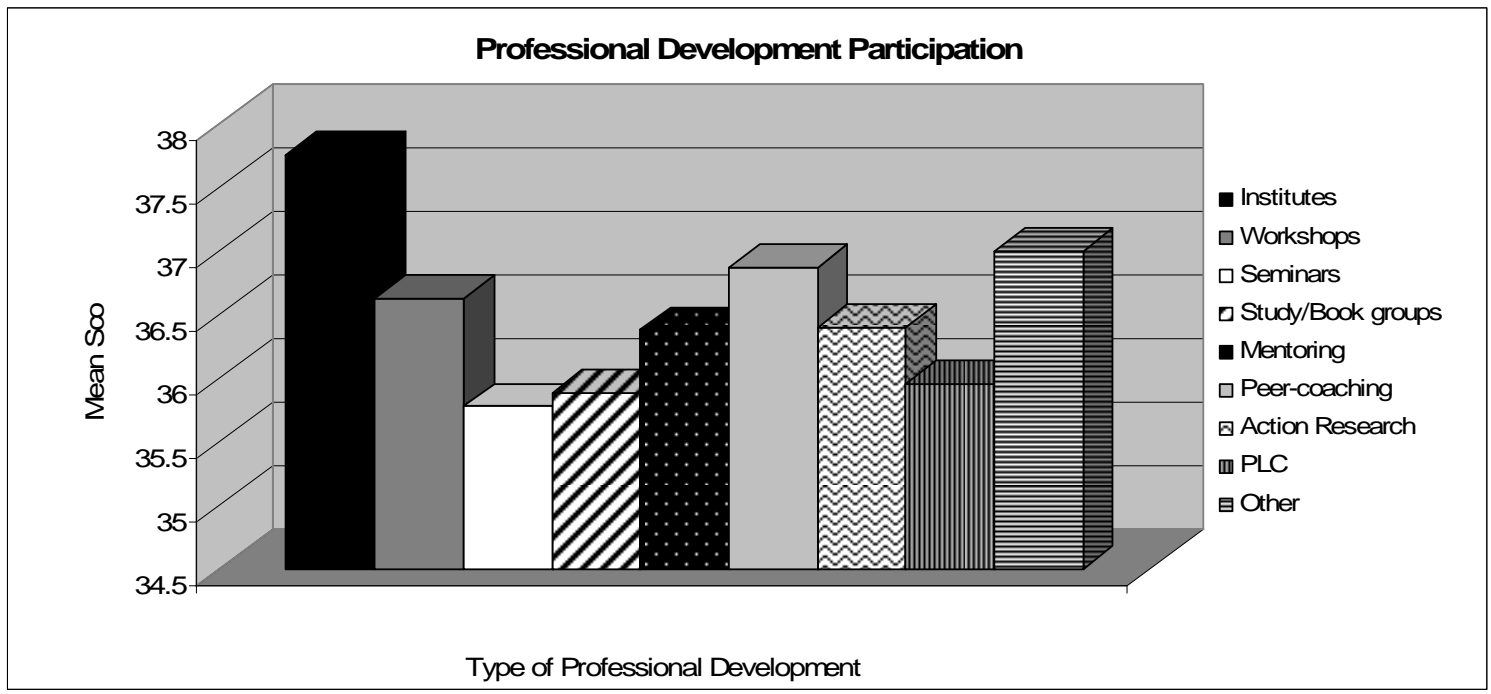

Figure 1. Mean score on literacy knowledge assessment survey graphed by Professional Development Types.

Professional development content. Less than half of the participants indicate having training in the various components of RtI (Table I). Forty percent of participants acknowledged having had training in professional learning communities, 23\% in coaching, and $17 \%$ in collaboration. Only $20 \%$ of the participants indicated having had training in universal screening, 34\% indicated having had training in progress monitoring, 31\% indicated having had training in data analysis, 26\% indicated having had training in the core reading program, and 11\% indicated having had training in interventions. The Data Analysis by literacy knowledge assessment analysis yielded a statistically significant finding (Table J) suggesting that those trained in data analysis possessed more literacy knowledge. Furthermore, data indicate that those participants who had training in interventions and data analysis were most successful on the literacy knowledge assessment (Figure 2). These results suggest that teachers who are provided 
training in using data to drive instruction and have been trained in implementing interventions have higher levels of literacy knowledge.

\section{Table I}

Standardized Literacy Knowledge Assessment Scores by Teacher Training-Professional Development Content

Dependent Variable: Raw score of items answered correctly on Items 1-60, Part III

\begin{tabular}{|c|c|c|c|}
\hline & $N$ & $M$ & $S D$ \\
\hline \multicolumn{4}{|c|}{ Core Reading Program } \\
\hline Yes & 9 & 39.22 & 4.086 \\
\hline No & 26 & 35.81 & 6.337 \\
\hline \multicolumn{4}{|c|}{ Data Analysis } \\
\hline Yes & 11 & 41.45 & 3.475 \\
\hline No & 24 & 34.50 & 5.634 \\
\hline \multicolumn{4}{|c|}{ Intervention } \\
\hline Yes & 4 & 41.75 & 3.594 \\
\hline No & 31 & 36.03 & 5.947 \\
\hline \multicolumn{4}{|c|}{ Universal Screening } \\
\hline Yes & 7 & 40.00 & 3.000 \\
\hline No & 28 & 35.86 & 6.282 \\
\hline \multicolumn{4}{|c|}{ Progress Monitoring } \\
\hline Yes & 12 & 39.00 & 5.293 \\
\hline No & 23 & 35.48 & 6.067 \\
\hline \multicolumn{4}{|c|}{ Collaboration/ } \\
\hline \multicolumn{4}{|c|}{ Problem-solving } \\
\hline Yes & 6 & 38.50 & 3.782 \\
\hline No & 29 & 36.31 & 6.325 \\
\hline \multicolumn{4}{|c|}{ Professional Learning } \\
\hline \multicolumn{4}{|c|}{ Communities } \\
\hline Yes & 14 & 38.86 & 4.605 \\
\hline No & 21 & 35.24 & 6.441 \\
\hline \multicolumn{4}{|c|}{ Coaching } \\
\hline Yes & 8 & 37.63 & 4.658 \\
\hline No & 27 & 36.41 & 6.369 \\
\hline
\end{tabular}


Table J

Univariate ANOVA and Multiple Comparison Results

Teacher Training - Professional Development Content

Dependent Variable: Raw score of items answered correctly on Items 1-60, Part III

\begin{tabular}{|c|c|c|c|c|}
\hline & F-value & $d f$ & $p$ & $\begin{array}{c}\text { Multiple } \\
\text { Comparisons }\end{array}$ \\
\hline $\begin{array}{l}\text { Core Reading Program } \\
\text { Yes } \\
\text { No }\end{array}$ & 2.261 & 1 & .142 & Yes $>$ No \\
\hline $\begin{array}{l}\text { Data Analysis } \\
\text { Yes } \\
\text { No }\end{array}$ & 14.151 & 1 & .001 & Yes $>$ No \\
\hline $\begin{array}{l}\text { Intervention } \\
\text { Yes } \\
\text { No }\end{array}$ & 3.476 & 1 & .071 & Yes $>$ No \\
\hline $\begin{array}{l}\text { Universal Screening } \\
\text { Yes } \\
\text { No }\end{array}$ & 2.833 & 1 & .102 & No $>$ Yes \\
\hline $\begin{array}{l}\text { Progress Monitoring } \\
\text { Yes } \\
\text { No }\end{array}$ & 2.888 & 1 & .099 & Yes $>$ No \\
\hline $\begin{array}{l}\text { Collaboration } \\
\text { Problem-solving } \\
\text { Yes } \\
\text { No }\end{array}$ & .660 & 1 & .422 & Yes $>$ No \\
\hline $\begin{array}{l}\text { Professional Learning } \\
\text { Communities } \\
\text { Yes } \\
\text { No }\end{array}$ & 3.284 & 1 & .079 & Yes $>$ No \\
\hline $\begin{array}{c}\text { Coaching } \\
\text { Yes } \\
\text { No } \\
\end{array}$ & .250 & 1 & .620 & Yes $>$ No \\
\hline
\end{tabular}




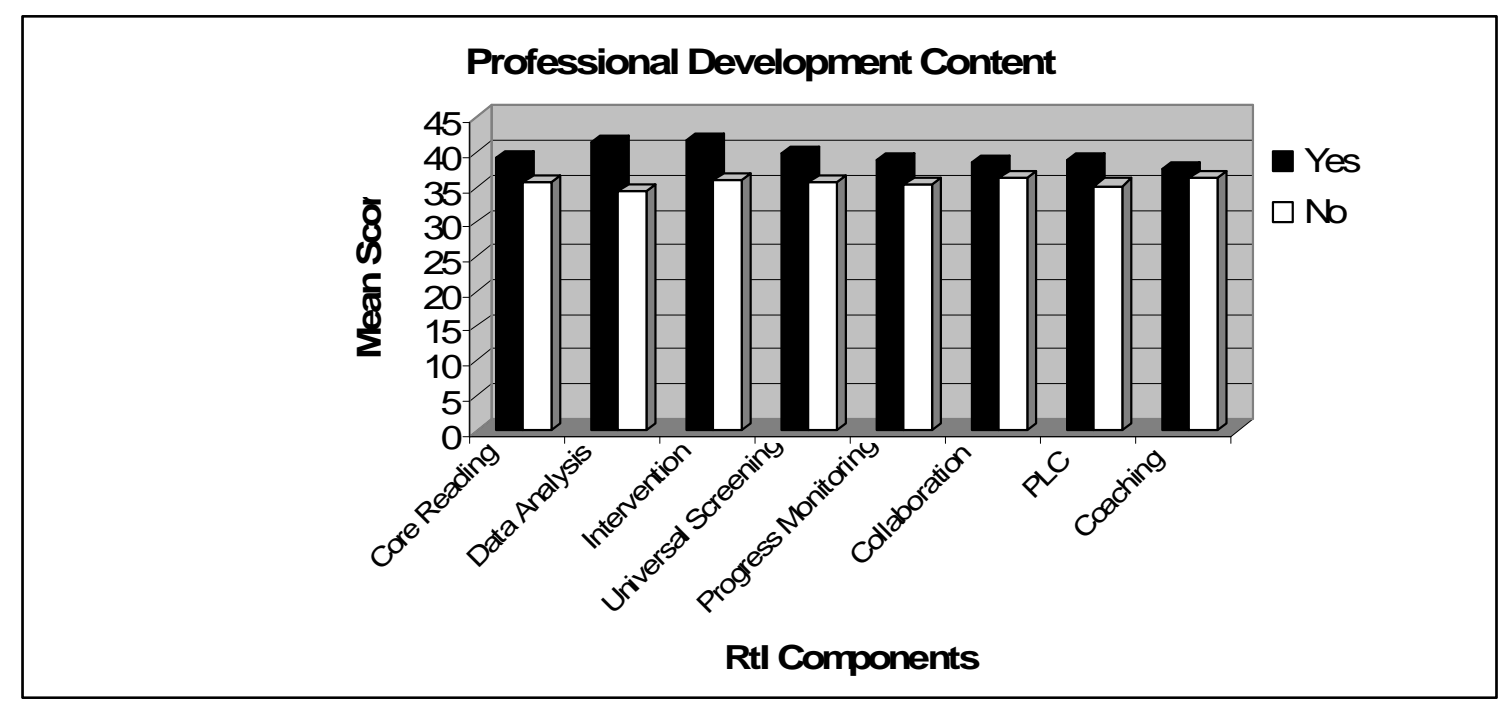

Figure 2. Mean score on literacy knowledge assessment survey graphed by RtI Content Covered in Professional Development. PLC=Professional Learning Communities.

\section{Research question 2: For those teachers who received a majority of their} training through coursework, is there a relationship between the number of classes taken and performance on the literacy knowledge assessment? To answer the second research question, a summary of the descriptive analysis results pertaining to the number of courses in reading instruction taken at a college or university are presented in Table K. The independent variable and its levels are identified as well as the dependent variable. The results from the univariate ANOVA analysis conducted on the number of courses in reading instruction taken at a collage or university are presented in Table L. Findings are discussed and followed by tables and a graph to visually display the results.

Table K shows that more than $50 \%$ of participants indicated taking at least four courses at a college or university (51\%) and while there was no statistically significant finding (Table L), according to Figure 3 those teachers who took at least four courses at a college or university scored higher on the literacy knowledge assessment. Seventeen percent of participants who took less than two courses scored lowest on the assessment 
suggesting that knowledge in literacy instruction may be generated through reading courses offered at institutions of higher education.

Table K

Standardized Literacy Knowledge Assessment Scores by Reading Instruction Courses Taken at a College and/or University Dependent Variable: Raw score of items answered correctly on Items 1-60, Part III

\begin{tabular}{llccc}
\hline & $N$ & $M$ & $S D$ \\
\hline Courses & 1 course & 4 & 32.00 & 7.528 \\
& $2-3$ courses & 11 & 36.18 & 5.492 \\
& 4 or more courses & 18 & 38.56 & 5.575 \\
& None & 2 & 32.00 & 4.243 \\
\hline
\end{tabular}

Table L

Univariate ANOVA and Multiple Comparison Results Reading Instruction Courses Taken at a College and/or University Dependent Variable: Raw score of items answered correctly on Items 1-60, Part III

\begin{tabular}{lcccc}
\hline & F-value & $d f$ & $p$ & $\begin{array}{c}\text { Multiple } \\
\text { Comparisons }\end{array}$ \\
\hline 1 course & 2.004 & 3 & .134 & 4 or more courses $>$ \\
$2-3$ courses & & & & $2-3$ courses $>1$ \\
4 or more courses & & & & course $>$ None \\
None & & & & \\
\hline
\end{tabular}




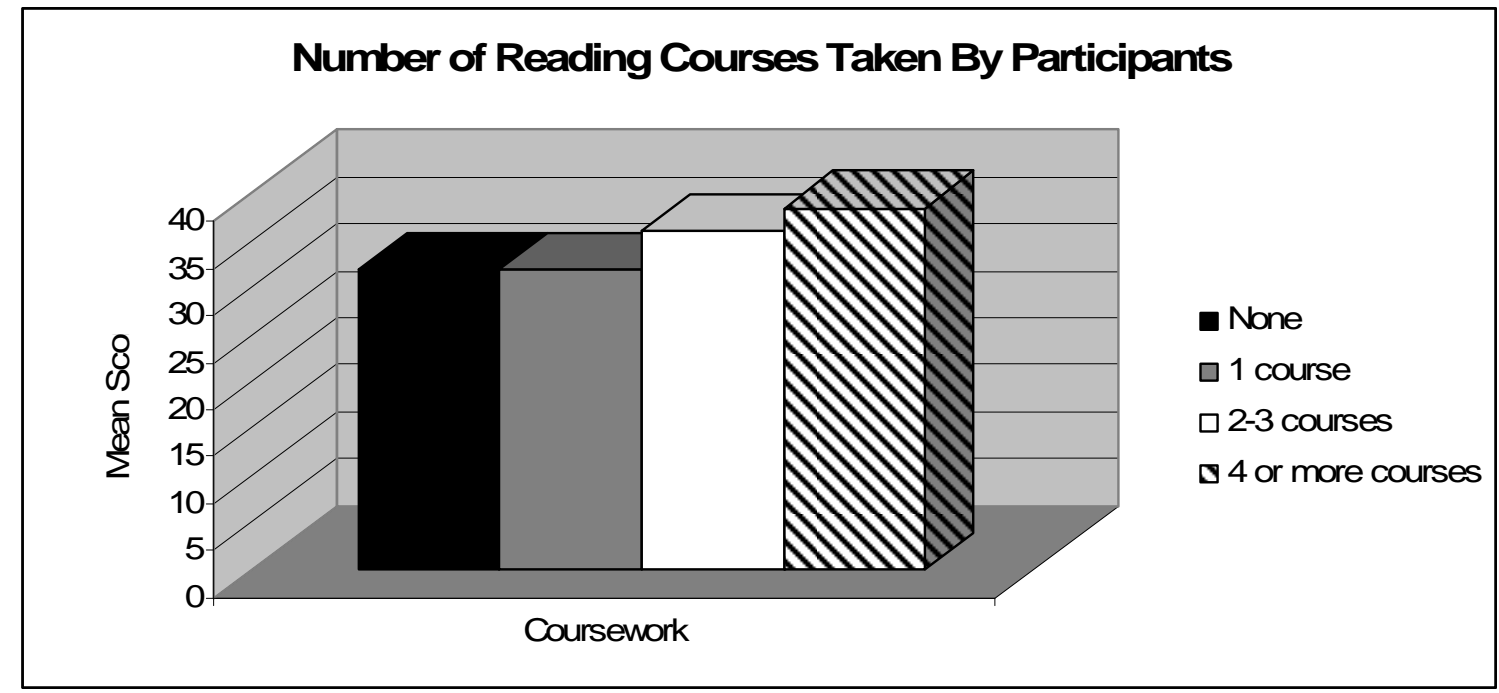

Figure 3. Mean score on literacy knowledge assessment survey graphed by Number of Reading Courses Taken by Participants at a College or University.

Research question 3: Is there a significant difference between teachers credentialed in special education and/or reading and those who are only content or general education credentialed teachers performance on the literacy knowledge assessment? To answer the third research question, a summary of the descriptive analysis results pertaining to primary teaching role, level of education, when highest degree was earned, and area of certification are presented in Table M. The independent variables and levels are identified as well as the dependent variable. A univariate ANOVA analysis is presented in Table N. A section discussing the findings for each independent variable and graphs to visually display the results follows. In addition, independent t-tests were conducted in order to determine whether teachers credentialed in special education or reading differed from those credentialed in general education. The results are shared in Table $\mathrm{O}$.

Primary teaching role. Thirty-seven percent of participants identified themselves as their primary teaching role being elementary level general education teachers, 31\% were secondary general education teachers (English/language arts), 17\% were special 
education teachers, and 14\% were reading teachers/reading specialists/literacy coaches. As Table $\mathrm{M}$ indicates and Figure 4 shows, teachers who identified themselves as reading teachers/reading specialists/literacy coaches and special education teachers scored higher on the literacy knowledge assessment than their general education counterparts. This chisquare test suggests that those who work and provide daily reading instruction and/or interventions to struggling readers tend to have more literacy knowledge. However, as indicated in Table $\mathrm{N}$ the data show no statistical significance in the primary teaching roles.

\section{Table M}

Standardized Literacy Knowledge Assessment Scores by Teacher Credentials Dependent Variable: Raw score of items answered correctly on Items 1-60, Part III

\begin{tabular}{lccc}
\hline & $N$ & $M$ & $S D$ \\
\hline Primary Teaching Role & & & \\
Elem. Education & 13 & 37.46 & 6.050 \\
English/Lang Arts & 11 & 33.27 & 4.452 \\
Special Education & 6 & 38.00 & 7.155 \\
Reading & 5 & 40.60 & 4.980 \\
Level of Education & 3 & & \\
Bachelors & 3 & 33.67 & 8.963 \\
Bachelors Plus & 5 & 39.67 & 3.512 \\
Master Equiv. & 3 & 36.40 & 7.987 \\
Masters & 21 & 40.00 & 5.568 \\
Masters Plus & 0 & 36.29 & - \\
Doctoral & & - & \\
When Highest Degree was & & & 5.833 \\
Earned & 17 & 35.18 & 3.969 \\
Within past 5 yrs. & 9 & 39.00 & 4.509 \\
5 - 10 yrs. ago & 3 & 35.33 & 8.931 \\
11 - 15 yrs. ago & 6 & 38.17 &
\end{tabular}


Table $N$

Univariate ANOVA and Multiple Comparison Results

Teacher Credentials

Dependent Variable: Raw score of items answered correctly on Items 1-60, Part III

F-value $d f \quad p \quad$ Multiple Comparisons

\begin{tabular}{|c|c|c|c|c|c|}
\hline $\begin{array}{l}\text { Primary } \\
\text { Teaching Role }\end{array}$ & $\begin{array}{l}\text { Elem. Ed. } \\
\text { Eng./Lang. } \\
\quad \text { Arts } \\
\text { Sp. Ed. } \\
\text { Reading }\end{array}$ & 2.321 & 3 & .095 & $\begin{array}{l}\text { Reading }>\text { Sp. } \\
\text { Ed.>Elem. Ed.> } \\
\text { Eng./Lang. Arts }\end{array}$ \\
\hline $\begin{array}{l}\text { Level of } \\
\text { Education }\end{array}$ & $\begin{array}{l}\text { Bach. } \\
\text { Bach. Plus } \\
\text { Master Eq. } \\
\text { Masters } \\
\text { Masters } \\
\quad \text { Plus } \\
\text { Doctoral }\end{array}$ & .605 & 4 & .662 & $\begin{array}{c}\text { Masters }>\text { Bach. } \\
\text { Plus }>\text { Master } \\
\text { Eq. }>\text { Masters } \\
\text { Plus }>\text { Bach. }\end{array}$ \\
\hline $\begin{array}{l}\text { When Highest } \\
\text { Degree was } \\
\text { Earned }\end{array}$ & $\begin{array}{l}<5 \text { yrs. } \\
5-10 \text { yrs. } \\
11-15 \text { yrs. } \\
16 \text { plus yrs. }\end{array}$ & .983 & 3 & .414 & $\begin{array}{c}\text { 5-10 yrs. }>16 \text { plus } \\
\text { yrs.> } 11-15 \text { yrs.>less } \\
\text { than } 5 \text { yrs }\end{array}$ \\
\hline $\begin{array}{l}\text { Certification } \\
\text { Area }\end{array}$ & $\begin{array}{l}\text { Elem. Ed. } \\
\text { Sp. Ed. } \\
\text { Dual } \\
\text { Eng./Lang. } \\
\quad \text { Arts }\end{array}$ & 2.214 & 3 & .106 & $\begin{array}{c}\text { Sp. Ed. }>\text { Elem. } \\
\text { Ed. }>\text { Dual }>\text { Eng./Lang. } \\
\text { Arts }\end{array}$ \\
\hline
\end{tabular}




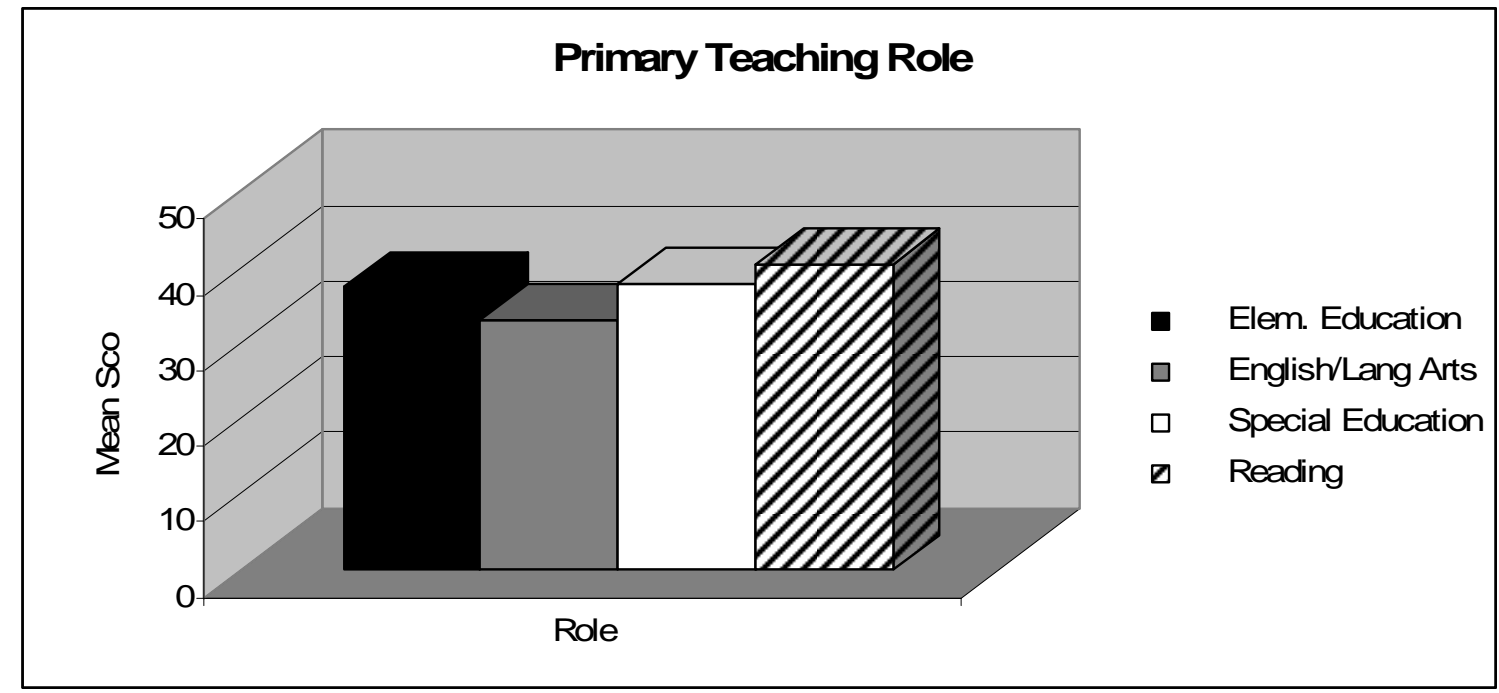

Figure 4. Mean score on literacy knowledge assessment survey graphed by Primary Teaching Role (Elementary Education, English/Language Arts, Special Education, and Reading).

Level of education. According to the participants' responses to their level of education, $9 \%$ of the teachers possessed a bachelor's degree, $9 \%$ have completed coursework beyond their bachelor's degree, 14\% have a master's equivalency, $9 \%$ have a master's degree, and $60 \%$ of the participants have earned college credits beyond the master's degree. As Table $\mathrm{M}$ indicates and Figure 5 shows, the $9 \%$ of participants who possessed a master's degree scored highest on the literacy knowledge assessment. While Table N shows no statistical significant findings for level of education, those who possessed only a bachelor's degree performed the poorest on the literacy knowledge assessment. Somewhat surprising are those who indicated having the highest level of education as their score on the literacy knowledge assessment was only slightly higher than those who possessed a bachelor's degree. Sixty-two percent of those who have a level of education beyond the master's degree are general education teachers with 33\% at the elementary level and $29 \%$ at the secondary level. Though these teachers earned a higher level of education, results on the literacy knowledge assessment were not higher. 


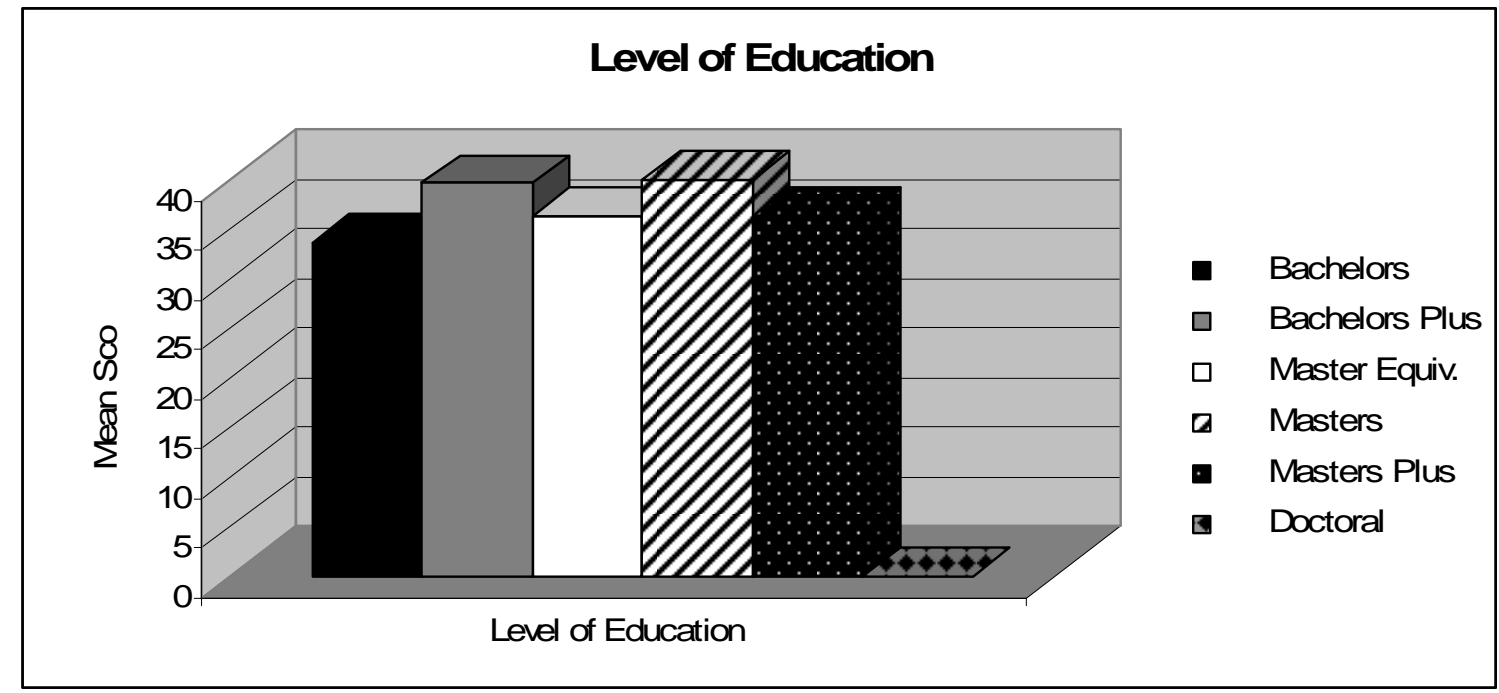

Figure 5. Mean score on literacy knowledge assessment survey graphed by Level of Education (Bachelors, Bachelors Plus, Masters Equivalency, Masters, Masters Plus, and Doctoral).

When highest degree was earned. Nearly half of the participants indicated earning their highest degree within the past five years, 26\% indicate earning their highest degree between five and 10 years ago, 9\% earned their highest degree 11 - 15 years ago, and $17 \%$ earned their highest degree more than 15 years ago. As Table M indicates and Figure 6 shows, those who earned their highest degree five - ten years ago scored highest on the literacy knowledge assessment with those participants receiving their most recent degrees within the past five years scoring lowest. While Table N shows no statistical significant findings for when the highest degree was earned, it is clear that there is no pattern established. The results suggest that when the highest degree was earned has no bearing on performance on the literacy knowledge assessment. 


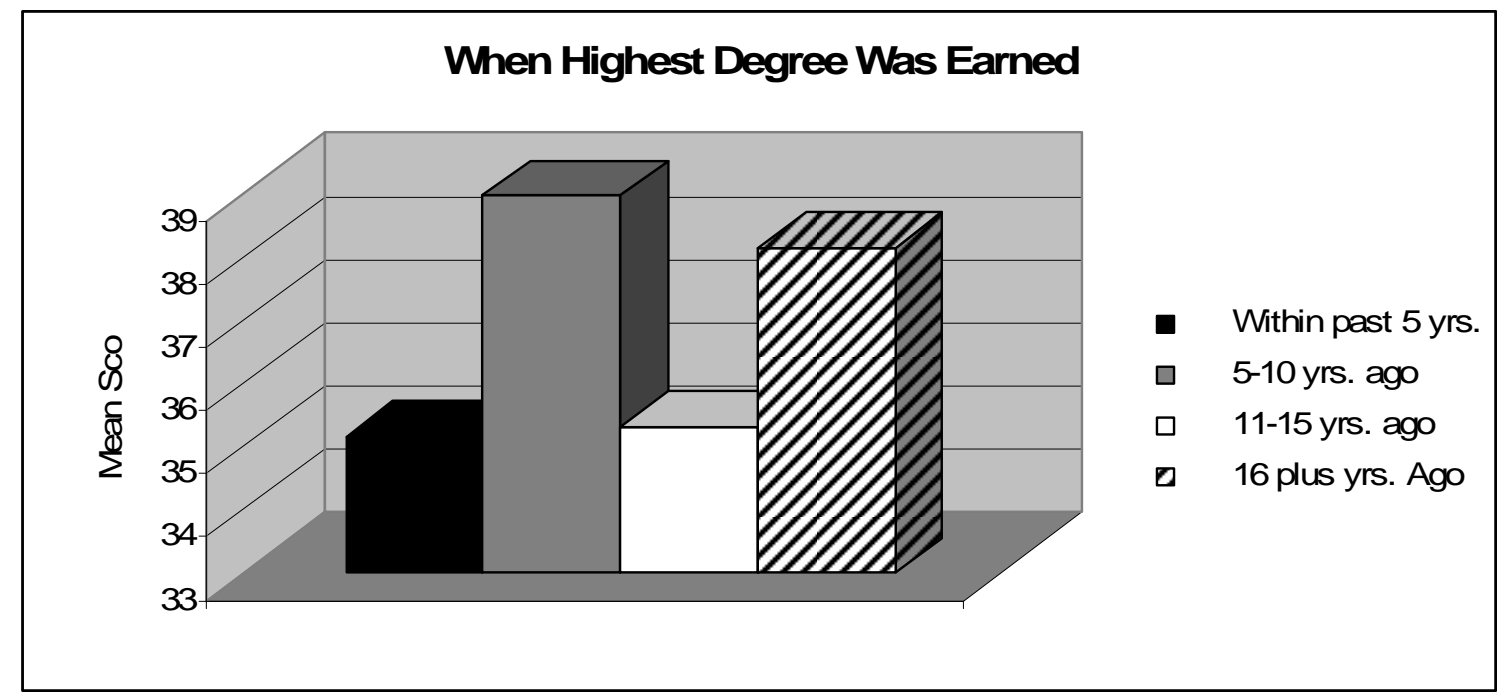

Figure 6. Mean score on literacy knowledge assessment survey graphed by When Highest Degree Was Earned.

Thirty-seven percent of participants were certified in elementary education, 34\% were certified in either English or middle level language arts, 20\% were dual certified in general education and either special education or reading, and 9\% were certified in special education only. As Table $\mathrm{M}$ indicates and Figure 7 shows, those certified in special education scored highest on the literacy knowledge assessment and those certified in only English or middle level language arts scored lowest. Table N shows no statistical significant findings for area of certification. The results suggest that those who have been trained as special educators have more literacy knowledge as measured by the literacy assessment. 


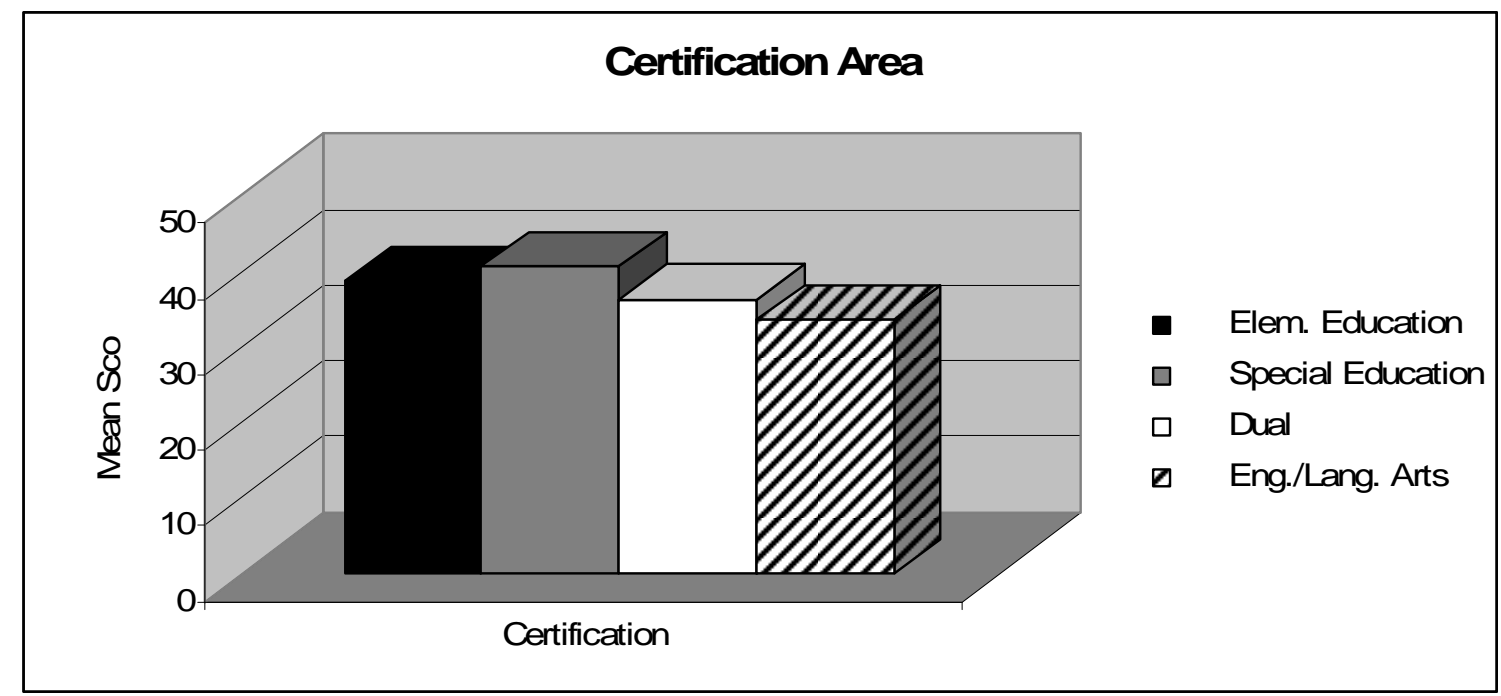

Figure 7. Mean score on literacy knowledge assessment survey graphed by Certification Area (Elementary Education, Special Education, Dual, and English/Language Arts).

Comparisons between teacher credentials. According to Table O, there was a significant effect between a few content areas specializations. For example, when considering Primary Teaching Role, reading teachers/reading specialists/literacy coaches receiving higher scores than secondary general education teachers (English/language arts). In addition, there was also a significant effect in the area of Teaching Certification as those certified in special education received higher scores than those certified in English or middle level language arts. Moreover, there was also a significant effect in the area of Teaching Certification as those who were dual certified in general education and special education or reading received higher scores than those certified in English or middle level language arts. This analysis suggests that those who are trained in reading and special education possess more literacy knowledge than those who are content certified as measured by teacher knowledge on the literacy assessment. 
Table O

Independent t-tests

Teacher Credentials

Dependent Variable: Raw score of items answered correctly on Items 1-60, Part III

\begin{tabular}{lrcr}
\hline & t-score & $d f$ & \\
\hline Primary Teaching Role & & & \\
Special Education vs. Reading & -.683 & 9 & $p=.512$ \\
Special Education vs. Elem. Ed. & .171 & 17 & $p=.867$ \\
Special Education vs. Eng./LA & 1.693 & 15 & $p=.111$ \\
Reading vs. Elem. Ed. & 1.028 & 16 & $p=.319$ \\
Reading vs. Eng./LA & 2.948 & 14 & $p<.05$ \\
Elem. Ed. vs. Eng. & 1.900 & 22 & $p=.071$ \\
Teaching Certification & & & \\
Special Education vs. Elem. Ed. & -.470 & 14 & $p=.646$ \\
Special Education vs. Dual & .988 & 8 & $p=.352$ \\
Special Education vs. Eng./LA & 2.202 & 13 & $p<.05$ \\
Dual vs. Elem. Ed. & .858 & 18 & $p=.402$ \\
Dual vs. Eng./LA & 2.360 & 23 & $p<.05$ \\
Elem. Ed. vs. Eng./LA & 1.077 & 17 & $p=.296$ \\
\hline
\end{tabular}

Research question 4: Is there a significant difference between novice (those

possessing less than one year to three years of public education teaching experience) and veteran (those possessing more than three years of public education teaching experience) teachers performance on the literacy knowledge assessment? To answer the third research question, a summary of the descriptive analysis results pertaining to years of teaching experience are presented in Table P. The independent variable and levels are identified as well as the dependent variable. A univariate ANOVA analysis is presented in Table Q. A section discussing the findings for the independent variables and a graph to visually display the results follows the tables. Independent samples t-tests were conducted in order to determine whether novice teachers differed from veteran teachers and is presented in Table R. 
Forty-three percent of the participants in this study indicated that they have been teaching for more than 19 years, 29\% have been teaching between 10 and 19 years, 20\% have been teaching $4-9$ years, and 9\% are novice teachers who have taught for less than four years. As evidenced in Table P and in Figure 8, those with the most experience had the highest mean score. Surprisingly, novice teachers scored next highest. Teachers who taught between four and nine years had the lowest score. There was no statistical significance found in this analysis (Table Q). This research suggests that years of teaching experience did not have much of an effect on teachers' literacy knowledge.

\section{Table P}

Standardized Literacy Knowledge Assessment Scores by Years of Teaching Experience Dependent Variable: Raw score of items answered correctly on Items 1-60, Part III

\begin{tabular}{lccc}
\hline & $N$ & $M$ & $S D$ \\
\hline $1-3$ yrs. & 3 & 37.33 & 8.327 \\
$4-9$ yrs. & 7 & 34.71 & 5.057 \\
$10-19$ yrs. & 10 & 36.50 & 5.401 \\
Over 20 yrs. & 15 & 37.60 & 6.653 \\
\hline
\end{tabular}

Note. Survey items for questions 1, 18-22 in Part I and questions 1, 11-16 in Part II were not analyzed because they were put into the survey for future analysis.

\section{Table Q}

Univariate ANOVA and Multiple Comparison Results

Years of Teaching Experience

Dependent Variable: Raw score of items answered correctly on Items 1-60, Part III

F-value $d f \quad p \quad$ Multiple Comparisons

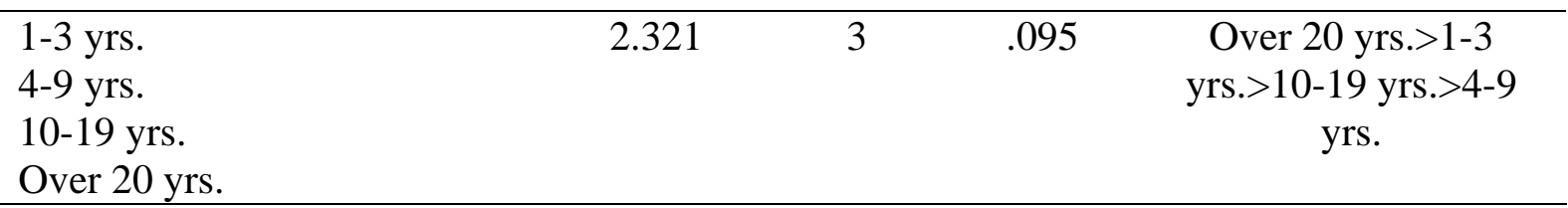




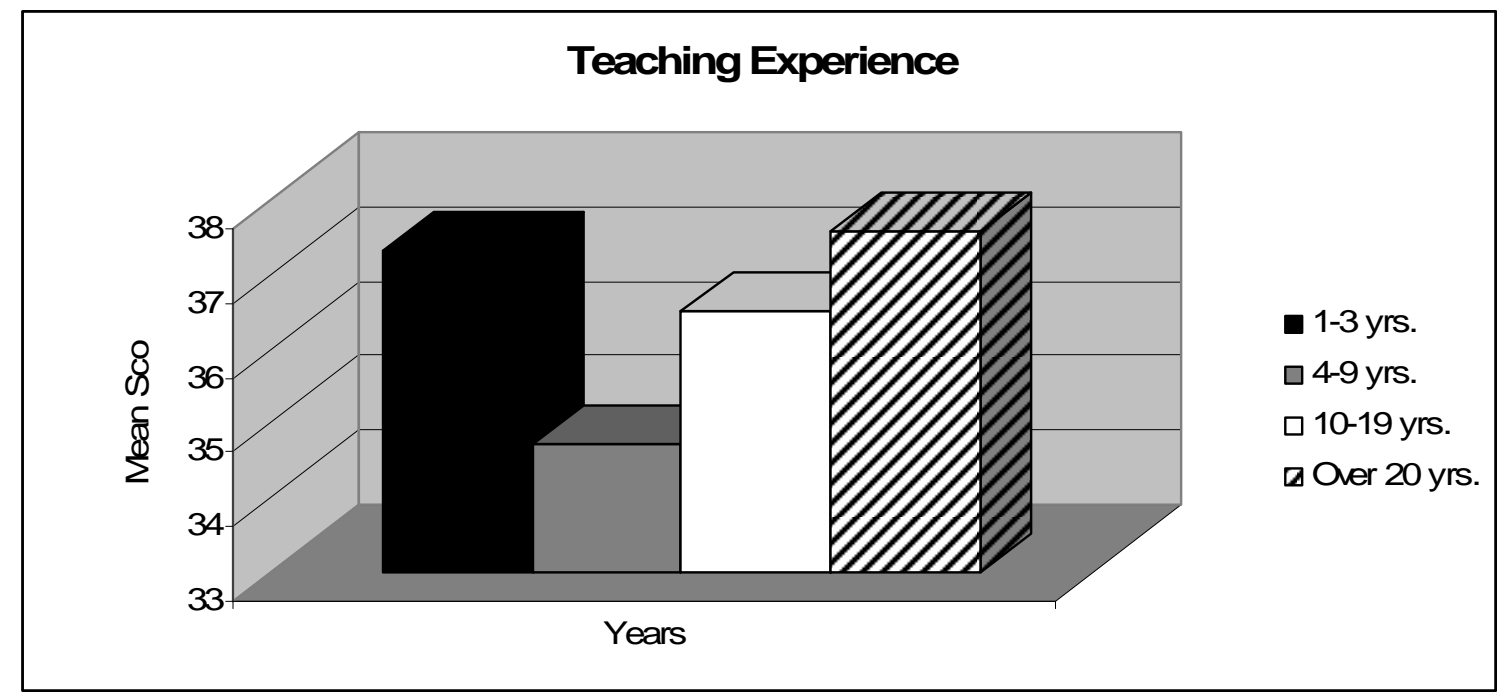

Figure 8. Mean score on literacy knowledge assessment survey graphed by Teaching Experience (years in the classroom).

However, independent t-tests for Years of Teaching Experience (Table R) did not yield statistically significant findings.

Table R

Independent t-tests

Years of Teaching Experience

Dependent Variable: Raw score of items answered correctly on Items 1-60, Part III

\begin{tabular}{crrr}
\hline Years of teaching & t-score & $d f$ & \\
\hline $1-3$ vs. $4-9$ & .628 & 8 & $p=.547$ \\
$1-3$ vs. $10-19$ & .210 & 11 & $p=.838$ \\
$1-3$ vs. 20 plus & -.061 & 16 & $p=.952$ \\
$4-9$ vs. $10-19$ & -.688 & 15 & $p=.502$ \\
$4-9$ vs. 20 plus & -1.014 & 20 & $p=.323$ \\
$10-19$ vs. 20 plus & -.435 & 23 & $p=.668$ \\
\hline
\end{tabular}

\section{Summary of Findings}

This chapter presented the findings of the statistical analysis of the data that include descriptive data analysis and multivariate ANOVA analysis for each of the four research questions as well as independent t-tests of the independent variables and the dependent variable for the last two questions. The findings are displayed in tables with graphs to illustrate findings and discussed in the narrative. 


\section{Chapter Five}

\section{Summary of Findings, Recommendations, and Implication for the Field}

This chapter contains the summary, conclusions, and recommendations for the study. This chapter is organized into 5 sections: (a) Summary of Findings, (b) Conclusions, (c) Limitations, (d) Recommendations, and (e) Implications.

\section{Summary of Findings}

The results of the statistical analyses for each of the research questions show the similarities and differences in the teacher characteristics (independent variables) and the performance on the literacy knowledge assessment (dependent variable).

Research question 1: For those teachers who received a majority of their training through professional development opportunities, is there a relationship between the number of activities/workshops attended and their performance on the literacy knowledge assessment? Participants were asked to respond to questions that asked about their professional development participation that included the types of professional development and time spent in each type. In addition, participants were asked to respond to questions that asked about their specific training in components of RtI (e.g., universal screening, interventions).

Professional development participation. Participants were asked to identify the types of professional development that they had participated specific to teaching reading. They were also asked to identify the time spent in these professional development offerings. The analysis did not yield a statistically significant difference. However, descriptive statistical analyses reveal that those who had participated in several hours of peer-coaching had the highest score among their peers. In addition, when not considering 
the levels (time spent) within the independent variables, those who indicated participation in institutes demonstrated better overall literacy knowledge.

Professional development content. Participants were asked to identify if they had received training in the core components of RtI. Responses for training in data analysis yielded a statistically significant difference. Teachers who had training in data analysis performed better on the literacy knowledge assessment. While none of the other responses yielded a statistically significant difference, descriptive statistical analysis reveals that those who had training in the core components of RtI performed better on the literacy knowledge assessment.

Research question 2: For those teachers who received a majority of their training through coursework, is there a relationship between the number of classes taken and performance on the literacy knowledge assessment? Participants were asked to respond to questions that asked about the number of courses specific to teaching reading at a college or university. While none of the responses yielded a statistically significant difference, descriptive statistical analysis and multiple comparison reveal that those who have taken more courses demonstrated increasing levels of literacy knowledge.

Research question 3: Is there a significant difference between teachers credentialed in special education and/or reading and those who are only content or general education credentialed teachers performance on the literacy knowledge assessment? Participants were asked to respond to demographic questions that included their primary teaching role, level of education, when highest degree was earned, and area(s) of certification. 
Primary teaching role. Participants were asked to respond to a question that asked their primary teaching role. While none of the responses yielded a statistically significant difference, descriptive statistical analysis revealed that those who indicated being a reading teacher/reading specialist/literacy coach scored higher on the literacy knowledge assessment. On the other hand, independent t-tests revealed a statistically significant difference between reading teachers/reading specialists/literacy coaches and secondary general education teachers (English/language arts) indicating a disparity in scores between the two roles with reading teachers/reading specialists/literacy coaches scoring significantly higher on the literacy knowledge assessment.

Level of education. Participants were asked to respond to a question that asked their level of education. None of the responses yielded a statistically significant difference. Descriptive statistical analysis revealed no pattern between level of education and performance on the literacy knowledge assessment.

When highest degree was earned. Participants were asked to respond to a question that asked when their highest degree was earned. None of the responses yielded a statistically significant difference. Descriptive statistical analysis revealed no pattern between when highest degree was earned and performance on the literacy knowledge assessment.

Certification area. Participants were asked to respond to a question that asked them to indicate all their areas of certification. None of the responses yielded a statistically significant difference. Descriptive statistical analysis revealed that those who were certified in special education performed better on the literacy knowledge assessment. Independent t-tests revealed a statistically significant difference between 
those certified in special education and English/middle level language arts with those certified in special education scoring significantly higher on the literacy knowledge assessment. In addition, a statistically significant difference between those dual-certified and those certified in English/middle level language arts was revealed with those who were dual-certified scoring significantly higher on the literacy knowledge assessment.

Research question 4: Is there a significant difference between novice (those possessing less than one year to three years of public education teaching experience) and veteran (those possessing more than three years of public education teaching experience) teachers performance on the literacy knowledge assessment?

Participants were asked to respond to questions that asked their years of experience including their current teaching role and overall teaching experience. None of the responses yielded a statistically significant difference. Descriptive statistical analysis revealed no pattern between years of experience and performance on the literacy knowledge assessment.

\section{Conclusions}

This study examined teachers' literacy knowledge in relation to teacher training in reading instruction (including professional development opportunities and coursework) and teaching credentials and experience. Consistent with previous studies (e.g., Cunningham et al., 2004; Mahar \& Richdale, 2008; Moats, 1994; Moats \& Foorman, 2003), teachers' literacy knowledge in this study was limited and demonstrated inconsistency among teacher characteristics (e.g., years of experience). The results demonstrated that those with relatively high levels of reading-related training - those who have taken multiple courses in reading instruction and were trained in specific aspects of 
reading instruction through professional development opportunities - scored higher on the literacy knowledge assessment than participants who had lower levels of reading-related training. This finding is consistent with McIntyre and Hellsten's (2008) findings that indicated statistical significance among the literacy knowledge of teachers who had taken courses specific to special education as well as those who took coursework related to linguistics. In addition, those with relatively high levels of reading-related experiences specifically those who teach struggling learners of reading and those certified in special education - scored higher on the literacy knowledge assessment than participants who had lower levels of reading-related experience.

Professional development participation. While this study indicated no statistical differences between the types of professional development and time spent in each, teachers who participated in more intense professional development such as multiday institutes scored higher on the literacy knowledge assessment. This finding is consistent with the findings of Brady et al. (2009) and McCutchen et al. (2009), whose studies indicated that intense professional development that included multi-day institutes involving collaboration between university and schools as well as in-class supports such as mentoring and peer-coaching improved knowledge of teachers.

If teachers are to remain knowledgeable of scientifically-based reading practices and effective instructional strategies, a continuum of professional development opportunities based on each school's unique needs (Frey \& Fisher, 2004) need to be provided. These opportunities should be directly related to improving student performance (Bondy \& Brownell, 2004; Cochran-Smith \& Lytle, 1999). This professional development focuses on teachers forming professional learning communities 
to engage in action research that drives instruction (Caro-Bruce, 2008). Through action research, professional learning community members may engage in collaborative data analysis and open discussion that ultimately leads to improved student performance (Bernhardt, 2008; Graybill, 2008). The National Staff Development Council advocates for job-embedded professional development such as coaching and mentoring teachers in best literacy practices that is collaborative in nature (Kise, 2008; McNeil \& Klink, 2008; Robbins, 2008). However, this research suggests that teachers do not possess the knowledge needed to engage in collaborative exchange essentially making these types of professional development seemingly premature and ineffective.

RtI components. This research suggests that teachers who were trained in data analysis performed better on the literacy knowledge assessment. This finding is consistent with research that indicated having data on student performances allowed teachers to analyze and formulate their own awareness of the importance of literacy components (e.g. phonemic awareness) in teaching reading (Al Otaiba and Lake; 2007). The findings in this research, while not significant, did indicate that having training in the components of RtI positively impacted performance on the literacy knowledge assessment.

Proper and careful implementation of RtI includes "extensive training" (Burns \& Ysseldyke, 2005, p. 17). Therefore, RtI professional development should include topics such as core reading program training, universal screening tool data collection and analysis, progress monitoring data collection and analysis, and targeted interventions for students who struggle in reading. Furthermore, opportunities are needed to help clarify teacher roles as traditional teacher responsibilities shift as the RtI process is rolled out 
across the country (Danielson et al., 2007). This includes embedding active rather than passive participation using a flexible scheduling process to allocate scarce resources and provide much needed staff development for teachers who teach struggling students (Johnson et al., 2006).

Pre-service teacher education. This research found that while not statistically significant, the number of courses taken at a college or university allowed teachers to score higher on the literacy knowledge assessment. While it is not clear if the courses taken by the participants were part of their bachelor's degree program or their postbachelor's education, pre-service teacher education is a key factor in preparing teachers for literacy instruction. In a study conducted on pre-service teachers, Shaw, Dvorak, and Bates (2007) found that formal training in reading resulting in increased literacy knowledge influenced the attitudes of pre-service teachers toward their perspective role as providers of literacy instruction. Moats and Foorman research (2003) also supports this assertion and suggests pre-service teachers' participation in coursework must seek to increase prospective teachers’ knowledge levels of teaching reading to students. In addition, research also suggests the notion that pre-service teachers who have specific coursework related to assessment were more readily able to determine appropriate assessment tools to be used (Mertler, 2005). More importantly, this type of professional development positively influences student performance (Hoffman et al., 2005). On the other hand, evidence exists that a lack of foundational literacy knowledge among teachers result from mediocre pre-service level coursework and experiences that perpetuates a continued lack of proficient reading skills among struggling readers (Joshi et al., 2006). Therefore, critical to the success of these pre-service efforts is scaffolding pre-service 
teachers' knowledge, skills, and attitudes during course offerings by embedding opportunities for practice in pre-service teacher placements (Al Otaiba \& Lake, 2007; Moats \& Foorman, 2003; Spear-Swerling, Brucker, \& Alfano, 2005) and incorporating the latest research to provide appropriate strategies for teachers to implement in the classroom (Connor et al., 2009).

Teacher credentials. This research found that those who possessed the highest level of education did not outperform those with lower levels of education as expected. Although not explored in this study, this finding may be more related to the content and coursework of the master's degree programs. According to Zumwalt and Craig (as cited in Hill, 2007), "little is known about the content of graduate coursework" (p. 113). Hill (2007) also points out that participation by teachers in graduate-level programming has not been shown to affect the knowledge and skills needed for teaching supporting the finding of this research. In addition, years of experience did not seem to influence performance on the literacy knowledge assessment. This is inconsistent with findings of other studies (McIntyre \& Hellsten, 2008) and was unexpected as "one expects a person's knowledge base to expand as more work experience is gained" (McIntire \& Hellsten, 2008, p. 33).

\section{Limitations}

This research has several limitations that limit the generalizability of the findings: First, all participants were from one southwestern Pennsylvania school district therefore, responses to questions may not be generalizable to other school systems. Second, the small sample size disallows for the generalizability of the results. Potential participants were contacted initially through email. When the desired response rate was not reached, 
the research contacted the principals of each school to see if they would distribute the email to their teachers. It is unknown if all principals distributed the survey to the potential participants. In addition, the researcher attended a faculty meeting where paper versions of the survey were provided to potential participants. None of the paper versions of the survey were completed or sent to the researcher. Third, the study was conducted in the midst of preparation for state assessments and deadlines for other district reporting responsibilities possibly impacting the number of voluntary participation in the study. Fourth, surveys often allow for superficial responses (Sagor, 2000) disallowing the researcher to determine quality and accurate responding to survey questions. Finally, online surveys provide no conclusive evidence that respondents are indeed the targeted participants compromising control over the response group (Coughlan, Cronin, \& Ryan, 2009; Lefever, Dal, \& Matthiasdottir, 2007).

\section{Recommendations}

After reviewing the findings of this study, there are several recommendations to support and organize future research in the area of literacy knowledge of teachers.

1. A larger sample of teachers would allow different types of analyses to be conducted to better understand the relationships of teachers' demographic characteristics and examine the interaction between the characteristics and the influence they may have on literacy knowledge levels of teachers.

2. This study did not develop and implement a professional development program, however, results hint at the effectiveness various professional development offerings have on the literacy knowledge of teachers. Explorations of intensive forms of professional development should be conducted focusing on the independent variables that 
had the most significant outcomes, designing and implementing a professional development program, then conducting a follow-up study to determine the effectiveness of the professional development in building literacy knowledge of teachers. Specifically, professional development opportunities honing teacher knowledge for practice through multi-day institutes and conducting ongoing professional development opportunities such as professional learning communities, mentoring, and coaching to increase knowledge in and of practice and engaging in data-based decision making should be implemented to examine the impact on literacy knowledge of teachers.

3. This study did not include gathering data on student performance. More studies should be conducted on the affect of teacher literacy knowledge on the reading performance of students as a result of improved professional development. The impact of professional development on the knowledge and skill levels of all teachers should be continually measured using student performance as a gauge (Desimone, 2009). Measuring the effectiveness of professional development has created a conundrum in the field with most researchers in agreement that improved student performance being the outcome (Desimone, 2009; Guskey, 2000; Guskey, 2003). Desimone (2009) identifies the core features of professional development for use as a framework for measuring professional development effectiveness. Through careful and thoughtful implementation of the core features of professional development (content, active learning, coherence, duration, and collective participation), it is anticipated that teacher knowledge and skills will increase leading to a change in instructional practice to improve student performance (Desimone, 2009). Regardless of the type of professional development implemented, teachers should be expected to engage in active collection of student data through 
progress monitoring activities, daily work samples, and formal assessment data, including these data as proof of effective professional development and their own knowledge and skills growth.

\section{Implications}

In summary, although all in-service teachers in this study had limited literacy knowledge as evidenced by scores on the literacy knowledge assessment, participants who were exposed to more intense types of professional development, were trained in the core components of RtI, and took more courses at a college or university performed better than their counterparts on the literacy knowledge assessment. Also, in-service teachers whose primary teaching role was teaching reading to struggling or beginning readers and those certified in special education tended to perform better on the literacy knowledge assessment.

The results of this study indicate that teachers' preparation can make a difference in the levels of literacy knowledge. The results suggests that as more research emerges about best practices in reading instruction, pre-service teacher preparation and postbaccalaureate programming must change and may need to consider incorporating more scientifically-based reading instructional practices and strategies as well as data-based decision making into the coursework pertaining to literacy instruction.

For teachers with limited formal preparation in the area of reading, on-the-job experience and professional development offerings are the primary avenues for acquiring knowledge in literacy and reading instruction. According to Cochran-Smith and Lytle (1999), the most effective professional development are those that promote high levels of collaboration. Professional learning communities provide this collaboration through the 
partnership of professionals and stakeholders (Servage, 2008). However, this collaboration is impacted by the knowledge levels of those involved. Teachers must have the prerequisite knowledge to effectively engage in true collaboration demonstrating knowledge for, of, and in practice. This suggests that professional development specialists need to design activities that appeal to and are appropriate for teachers. Administrators also are key players as they collaborate with professional development coordinators to support efforts to improve literacy knowledge of their teachers. This can occur as training is matched to teacher performance on the Survey of Teacher Knowledge in Literacy Instruction. Ideally, the content of these professional development sessions will improve the knowledge, skills, and dispositions for teaching literacy strategies for all teachers. 


\section{References}

Adams, M. J. (1990). Beginning to read: Thinking and learning about print. Cambridge, MA: The MIT Press.

Al-Hazza, T. C., Fleener, C., \& Hager, J. (2008). Primary teachers' knowledge and knowledge calibration of early literacy practices. Reading Matrix: An International Online Journal, 8(2), 1-11.

Allington, R. L., \& McGill-Franzen, A. (2000). Looking back, looking forward: A conversation about teaching reading in the 21st century. Reading Research Quarterly, 35(1), 136-153.

Al Otaiba, S., Kosanovich-Grek, M. L., Torgesen, J. K., Hassler, L., \& Wahl, M. (2005). Reviewing core kindergarten and first-grade reading programs in light of No Child Left Behind: An exploratory study. Reading \& Writing Quarterly, 21(4), $377-400$.

Al Otaiba, S., \& Lake, V. E. (2007). Preparing special educators to teach reading and use curriculum-based assessments. Reading \& Writing, 20(6), 591-617.

Armstrong, K., Cusumano, D. L., Todd, M., \& Cohen, R. (2008). Literacy training for early childhood providers: Changes in knowledge, beliefs, and instructional practices. Journal of Early Childhood Teacher Education, 29, 297-308.

Austin, M. C., \& Morrison, C. (1963). The first R: The Harvard report on reading in elementary schools. New York, NY: MacMillan.

Baker, B. (2007). Preparing teachers to support struggling first-grade readers. Journal of Early Childhood Teacher Education, 28, 233-242. 
Barnes, A. C., \& Harlacher, J. E. (2008). Clearing the confusion: Response-tointervention as a set of principles. Education and Treatment of Children, 31(3), 417-431.

Baumann, J. F., Hoffman, J. V., Duffy-Hester, A. M., \& Ro, J. M. (2000). The first R yesterday and today: U.S. elementary reading instruction practices reported by teachers and administrators. Reading Research Quarterly, 35(3), 338-377.

Bergstrom, M. K. (2008). Professional development in response to intervention: Implementation of a model in a rural region. Rural Special Education Quarterly, 27(4), 27-36.

Berkeley, S., Bender, W. N., Peaster, L. G., \& Saunders, L. (2009). Implementation of response to intervention: A snapshot of progress. Journal of Learning Disabilities, 42(1), 85-95.

Boling, C. J., \& Evans, W. H. (2008). Reading success in the secondary classroom. Preventing School Failure, 52(2), 59-66.

Bondy, E., \& Brownell, M. T. (2004). Getting beyond the research to practice gap: Researching against the grain. Teacher Education and Special Education, 27(1), 47-56.

Bos, C., Mather, N., Dickson, S., Podhajski, B., \& Chard, D. (2001). Perceptions and knowledge of preservice and inservice educators about early reading instruction. Annals of Dyslexia, 51, 97-120.

Brabham, E. G., \& Villaume, S. K. (2003). Scientifically based reading research - A call for an expanded view. The Reading Teacher, 56(7), 698-701. 
Bradley, R., Danielson, L., \& Doolittle, J. (2007). Responsiveness to intervention: 1997 to 2007. TEACHING Exceptional Children, 39(5), 8-12.

Brady, S., Gillis, M., Smith, T., Lavalette, M., Liss-Bronstein, L., Lowe, E., ...Wilder, T. D. (2009). First grade teachers' knowledge of phonological awareness and code concepts: Examining gains from an intensive form of professional development and corresponding teacher attitudes. Reading and Writing, 22, 425-455.

Brown, Elizabeth. (2006). History of reading instruction. The Phonics Page. Retrieved from http://www.thephonicspage.org/On\%20Phonics/historyofreading.html

Brozo, W. G. (2010). Response to intervention or responsive instruction? Challenges and possibilities of response to intervention for adolescent literacy. Journal of Adolescent \& Adult Literacy, 53(4), 277-281.

Bryant, D. P., Linan-Thompson, S., Ugel, N., Hamff, A., \& Hougen, M. (2001). The effects of professional development for middle school general and special education teachers on implementation of reading strategies in inclusive content area classes. Learning Disability Quarterly, 24, 251-264.

Burns, M. K., \& Ysseldyke, J. E. (2005). Comparison of existing response-tointervention models to identify and answer implementation questions. The California School Psychologist, 10, 9-20.

Bursuck, W. D., Smith, T., Munk, D., Damer, M., Mehlig, L., \& Perry, J. (2004). Evaluating the impact of a prevention-based model of reading on children who are at risk. Remedial and Special Education, 25(5), 303-313. 
Carlisle, J. F., Correnti, R., Phelps, G., \& Zeng, J. (2009). Exploration of the contribution of teachers' knowledge about reading to their students' improvement in reading. Reading \& Writing, 22, 457-486.

Carnine, D. W., Silbert, J., Kame'enui, E. J., Tarver, S. G., \& Jungjohann, K. (2006). Teaching struggling and at-risk readers: A direct instruction approach. Upper Saddle River, NJ: Pearson Education, Inc.

Caro-Bruce, C. (2008). Action research. In L. B. Easton (Ed.), Powerful designs for professional learning (2 ${ }^{\text {nd }}$ Ed.) (pp. 63-70). Oxford, OH: National Staff Development Council.

Center for Rural Pennsylvania, The. (n.d.). Rural municipalities/school districts. Retrieved from http://www.ruralpa2.org/rural_muni_sd.cfm?countyname=Adams\&schooldistrict =ALL\&ruralurbanstatus=ALL\&orderby=entity\&submit=Search

Chall, J. (1967). Learning to read: The great debate. New York: McGraw-Hill, Inc.

Chard, D. J., Stoolmiller, M., Harn, B. A., Wanzek, J., Vaughn, S., Linan-Thompson, S., et al. (2008). Predicting reading success in a multilevel schoolwide reading model: A retrospective analysis. Journal of Learning Disabilities, 41(2), 174-188.

Charles, C. M., \& Mertler, C. A. (2002). Introduction to educational research (4th ed.). Boston: Allyn \& Bacon.

Cochran-Smith, M. \& Lytle, S. L. (1999). Relationships of knowledge and practice: Teacher learning in communities. In A. Iran-Nejar \& P. D. Pearson (Eds.), Review of research in education (pp. 249-305). Washington, DC: American Educational Research Association. 
Connor, C. M., Jakobsons, L. J., Crowe, E. C., \& Meadows, J. G. (2009). Instruction, student engagement, and reading skill growth in reading first classrooms. The Elementary School Journal, 109(3), 221-250.

Cooper, J. D. (2000). Literacy: Helping children construct meaning (4 ${ }^{\text {th }}$ ed.). Boston, MA: Houghton Mifflin Company.

Coughlan, M., Cronin, P., \& Ryan, F. (2009). Survey research: Process and limitations. International Journal of Therapy \& Rehabilitation, 16(1), 9-15.

Crawford, E., \& Torgesen, J. (n.d.). Teaching all students to read: Practices from Reading First schools with strong intervention outcomes [complete report]. Florida Center for Reading Research.

Crim, C., Hawkins, J., Thornton, J., Rosof, H. B., Copley, J., \& Thomas, E. (2008). Early childhood educators' knowledge of early literacy development. Issues in Teacher Education, 17(1), 17-30.

Cunningham, A. E., Perry, K. E., Stanovich, K. E., \& Stanovich, P. J. (2004).

Disciplinary knowledge of K-3 teachers and their knowledge calibration in the domain of early literacy. Annals of Dyslexia, 54(1), 139-167.

Danielson, L., Doolittle, J., \& Bradley, R. (2005). Past accomplishments and future challenges. Learning Disability Quarterly, 28, 137-139.

Danielson, L., Doolittle, J., \& Bradley, R. (2007). Professional development, capacity building, and research needs: Critical issues for response to intervention implementation. School Psychology Review, 36(4), 632-637.

Dean, V. J., Burns, M. K., Grialou, T., \& Varro, P. J. (2006). Comparison of 
ecological validity of learning disabilities diagnostic models. Psychology in the Schools, 43(2), 157-168.

Deno, S., Reschly, A., Lembke, E., Magnusson, D., Callender, S., Windram, H., ... Stachel, N. (2009). Developing a school-wide progress-monitoring system. Psychology in the Schools, 46(1), 44-55.

Deshler, D. D., Mellard, D. F., Tollefson, J. M., \& Byrd, S. E. (2005). Research topics in responsiveness to intervention: Introduction to the special series. Journal of Learning Disabilities, 38(6), 483-484.

Desimone, L. M. (2009). Improving impact studies of teachers' professional development: Toward better conceptualizations and measures. Educational Researcher, 38(3), 181-199.

Ehri, L., Nunes, S., Willows, D., Schuster, B., Yaghoub-Zadeh, Z., \& Shanahan, T. (2001). Phonemic awareness instruction helps children learn to read: Evidence from the National Reading Panel's meta-analysis. Reading Research Quarterly, 36(3), 250-287.

Eldredge, J. (2005). Foundations of fluency: An exploration. Reading Psychology, 26(2), $161-181$.

Engen, L., \& Høien, T. (2002). Phonological skills and reading comprehension. Reading \& Writing, 15(7/8), 613-631.

Federal Education Budget Project. (n.d.). Conewago Valley School District. Retrieved from http://febp.newamerica.net/k12/pa/4206550

Fenton, J. (n.d). 2009 PSSA results. The Morning Call. Retrieved from http://projects.mcall.com/PSSA- 
results/district/112011603/CONEWAGO\%20VALLEY\%20SD/

Flesch, R. (1955). Why Johnny can't read. New York: Harper \& Row, Publishers, Incorporated.

Foorman, B. R., \& Moats, L. C. (2004). Conditions for sustaining research-based practices in early reading instruction. Remedial and Special Education, 25(1), 5160.

Foster, W., \& Miller, M. (2007). Development of the literacy achievement gap: A longitudinal study of kindergarten through third grade. Language, Speech, \& Hearing Services in Schools, 38(3), 173-181.

Freedman, L., \& Carver, C. (2007). Preservice teacher understandings of adolescent literacy development: Naïve wonder to dawning realization to intellectual rigor. Journal of Adolescent \& Adult Literacy, 50(8), 654-665.

Frey, N., \& Fisher, D. (2004). School change and teacher knowledge: A reciprocal relationship. Teacher Education and Special Education, 27(1), 57-67.

Fuchs, D., \& Fuchs, L. S. (2006). Introduction to response to intervention: What, why, and how valid is it? Reading Research Quarterly, 41(1), 93-99.

Fuchs, D., \& Deshler, D. D. (2007). What we need to know about responsiveness to intervention (and shouldn't be afraid to ask). Learning Disabilities Research \& Practice (Blackwell Publishing Limited), 22(2), 129-136.

Fuchs, L. S., \& Fuchs, D. (2006). A framework for building capacity for responsiveness to intervention. School Psychology Review, 35(4), 621-626.

Gamse, B., Jacob, R., Horst, M., Boulay, B., Unlu, F., \& Institute of Education Sciences (ED), N. (2008). Reading First Impact Study. Final Report. Executive Summary. 
NCEE 2009-4039. National Center for Education Evaluation and Regional Assistance.

Gerber, M. M. (2005). Teachers are still the test: Limitations of response to instruction strategies for identifying children with learning disabilities. Journal of Learning Disabilities, 38(6), 516-524.

Gersten, R., \& Dimino, J. A. (2006). RTI (response to intervention): Rethinking special education for students with reading difficulties (yet again). Reading Research Quarterly, 41(1), 99-108.

Gerstl-Pepin, C. I., \& Woodside-Jiron, H. (2005). Tensions between the "science" of reading and a "love of learning": One high-poverty school's struggle with NCLB. Equity \& Excellence in Education, 38(3), 232-241.

Gibbons, K. (n.d.). Evaluating RTI's effectiveness over the long term. Retrieved May 5, 2009, from http://www.aasa.org/publications/contentcfm?PreviewContentItem=51249

Gordan, S. P. (2004). Professional development for school improvement-empowering learning communities. Boston: Pearson Education, Inc.

Granello, D. H., \& Wheaton, J. E. (2004). Online data collection: Strategies for research. Journal of Counseling \& Development, 82, 387-393.

Gray, E. (2008). Understanding dyslexia and its instructional implications: A case to support intense intervention. Literary Research and Instruction, 47(2), 116-123.

Graybill, O. (2008). Dialogue. In E. B. Easton (Ed.). Powerful designs for professional learning (2 ${ }^{\text {nd }}$ Ed.) (pp. 131-141). Oxford,OH: National Staff Development Council. 
Greenlaw, C., \& Brown-Welty, S. (2009). A comparison of web-based and paper-based survey methods - testing assumptions of survey mode and response cost. Evaluation Review, 33(5), 464-480.

Guskey, T. R. (2000). Evaluating professional development. Thousand Oaks, CA: Corwin Press, Inc.

Guskey, T. R. (2003). What makes professional development effective?. Phi Delta Kappan, 84(10), 748-750.

Hale, J. B., Kaufman, A., Naglieri, J. A., \& Kavale, K. A. (2006). Implementation of IDEA: Integrating response to intervention and cognitive assessment methods. Psychology in the Schools, 43(7), 753-770.

Harn, B. A., Linan-Thompson, S., \& Roberts, G. (2008). Intensifying instruction: Does additional instructional time make a difference for the most at-risk first graders?. Journal of Learning Disabilities, 41(2), 115-125.

Hawkins, R., Kroeger, S., Musti-Rao, S., Barnett, D., \& Ward, J. (2008). Preservice training in response to intervention: Learning by doing an interdisciplinary field experience. Psychology in the Schools, 45(8), 745-762.

Hempenstall, K. (1997). The whole language-phonics controversy: An historical perspective. Educational Psychology, 17(4), 399-418.

Hempenstall, K. (2006). What brain research can tell us about reading instruction. Learning Difficulties Australia Bulletin, 38(1), 15-16.

Hill, H. C. (2007). Learning in the teaching workforce. The Future of Children, 17(1), 111-127. 
Hines, M. B., Conner, J., Campano, G., Damico, J., Enoch, M., \& Nam, D. (2007). National mandates and statewide enactments: Inquirty in/to large-scale reform. English Teaching: Practice and Critique, 6(3), 76-91.

Hoffman, J. V., Roller, C., Maloch, B., Sailors, M., Duffy, G., Beretvas, S. N., \& National Commission on Excellence in Elementary Teacher Preparation for Reading Instruction. (2005). Teachers' preparation to teach reading and their experiences and practices in the first three years of teaching. The Elementary School Journal, 105(3), 267-287.

Holden, C. (2004). Training the brain to read. Science, 304(5671), 677.

Holdnack, J. A., \& Weiss, L. G. (2006). IDEA 2004: Anticipated implications for clinical practice - integrating assessment and intervention. Psychology in the Schools, 43(8), 871-882.

Jackson, J. B., Paratore, J. R., Chard, D. J., \& Garnick, S. (1999). An early intervention supporting the literacy learning of children experiencing substantial difficulty. Learning Disabilities Research \& Practice, 14(4), 254-267.

Jacobs, J., Gregory, A., Hoppey, D., \& Yendol-Hoppey, D. (2009). Data literacy: Understanding teachers' data use in a context of accountability and response to intervention. Action in Teacher Education, 31(3), 41-55.

.Jankowski, E. (2003). Heartland area education agency's problem solving model: An outcomes-driven special education paradigm. Rural special education quarterly, 22,29-36.

Johnson, E., Mellard, D. F., \& Byrd, S. E. (2006). Challenges with SLD identification: What is the SLD problem?. TEACHING Exceptional Children Plus, 3(1). 
Joshi, R., Binks, E., Hougen, M., Dahlgren, M., Ocker-Dean, E., \& Smith, D. (2009). Why elementary teachers might be inadequately prepared to teach reading. Journal Of Learning Disabilities, 42(5), 392-402.

Kamps, D., Abbott, M., Greenwood, C., Wills, H., Veerkamp, M, \& Kaufman, J. (2008). Effects of small-group reading instruction and curriculum differences for students most at risk in kindergarten: Two-year results for secondary- and tertiary- level interventions. Journal of Learning Disabilities, 41(2), 101-114.

Kashi, T. L. (2008). Response to intervention as a suggested generalized approach to improving minority AYP scores. Rural Special Education Quarterly, 27(4), 3744.

Kavale, K. A., Holdnack, J. A., \& Mostert, M. P. (2006). Responsiveness to intervention and the identification of specific learning disability: A critique and alternative proposal. Learning Disability Quarterly, 29(2), 113-127.

Kice, J. A. G. (2008). Differentiated coaching. In E. B. Easton (Ed.). Powerful designs for professional learning $\left(2^{\text {nd }}\right.$ Ed.) (pp. 143-154). Oxford,OH: National Staff Development Council.

Kim, J. (2008). Research and the reading wars. Phi Delta Kappan, 89(5), 372-375.

Kindig, J. (2006). Here, there, and everywhere: Reading first in the library. Library Media Connection, 24(7), 38-30.

Klingner, J. K., \& Edwards, P. A. (2006). Cultural considerations with response to intervention models. Reading Research Quarterly, 41(1), 108-117.

Kovaleski, J. F. (2007). Response to intervention: Considerations for research and systems change. School Psychology Review, 36(4), 638-646. 
Kovaleski, J. F., \& Glew, M. C. (2006). Bringing instructional support teams to scale: Implications of the Pennsylvania experience. Remedial and Special Education, 27(1), 16-25.

Kozen, A. A., Murray, R. K., \& Windell, I. (2006). Increasing all students' chance to achieve: Using and adapting anticipating guides with middle school learners. Intervention in School and Clinic, 41(4), 195-200.

Kratochwill, T. R., Volpiansky, P., Clements, M., \& Ball, C. (2007). Professional development in implementing and sustaining multitier prevention models: Implications for response to intervention. School Psychology Review,36(4), 618631.

Kroese, J., Hynd, G., Knight, D., Hiemenz, J., \& Hall, J. (2000). Clinical appraisal of spelling ability and its relationship to phonemic awareness (blending, segmenting, elision, and reversal), phonological memory, and reading in reading disabled, ADHD, and normal children. Reading and Writing: An Interdisciplinary Journal, 13(1-2), 105-131.

Lefever, S., Dal, M., \& Matthiasdottir, A. (2007). Online data collection in academic research: Advantages and limitations. British Journal of Educational Technology, 38(4), 574-582.

Lose, M. (2007). A child's response to intervention requires a responsive teacher of reading. The Reading Teacher, 61(3), 276-279.

Mahar, N. E., \& Richdale, A. L. (2008). Primary teachers' linguistic knowledge and perceptions of early literacy instruction. Australian Journal of Learning Difficulties, 13(1), 17-37. 
Mahdavi, J., \& Beebe-Frankenberger, M. (2009). Pioneering RTI systems that work: Social validity, collaboration, and context. TEACHING Exceptional Children, 42(2), 64-72.

Malmgren, K. W., \& Trezek, B. J. (2009). Literacy instruction for secondary students with disabilities. Focus on Exceptional Children, 41(6), 1-12.

Manning, M., Bullock, L., \& Gable, R. (2009). Personnel preparation in the area of emotional and behavioral disorders: A reexamination based on teacher perceptions. Preventing School Failure, 53(4), 219-226.

Manzo, K. (2008). Reading first doesn't help pupils get it. Education Week, 27(36).

Marston, D. (2005). Tiers of intervention in responsiveness to intervention: Prevention outcomes and learning disabilities identification patterns. Journal of Learning Disabilities, 38(6), 539-544.

Martinez, M. G., \& McGee, L. M. (2000). Children's literature and reading instruction: Past, present, and future. Reading Research Quarterly, 35(1), 154-169.

Mastropieri, M., \& Scruggs, T. (2005). Feasibility and consequences of response to intervention: examination of the issues and scientific evidence as a model for the identification of individuals with learning disabilities. Journal Of Learning Disabilities, 38(6), 525-531.

Mastropieri, M. A., \& Scruggs, T. E. (2010). The inclusive classroom: Strategies for effective differentiated instruction ( $4^{\text {th }}$ Ed.). Upper Saddle River, NJ: Merrill. Mather, N., Bos, C., \& Babur, N. (2001). Perceptions and knowledge of preservice and inservice teachers about early literacy instruction. Journal of Learning Disabilities, 34(5), 472-482. 
McCutchen, D., Abbott, R. D., Green, L. B., Beretvas, S. N., Cox, S., Potter, N. S., ... Gray, A. L. (2002). Beginning literacy: Links among teacher knowledge, teacher pratice, and student learning. Journal of Learning Disabilities, 35(1), 69-86.

McCutchen, D., Green, L., Abbott, R. D., \& Sanders, E. A. (2009). Further evidence for teacher knowledge: Supporting struggling readers in grades three through five. Reading and Writing, 22, 401-423.

McCutchen, D., Harry, D. R., Cunningham, A. E., Cox, S., Sidman, S., \& Covill, A. E. (2002). Reading teachers' knowledge of children's literature and English phonology. Annals of Dyslexia, 52, 207-228.

McIntyre, L. J., \& Hellsten, L. M. (2008). Differences in teachers' knowledge of language. Exceptionality Education Canada, 18(2), 24-37.

McKay, M., \& Thompson, G. (2009). Reading vocabulary influences in phonological recoding during the development of reading skill: a re-examination of theory and practice. Reading \& Writing, 22(2), 167-184.

McLeskey, J., \& Waldron, N. L. (2004). Three conceptions of teacher learning: Exploring the relationship between knowledge and the practice of teaching. Teacher Education and Special Education, 27(1), 3-14.

McNeil, P. W., \& Klink, S. M. (2008). School coaching. In E. B. Easton (Ed.). Powerful designs for professional learning ( $2^{\text {nd }}$ Ed.) (pp. 209-218). Oxford,OH: National Staff Development Council.

Meisels, S. J., Bickel, D. D., Nicholson, J., Xue, Y, \& Atkins-Burnett, S. (2001). Trusting 
teachers' judgments: A validity study of a curriculum-embedded performance assessment in kindergarten to grade 3. American Educational Research Journal, 38(1), 73-95.

Mellard, D. F., Byrd, S. E., Johnson, E., Tollefson, J. M., \& Boesche, L. (2004).

Foundations and research on identifying model responsiveness-to-intervention sites. Learning Disability Quarterly, 27(4), 243-256.

Mellard, D. F., Deshler, D. D., \& Barth, A. (2004). LD identification: It's not simply a matter of building a better mousetrap. Learning Disability Quarterly, 27(4), 229-242.

Mercer, C. D., Campbell, K. U., Miller, M. D., Mercer, K. D., \& Lane, H. B. (2000). Effects of a reading fluency intervention for middle schoolers with specific learning disabilities. Learning Disabilities Research \& Practice, 15(4), 179-189.

Mertens, D. M., \& McLaughlin, J. A. (2004). Research and evaluation methods in special education. Thousand Oaks, CA: Corwin Press.

Mertler, C. A. (2005). Secondary teachers' assessment literacy: Does classroom experience make a difference? American Secondary Education, 33(2), 76-92.

Mesmer, E. M., \& Mesmer, H. A. E. (2008). Response to intervention (RTI): What teachers of reading need to know. The Reading Teacher, 62(4), 280-290.

Miller, W. H. (2000). Strategies for developing emergent literacy. Boston, MA: McGraw-Hill.

Moats, L. C. (1994). The missing foundation in teacher education: Knowledge of the structure of spoken and written language. Annals of Dyslexia, 44(1), 81-102. 
Moats, L. (2009). Knowledge foundations for teaching reading and spelling. Reading \& Writing, 22, 279-399.

Moats, L. C., \& Foorman, B. R. (2003). Measuring teachers' content knowledge of language and reading. Annals of Dyslexia, 53, 23-45.

Moje, E. B. (2008). Foregrounding the disciplines in secondary literacy teaching and learning: A call for change. Journal of Adolescent \& Adult Literacy, 52(2), 96107.

Mokhtari, K., Rosemary, C. A., \& Edwards, P. A. (2007). Making instructional decisions based on data: What, how, and why. The Reading Teacher, 61(4), 354-359.

Moore, D. W., Monaghan, E. J., \& Hartman, D. K. (1997). Values of literacy history. Reading Research Quarterly, 32(1), 90-102.

Moore, J., \& Whitfield, V. (2009). Building schoolwide capacity for preventing reading failure. Reading Teacher, 62(7), 622-624.

Munoz, M. A., Guskey, T. R., \& Aberli, J. R. (2009). Struggling readers in urban high schools: Evaluating the impact of professional development in literacy. Planning \& Changing, 40(1/2), 61-85.

Murawski, W., \& Hughes, C. (2009). Response to intervention, collaboration, and coteaching: A logical combination for successful systemic change. Preventing School Failure, 53(4), 267-277.

Murphy, C., \& Murphy, M. (2008). Study groups. In. L. B. Easton (Ed.), Powerful designs for professional learning ( $2^{\text {nd }}$ Ed.) (pp. 243-247). Oxford, OH: National Staff Development Council. 
National Center for Education Statistics. (2004). Who teaches reading in public elementary schools? The assignments and educational preparation of reading teachers. Retrieved from http://nces.ed.gov/pubs2004/2004034.pdf

National Institute of Child Health and Human Development. (2000). Teaching children to read: An evidence-based assessment of the scientific research literature on reading and its implications for reading instruction (NIH Publication No. 004769).

Nulty, D. D. (2008). The adequacy of response rates to online and paper surveys: What can be done?. Assessment \& Evaluation in Higher Education, 33(3), 301-314.

Nunn, G. D., Jantz, P. B., \& Butikofer, C. (2009). Concurrent validity between teacher efficacy and perceptions of response to intervention outcomes. Journal of Instructional Psychology, 36(3), 215-218.

Oortwijn, M., Boekaerts, M., \& Vedder, P. (2008). The impact of the teacher's role and pupils' ethnicity and prior knowledge on pupils' performance and motivation to cooperate. Instructional Science: An International Journal of the Learning Sciences, 36(3), 251-268.

Palenchar, L., \& Boyer, L. (2008). Response to intervention: Implementation of a statewide system. Rural Special Education Quarterly, 27(4), 18-26.

Palumbo, A., \& Sancore, J. (2009). Helping struggling middle school literacy learners achieve success. The Clearing House, 82(6), 275-280.

Parris, S. R., \& Block, C. C. (2007). The expertise of adolescent literacy teachers. Journal of Adolescent \& Adult Literacy, 50(7), 582-596.

Pearson, P. (2004). The Reading Wars. Educational Policy, 18(1), 216-252. 
Pennsylvania Department of Education. (2010). Per cent of students on free/reduced lunch. Retrieved from http://www.portal.state.pa.us/portal/server.pt/community/pre_k_counts/8742/stud ent_on_free_reduced_lunch/522216.

Phelps, G. (2009). Just knowing how to read isn't enough! Assessing knowledge for teaching reading. Educational Assessment, Evaluation and Accountability, 21(2), 137-154.

Pressley, M., Yokoi, L., Rankin, J., Wharton-McDonald, R., \& Mistretta, J. (1997). A survey of the instructional practices of grade 5 teachers nominated as effective in promoting literacy. Scientific Studies of Reading, 1(2), 145-160.

Pullen, P. (personal communication, October 18, 2009)

Quick, B. (1998). Beginning reading and developmentally appropriate practice (DAP): Past, present, and future. Peabody Journal of Education, 73(3/4), 253.

Rankin-Erickson, J. L., \& Pressley, M. (2001). A survey of instructional practices of special education teachers nominated as effective teachers of literacy. Learning Disabilities Practice, 15(4), 206-225.

Rasinski, T., \& Hoffman, J. (2003). Oral reading in the school literacy curriculum. Reading Research Quarterly, 38(4), 510-522.

Reschley, D. J. (2005). Learning disabilities identification: Primary intervention, secondary intervention, and then what?. Journal of Learning Disabilities, 38(6), 510-515.

Reutebuch, C. K. (2008). Succeed wit ha response-to-intervention model. Intervention in School and Clinic, 44(2), 126-128. 
Reynolds, C. R., \& Shaywitz, S. E. (2009). Response to intervention: Ready or not? Or, from wait-to-fail to watch-them-fail. School Psychology Quarterly, 24(2), 130145.

Richek, M. A., Caldwell, J. S., Jennings, J. H., \& Lerner, J. W. (1996). Reading problems: Assessment and teaching strategies ( $3^{\text {rd }}$ ed.). Boston, MA: Allyn and Bacon.

Risko, V. J., Roller, C. M., Cummins, C., Bean, R. M., Block, C. C., Anders, P. L., \& Flood, J. (2008). A critical analysis of research on reading teacher education. Reading Research Quarterly, 43(3), 252-288.

Robbins, P. (2008). Mentoring. In E. B. Easton (Ed.). Powerful designs for professional learning (2 ${ }^{\text {nd }}$ Ed.) (pp. 185-197). Oxford,OH: National Staff Development Council.

Rodgers, G. E. (2004). Why Noah Webster's way was the right way. Retrieved from http://www.donpotter.net/PDF/WHY\%20NOAH\%20WEBSTER\%20WAS\%20RI GHT.pdf

Roehrig, A. D., Duggar, S. W., Moats, L., Glover, M., \& Mincey, B. (2008). When teachers work to use progress monitoring data to inform literacy instruction: Identifying potential supports and challenges. Remedial and Special Education, 29(6), 364-382.

Roehrig, A. D., Guidry, L. O., Bodur, Y., Guan, Q., Guo, Y., \& Pop, M. (2008). Guided field observations: Variables related to preservice teachers' knowledge about effective primary reading instruction. Literacy Research and Instruction, 47, 7698. 
Roehrig, A. D., Turner, J. E., Grove, C. M., Schneider, N., \& Liu, Z. (2009). Degree of alignment between beginning teachers practices and beliefs about effective classroom practices. The Teacher Educator, 44, 164-187.

Ross, D. D., \& Blanton, L. (2004). Inquiry communicaties in special education teacher education. Teacher Education and Special Education, 27(1), 15-23.

Sabornie, E. J., Evans, C., \& Cullinan, D. (2006). Comparing characteristics of highincidence disability groups: A descriptive review. Remedial and Special Education, 27(2), 95-104.

Sagor, R. (2000). Guiding school improvement with action research. Alexandria, VA: Association for Supervision and Curriculum Development.

Sax, L. J., Gilmartin, S. K., \& Bryant, A. N. (2003). Asessing response rates and nonresponse bias in web and paper surveys. Research in Higher Education, 44, 409-431.

Servage, L. (2008). Critical and transformative practices in professional learning communities. Teacher Education Quarterly, 35(1), 63-77.

Shaw, D. M., Dvorak, M. J., \& Bates, K. (2007). Promise and possibility - hope for teacher education: Pre-service literacy instruction can have an impact. Reading Research and Instruction, 46(3), 223-254.

Shaywitz, B., Lyon, G., \& Shaywitz, S. (2006). The role of functional magnetic resonance imaging in understanding reading and dyslexia. Developmental Neuropsychology, 30(1), 613-632.

Shaywitz, S., Mody, M., \& Shaywitz, B. (2006). Neural mechanisms in dyslexia. Current Directions in Psychological Science, 15(6), 278-281. 
Shaywitz, S., Shaywitz, B., Pugh, K., Fulbright, R., Constable, R., Mencl, W., ... Gore, J.C. (1998). Functional disruption in the organization of the brain for reading in dyslexia. Proceedings Of The National Academy Of Sciences Of The United States Of America, 95(5), 2636-2641.

Shen, J., \& Cooley, V. (2008). Critical issues in using data for decision-making. International Journal of Leadership in Education, 11(3), 319-329.

Sherman, J., Rasmussen, C., \& Baydala, L. (2008). The impact of teacher factors on achievement and behavioural outcomes of children with Attention Deficit/Hyperactivity Disorder (ADHD): aA review of the literature. Educational Research, 50(4), 347-360.

Shinn, M. R. (2007). Identifying students at risk, monitoring performance, and determining eligibility within response to intervention: Research on educational need and benefit from academic intervention. School Psychology Review, 36(4), 601-617.

Simmons, D. C., Coyne, M. D., Kwok, O., McDonagh, S., Harn, B. A., \& Kame'enui, E. J. (2008). Indexing response to intervention: A longitudinal study of reading risk from kindergarten through third grade. Journal of Learning Disabilities, 41(2), 158-173.

Smith, J. M. , Fien, H., Basaraba, D., \& Travers, P. (2009). Planning, evaluating, and improving tiers of support in beginning reading. Teaching Exceptional Children, 41(5), 16-22.

Smith, R., \& Leonard, P. (2005). Collaboration for inclusion: Practitioner perspectives. Equity \& Excellence in Education, 38(4), 269-279. 
Soodak, L., \& Podell, D. (1994). Teachers' thinking about difficult-to-teach students. Journal of Educational Research, 88(1), 44.

Spear-Swerling, L., \& Brucker, P. O. (2004). Preparing novice teachers to develop basic reading and spelling skills in children. Annals of Dyslexia, 54(2), 332-364.

Spear-Swerling, L., Brucker, P. O., \& Alfano, M. P. (2005). Teachers' literacy-related knowledge and self-perceptions in relation to preparation and experience. Annals of Dyslexia, 55(2), 266-296.

Speece, D. L. (2005). Hitting the moving target known as reading development: Some thoughts on screening children for secondary interventions. Journal of Learning Disabilities, 38(6), 487-493.

Stecker, P. (2007). Tertiary intervention. Teaching Exceptional Children, 39(5), 50-57.

Stecker, P. M., Fuchs, D., \& Fuchs, L. S. (2008). Progress monitoring as essential practice within response to intervention. Rural Special Education Quarterly, 27(4), 10-17.

Torgesen, J. (2009). The response to intervention instructional model: Some outcomes from a large-scale implementation in reading first schools. Child Development Perspectives, 3(1), 38-40

Urban, W. J., \& Wagoner, J. L. (2009). American education: A history (4 ${ }^{\text {th }}$ Ed.). New York: Routledge.

U. S. Department of Education. (2007). The nation's report card - reading 2007. Institute of Education Sciences, National Center for Education Statistics. 
Vaughn, S. Linan-Thompson, S., \& Hickman, P. (2003). Response to instruction as a means in identifying students with reading/learning disabilities. Exceptional Children, 69(4), 391-409.

Vaughn, S., Wanzek, J., Murray, C. S., Scammacca, N., Linan-Thompson, S., \& Woodruff, A. L. (2009). Response to early reading intervention: Examining higher and lower responders. Exceptional Children, 75(2), 165-183.

Westwood, P., Knight, B. A., \& Redden, E. (1997). Assessing teachers' beliefs about literacy acquisition: The development of the teachers' beliefs about literacy questionnaire (TBALQ). Journal of Research in Reading, 20(3), 224-235.

Whitfield, P. T. (2005). No Child Left Behind: Leaving the arts behind in developing young children's literacy. Journal of Children \& Poverty, 11(1), 43-54.

Wiener, R., \& Soodak, L. (2008). Special education administrators' perspectives on response to intervention. Journal of Special Education Leadership, 21(1), 39-45.

Wise, J., Sevcik, R., Morris, R., Lovett, M., \& Wolf, M. (2007). The relationship among receptive and expressive vocabulary, listening comprehension, pre-reading skills, word identification skills, and reading comprehension by children with reading disabilities. Journal of Speech, Language \& Hearing Research, 50(4), 10931109.

Xu, Y., \& Drame, E. (2008). Culturally appropriate context: Unlocking the potential of response to intervention for English language learners. Early Childhood Education Journal, 35(4), 305-311.

Zirkel, P. A. (2007). What does the law say?. TEACHING Exceptional Children, 39(5), 65-67. 
Zumwalt, K., \& Carig, E. (2005). Teachers characteristics: Research on the indicators of quality. In M Cochran-Smith \& K. Zeichner (Eds.). In Studying Teacher Education: The Report of the AERA Panel on Research and Teacher Education. Mahwah, NJ: Lawrence Erlbaum Associates. 
Appendix A

\section{SURVEY COVER PAGE}

\section{Survey of Teacher Knowledge in Literacy Instruction}

Conducted by doctoral student and faculty in the

Department of Special Education

West Virginia University

The purpose of this research study is to explore teacher knowledge in literacy instruction. The study is being done as a dissertation study in the West Virginia University's School of Human Resources and Education's doctoral program in Special Education. This research is designed to provide a better understanding of reading instruction knowledge as schools implement Response to Intervention in literacy instruction in schools.

- Your completion and return of this online survey is considered to reflect your consent to participate in this study. If you have questions about the survey or your rights as a participant in the study, you may call the staff of the WVU Institutional Review Board for the Protection of Human Subjects at 304-2937073.

- All responses to this online survey are completely anonymous and cannot be traced to you in any way.

- If you do not wish to answer a question, you may choose to not select an indicator or leave the textbox blank.

- There will be no penalty if you choose not to participate in this study.

- If you have any questions about this survey, please contact Amy Conner Love, study coordinator, at alove6@mix.wvu.edu or 814-221-5931.

Please click on the link below to access the Survey of Literacy Instructional Knowledge of Teachers

Literacy Instructional Knowledge

Thank you for your time.

Amy Love, Doctoral Student, Principal Investigator

Elizabeth Dooley, Ed.D., Associate Provost-Co-Investigator

David Hoppey, Ph.D., Assistant Professor-Co- Investigator

West Virginia University's IRB acknowledgment of this study is on file. 


\section{TEACHER SURVEY}

The Individuals with Disabilities Education Act (IDEA) now allows school systems to use the Response to Intervention (RtI) Model, a tiered approach to providing instruction targeted to meet student learning needs, as a method of identifying students with specific learning disability (SLD). All teachers must possess the appropriate knowledge in reading instruction to meet the needs of students as to not perpetuate the problem of misdiagnosis within special education.

Please respond to the following questions to share your knowledge of reading instruction.

\section{Part I. Demographic Data for Teachers and Paraprofessionals}

1. Please indicate your gender by checking the appropriate box.

Male

Female

2. What is your current PRIMARY teaching role?

General Education Teacher - Kindergarten $-3^{\text {rd }}$ Grade

General Education Teacher $-4^{\text {th }}-6^{\text {th }}$ Grade

Secondary English Teacher $-7^{\text {th }}-12^{\text {th }}$ Grade

Special Education Teacher - Kindergarten $-3^{\text {rd }}$ Grade

Special Education Teacher $-4^{\text {th }}-6^{\text {th }}$ Grade

Special Education Teacher $-7^{\text {th }}-12^{\text {th }}$ Grade

Reading Teacher/Specialist or Literacy Coach

English Language Learner Teacher

Other: (Insert)

3. What is the highest level of education you possess?

I have a doctoral degree.

I have a master's degree plus additional coursework.

I have a master's degree.

I have a master's equivalency.

I have a bachelor's degree plus master's level coursework.

I have a bachelor's degree.

4. When did you earn your highest degree?

Within the past 5 years

5-10 years ago

11-15 years ago

16 or more years ago 
5. What is your current teaching certification status? Check all that apply.

I am certified in elementary education.

I am certified in special education.

I am certified in reading.

I am certified in middle level or secondary English/Language Arts

I am working on emergency permit for my current position but am certified in another area of education.

I am working on emergency permit and not certified in any other area of education.

6. How many years of teaching experience do you have in your current position/grade?

Over 20 years

10-19 years

4-9 years

1-3 years

7. How many years of overall teaching experience do you have?

Over 20 years

$10-19$ years

4-9 years

1-3 years

8. How many college and/or university courses in teaching reading or teaching children with reading problems have you taken?

1 course offered through a college/university

2-3 courses offered through a college/university

4 or more courses offered through a college/university

None

Professional development is the "process and activities designed to enhance the professional knowledge, skills, and attitudes of educators..." (Guskey, 2000, p. 16). These activities might include training sessions, workshops, seminars, study groups, mentoring, peer-coaching, and action research (Gordon, 2004; Guskey, 2000).

9. Select the professional development activities related to reading instruction that you have participated? Select all that apply. Indicate the approximate time spent in each activity selected.

Institutes - Institutes are "intensive [one to three weeks] learning experiences in a specific area of study" (Gordon, 2004, p. 32).

1-3 hours

$1 / 2$ to 1 day

2-3 days

4 or more days 
Workshops - Workshops focus on teaching educators' specific skills and strategies for use in the classroom and are typically spaced several weeks apart with the expectation of teachers practicing learned skills between workshops (Gordon, 2004).

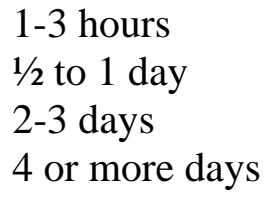

Seminars - "Seminars are small groups working closely with acknowledged experts in the field. Participants meet regularly to receive training..." (Gordon, 2004, p. 32).
1-3 hours
$1 / 2$ to 1 day
2-3 days
4 or more days

Study/Book groups - Study groups are comprised of teachers and professionals who collectively meet in a small group to discuss and share new information and ideas from the field to be used in the classroom to enhance student performance (Murphy \& Murphy, 2008).
1-3 hours
$1 / 2$ to 1 day
2-3 days
4 or more days

Mentoring - Mentoring is defined as activities (e.g., co-planning, co-teaching, problemsolving, observations) occurring between a veteran teacher and a novice teacher to help with acclimation to the school or subject area (Robbins, 2008).
$1-3$ hours
$1 / 2$ to 1 day
2-3 days
4 or more days

Peer-coaching - McNeil and Klink (2008) define a coach as "a person who helps others move from where they are to where they want to be" (p. 210) in terms of facilitating problem solving in the classroom.

1-3 hours

$1 / 2$ to 1 day

2-3 days

4 or more days 
Action Research - Action research is defined as engaging in data collection of student performance and using this information to analyze your teaching practices and make changes as appropriate (Caro-Bruce, 2008).

$$
\begin{aligned}
& 1-3 \text { hours } \\
& 1 / 2 \text { to } 1 \text { day } \\
& 2-3 \text { days } \\
& 4 \text { or more days }
\end{aligned}
$$

Professional Learning Community - Professional Learning Communities are collaborative group of professionals and stakeholders who meet regularly to plan and analyze curriculum and assessment results (Servage, 2008).

$1-3$ hours

$1 / 2$ to 1 day

2-3 days

4 or more days

Other

$$
\begin{aligned}
& 1-3 \text { hours } \\
& 1 / 2 \text { to } 1 \text { day } \\
& 2-3 \text { days } \\
& 4 \text { or more days }
\end{aligned}
$$

10. How confident do you feel in your ability to teach reading to student from the following backgrounds as a result of your coursework and/or professional development?

a) English as second language learners

Not at all confident

Somewhat confident

Confident

Completely confident

b) Students from low socioeconomic backgrounds

Not at all confident

Somewhat confident

Confident

Completely confident

c) Students with specific learning disabilities

Not at all confident

Somewhat confident

Confident

Completely confident 
d) Students with other disabilities

Not at all confident

Somewhat confident

Confident

Completely confident

e) Students from different racial backgrounds (e.g., Black, Asian, Hispanic)

Not at all confident

Somewhat confident

Confident

Completely confident

\section{Part II. Response to Intervention - Professional Development and Implementation}

1. To what extent have you participated in RtI Implementation to date?

I am working in a school that is currently in its first year of implementation of RtI

I am working in a school that is currently in its second year of implementation of RtI

I am working in a school that has been implementing RtI for more than two years

I am working in a school that is now receiving initial training for future implementation of RtI

I have attended workshops/presentations but have not been involved in implementation of RtI

I have not attended workshops and am working in a school that has not been involved in implementation of RtI

I had no prior knowledge or awareness of the RtI Initiative

2. What professional development opportunities have you participated in to learn how to implement RtI? Check all that apply.

I have been trained on the purpose and key components of a research based core reading program

I have been trained on data analysis for instructional decision-making

I have been trained on explicit, systematic intervention planning and delivery

My school has been trained in the use of universal screening tools.

My school has been trained in a progress monitoring process for students in Tiers II and III.

My school has been trained in effective collaboration and the use problem solving steps to meet the needs of struggling students.

My school has established professional learning communities to aid in the implementation of RtI

My school has established instructional coaching to aid in the implementation o RtI

I have not yet participated in professional development related to RtI 
3. How much time have you spent in professional development activities related to implementing RtI?

None

1 hour overview

$1 / 2$ day

1 day

2-3 days

4 or more days

4. To what extent do you feel this professional development prepared you to implement RtI?

I feel adequately prepared and confident in my ability to implement RtI

I feel adequately prepared but still unsure about how to implement RtI

I feel inadequately prepared but still confident in my ability to implement RtI

I feel inadequately prepared and quite unsure about to implement RtI

I have not yet participated in professional development related to RtI

5. Teachers are trained to implement our school's research-based core reading program. Strongly agree

Agree

Disagree

Strongly Disagree

6. Teachers are trained to implement research-based interventions to address students' academic or behavioral difficulties.

Strongly agree

Agree

Disagree

Strongly Disagree

7. Teachers are trained to analyze universal screening data to identify students needing targeted group and/or individualized interventions.

Strongly agree

Agree

Disagree

Strongly Disagree

8. Teachers are trained how to collect and analyze progress monitoring data.

Strongly agree

Agree

Disagree

Strongly Disagree 


\section{Part III. Teacher Knowledge Survey}

(Answers in italics)

1. How many speech sounds (phonemes) are in the following words?
a. edge: $1 \quad 2 \quad 2 \quad 3 \quad 4 \quad 5$
b. thrill: $\quad 1 \quad 2 \quad 3 \quad 4 \quad 4 \quad 5$
c. does: $11 \quad 2 \quad 3 \quad 4 \quad 5$
d. sawed: $\quad 1 \quad 2 \quad 3 \quad 4 \quad 5$
e. fix: $\quad \begin{array}{lllll}1 & 2 & 3 & 4 & 5\end{array}$

2. What is the third speech sound (phoneme) in the word wretch?: $/ c h /$ /e/ $/ \mathrm{t} / \quad / \mathrm{r} /$

3. Read the first word in each line and note the sound that is represented by the underlined letter or letter cluster. Then select the word that contains the same sound.
a. push: although sugar duty pump
b. weigh: pie height raid friend
c. was: miss nose votes rise
d. intend: this whistle baked pizza
e. ring: sink handle Rheingold signal

4.Count the number of syllables that you perceive in each of the following words. For example, the word "higher" has 2 syllables, the word "threat" has one, and the word "physician" has 3.
a. walked: $1 \begin{array}{lllll}1 & 2 & 3 & 4 & 5\end{array}$
b. capital: $\quad 1 \quad 2 \quad 3 \quad 4 \quad 5$
c. decidedly: $\quad 1 \quad 2 \quad 2 \quad 3 \quad 4 \quad 5$
d. recreational: $\quad \begin{array}{lllll}1 & 2 & 3 & 4 & 5\end{array}$
$\begin{array}{llllll}\text { e. shirt: } & 1 & 2 & 3 & 4 & 5\end{array}$

5. A syllable is:

The same as a rime.

A unit of speech organized around a vowel sound.

A sequence of letters that includes one or more vowel sounds.

Equivalent to a morpheme. 
6.An example of a closed syllable is: keep clothes up heard

7. Which word begins with a long vowel, open syllable? favor pleasant sunny planet comet

8. All of the following are irregular, high frequency words except: when does were said

9. A nonsense word that does not follow English spelling patterns is: shease toyn squive clow

10. Which word has a prefix? definition proactive mistletoe super hamburger

12. Which word has a prefix: missile distance commit interest furnish

13. A word with a prefix and suffix is: unable replaster mistletoe requirement

14. Which word does not have a prefix, root, suffix construction? prevalidate returnable unhistorical subtraction anxiety

15. Which of the following words has an adjective suffix? natural apartment city encircle emptiness

16. A compound noun is: weather tunafish himself already

17. Which word is a compound? otherwise selfish butternut wrapped although

18. Which word has a schwa? eagerly prevent definition formulate story

19. The "d" in "puddle" is doubled because: There are two /d/ phonemes in the spoken word. The sound / $\mathrm{d} /$ becomes a tongue flap in the middle position. The first " $d$ " belongs to the first syllable and the last " $d$ " belongs to the last syllable; they stay when the syllables are joined.

An extra "d" was put in to keep the first vowel short. 
20. Why is there a double $\underline{n}$ in stunning?

Because the word ends in a single consonant preceded by a single vowel, and the ending begins with a vowel.

Because the final consonant is always doubled when adding -ing.

Because the letter $\underline{u}$ has many different pronunciations.

Because the consonant $\underline{\mathrm{n}}$ is not well articulated and needs to be strengthened.

There is no principle or rule to explain this.

21. Which word has a final or ending consonant blend?

plaque sting blithe quaint which

22. Which word contains a consonant digraph?

first pumpkin squawk think scratch

23. For each of the following words, find one in the row that ends in the same sound:

a. dogs: miss his decks niece

b. coached: trapped screamed twisted filled

c. knew: sew coy igloo though

d. shrink: antique fatigue mints sting

e. stir: burr squirrel heard nerve

24. A word that is an example of the "y rule" for adding endings is:

easier hoping enjoyable plowed

25. Which of these words is NOT a magic-e syllable?

time peace hope wage drove

26. Which word is an example of this spelling rule: drop silent e when adding a suffix \ that begins with a vowel?

grimy lady stately beautifully strangely

27. What is a kernel or "bare bones" sentence made of?

First word capitalized with end punctuation.

An elaborated subject.

A subject and a predicate.

A subject, predicate, object, and modifiers.

A clause. 
28. For skilled readers, listening and reading comprehension are usually about equal. For readers in $\mathrm{K}-3$, it is true that:

Reading comprehension is better than listening comprehension.

Listening comprehension is better than reading comprehension.

Reading and listening comprehension was comparable, about the same.

The relation between reading and listening is idiosyncratic.

29. The following are ways to increase reading fluency:

Extra practice writing and reading complex phonic elements.

Repeated readings of easy text.

Both of the above.

Neither of the above.

30. If a student spells the word "electricity" as "elektrisuty" which of the following is most likely true?

The student does not know sound-symbol correspondence.

The student has a poor ear for the sounds in our language.

The student does not know the base word and suffix from which the word

"electricity" was constructed.

The student has a poor visual memory.

All of the above.

31. The $/ \mathrm{k} /$ sounds in lake and lack are spelled differently. Why is lack spelled with ck?

The $/ \mathrm{k} /$ sound ends the word.

The word is a verb.

$\underline{c k}$ is used immediately after a short vowel.

$\underline{\mathrm{c}}$ and $\mathrm{k}$ produce the same sound.

There is no principle or rule to explain this.

32. A student writes: "I have finely finished my math project." Her misspelling of the word finally most likely indicates that she:

is not attentive to the sounds in the word.

does not know basic letter-sound relations.

has not matched spelling to the meaningful parts (morphemes) of the word.

has a limited vocabulary.

has a limited knowledge of sight words. 
33. For each word, determine the number of morphemes:
a. salamander: $1 \quad \begin{array}{lllll}2 & 3 & 4 & 5\end{array}$
$\begin{array}{llllll}\text { b. crocodile: } & 1 & 2 & 3 & 4 & 5\end{array}$
$\begin{array}{llllll}\text { c. attached: } & 1 & 2 & 3 & 4 & 5\end{array}$
d. unbelievable: $\quad 1 \quad 2 \quad 3 \quad 4 \quad 5$
e. finger: $1 \quad \begin{array}{lllll} & 2 & 3 & 4 & 5\end{array}$

34. Which of the following is a feature of English spelling?

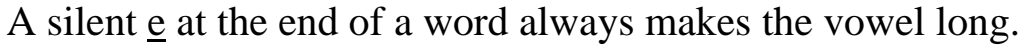

Words never end in the letters " $j$ " and "v."

When two vowels go walking, the first one does the talking.

A closed syllable must begin with a consonant.

All of the above.

35. Student must be able to orally segment and blend the phonemes in complex syllables before they can benefit from instruction in letter-sound correspondence.

True False

36. If a student is "glued to print," reading slowly word-by-word, the student should be \ told to read faster and to stop spending so much effort to decode.

True False

37. Screening at the end of kindergarten can be efficient, reliable, and valid for predicting a child's silent passage reading comprehension at the end of $3^{\text {rd }}$ grade.

True False

38. The best remedy for a weakness in nonsense word reading is lots of practice in reading nonsense words.

True False

39. Timed letter naming on DIBELS is a good risk-indicator for later reading comprehension.

True False

40. Phonological awareness exercises should always include letters or print.

True False

41. A closed syllable always begins with a consonant.

True False 
Thank you for participating in this study examining the literacy knowledge of teachers and the impact it may have on the implementation of Response to Intervention (RtI). We appreciate your willingness to support this research and the time and thought you put into completing the survey questions. 
Appendix B

\section{Consent Forms - School District and Schools}

November 2, 2009

To Whom It May Concern,

As a Superintendent of Conewago Valley School District, I am writing to give permission for Amy Conner Love to conduct her research study at New Oxford Elementary, Conewago Township Elementary, Conewago Valley Intermediate, New Oxford Middle, and New Oxford High Schools. I understand this study will investigate the knowledge levels elementary general education teachers, reading teachers/specialists, literacy coaches, elementary and secondary special educators, teachers of English language learners, and secondary language arts/English teacherspossess in reading instruction. This study will include an online survey for classroom teachers as well as an option to take a paper and pencil version of the survey if needed. I also understand that this study, which I am giving permission to be conducted, is being done as a dissertation study as part of the West Virginia University's School of Human Resources and Education's doctoral program in Special Education.

Signature

Title 
December 6, 2009

\section{To Whom It May Concern,}

As principal of Conewago Township Elementary School, I am writing to give permission for Amy Conner Love to conduct her research study at Conewago Township Elementary School. I understand this study will investigate the knowledge levels elementary general education teachers, reading teachers/specialists, literacy coaches, special educators, and teachers of English language learners possess in reading instruction. This study will include an online survey for classroom teachers as well as an option to take a paper and pencil version of the survey if needed. I also understand that this study, which I am giving permission to be conducted, is being done as a dissertation study as part of the West Virginia University's School of Human Resources and Education's doctoral program in Special Education.

Signature

Title 
December 6, 2009

\section{To Whom It May Concern,}

As principal of Conewago Valley Intermediate School, I am writing to give permission for Amy Conner Love to conduct her research study at Conewago Valley Intermediate School. I understand this study will investigate the knowledge levels elementary general education teachers, reading teachers/specialists, literacy coaches, special educators, and teachers of English language learners possess in reading instruction. This study will include an online survey for classroom teachers as well as an option to take a paper and pencil version of the survey if needed. I also understand that this study, which I am giving permission to be conducted, is being done as a dissertation study as part of the West Virginia University's School of Human Resources and Education's doctoral program in Special Education.

Signature

Title 
December 6, 2009

\section{To Whom It May Concern,}

As principal of New Oxford Elementary School, I am writing to give permission for Amy Conner Love to conduct her research study at New Oxford Elementary School. I understand this study will investigate the knowledge levels elementary general education teachers, reading teachers/specialists, literacy coaches, special educators, and teachers of English language learners possess in reading instruction. This study will include an online survey for classroom teachers as well as an option to take a paper and pencil version of the survey if needed. I also understand that this study, which I am giving permission to be conducted, is being done as a dissertation study as part of the West Virginia University's School of Human Resources and Education's doctoral program in Special Education.

Signature

Title 
December 6, 2009

\section{To Whom It May Concern,}

As principal of New Oxford High School, I am writing to give permission for Amy Conner Love to conduct her research study at New Oxford High School. I understand this study will investigate the knowledge levels reading teachers/specialists, literacy coaches, special educators, teachers of English language learners, and secondary language arts/English teachers possess in reading instruction. This study will include an online survey for classroom teachers as well as an option to take a paper and pencil version of the survey if needed. I also understand that this study, which I am giving permission to be conducted, is being done as a dissertation study as part of the West Virginia University's School of Human Resources and Education's doctoral program in Special Education.

Signature

Title 
December 6, 2009

\section{To Whom It May Concern,}

As principal of New Oxford Middle School, I am writing to give permission for Amy Conner Love to conduct her research study at New Oxford Middle School. I understand this study will investigate the knowledge levels reading teachers/specialists, literacy coaches, special educators, teachers of English language learners, and secondary language arts/English teachers possess in reading instruction. This study will include an online survey for classroom teachers as well as an option to take a paper and pencil version of the survey if needed. I also understand that this study, which I am giving permission to be conducted, is being done as a dissertation study as part of the West Virginia University's School of Human Resources and Education's doctoral program in Special Education.

Signature

Title 


\section{Table F}

\section{Appendix C}

Correct responses on each Literacy Knowledge Assessment item (N=35)

How many speech sounds (phonemes) are in the following words?

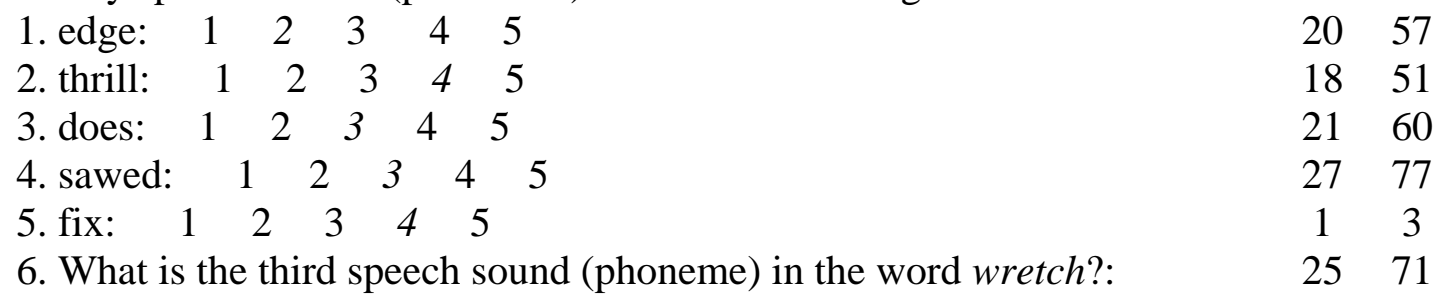

$$
\text { /ch/ /e/ /t/ /r/ }
$$

Read the first word in each line and note the sound that is represented by the underlined letter or letter cluster. Then select the word that contains the same sound.

7. push: although sugar duty pump $\quad 32 \quad 91$

8. weigh: pie height raid friend $\quad 32 \quad 91$

9. was: miss nose votes rise 2366

10. intend: this whistle baked pizza $\quad 28 \quad 80$

11. ring: sink handle Rheingold signal $\quad 12 \quad 34$

Count the number of syllables that you perceive in each of the following words. For example, the word "higher" has 2 syllables, the word "threat" has one, and the word "physician" has 3.

12. walked: $1 \begin{array}{lllll} & 2 & 3 & 4 & 5\end{array}$

$26 \quad 74$

13. capital: $120 \quad 3 \quad 4 \quad 5$

35100

14. decidedly: $1 \quad 2 \quad 3 \quad 4 \quad 5$

35100

15. recreational: $1 \begin{array}{llllllll}1 & 2 & 3 & 4 & 5 & 35 & 100\end{array}$

$\begin{array}{lllllllll}\text { 16. shirt: } & 1 & 2 & 3 & 4 & 5 & 31 & 89\end{array}$

17. A syllable is:

The same as a rime.

A unit of speech organized around a vowel sound.

A sequence of letters that includes one or more vowel sounds.

Equivalent to a morpheme.

18. An example of a closed syllable is: keep clothes up heard

19. Which word begins with a long vowel, open syllable?

favor pleasant sunny planet comet

20. All of the following are irregular, high frequency words except: $\quad 2160$ when does were said

21. A nonsense word that does not follow English spelling patterns is: $\quad 2571$ shease toyn squive clow

22. Which word has a prefix?

35100

definition proactive mistletoe super hamburger 
23. Which word has a prefix:

n $\%$

missile distance commit interest furnish

24. A word with a prefix and suffix is: $\quad 17 \quad 49$

unable replaster mistletoe requirement

‘ 25. Which word does not have a prefix, root, suffix construction? $\quad 33 \quad 94$ prevalidate returnable unhistorical subtraction anxiety

26. Which of the following words has an adjective suffix? $\quad 15 \quad 43$ natural apartment city encircle emptiness

27. A compound noun is: weather tunafish himself already

28. Which word is a compound? otherwise selfish butternut wrapped although

29. Which word has a schwa? eagerly prevent definition formulate story

30. The "d" in "puddle" is doubled because:

There are two /d/ phonemes in the spoken word.

The sound / $\mathrm{d}$ / becomes a tongue flap in the middle position.

The first " $d$ " belongs to the first syllable and the last " $d$ " belongs to the last syllable; they stay when the syllables are joined.

An extra "d" was put in to keep the first vowel short.

31. Why is there a double $\underline{n}$ in stunning?

Because the word ends in a single consonant preceded by a single vowel, and the ending begins with a vowel.

Because the final consonant is always doubled when adding -ing.

Because the letter $\underline{u}$ has many different pronunciations.

Because the consonant $\underline{\underline{n}}$ is not well articulated and needs to be strengthened.

There is no principle or rule to explain this.

32. Which word has a final or ending consonant blend?

$10 \quad 29$

plaque sting blithe quaint which

33. Which word contains a consonant digraph?

first pumpkin squawk think scratch

For each of the following words, find one in the row that ends in the same sound:

34. dogs: miss his decks niece $17 \quad 49$

35. coached: trapped screamed twisted filled $\quad 27 \quad 77$

36. knew: sew coy igloo though $\quad 28 \quad 80$

37. shrink: antique fatigue mints sting $\quad 30 \quad 86$

38. stir: burr squirrel heard nerve $\quad 32 \quad 91$

39. A word that is an example of the "y rule" for adding endings is: $\quad 28 \quad 80$ easier hoping enjoyable plowed

Continued 


\begin{tabular}{lcc} 
& $\mathrm{n}$ & $\%$ \\
\hline 40. Which of these words is NOT a magic-e syllable? & 29 & 83 \\
time peace hope wage drove & & \\
41. Which word is an example of this spelling rule: drop silent e when & 28 & 80 \\
adding a suffix that begins with a vowel? & \\
grimy lady stately beautifully strangely & 28 & 80 \\
42. What is a kernel or "bare bones" sentence made of? & \\
First word capitalized with end punctuation. & \\
An elaborated subject. & \\
A subject and a predicate. & \\
A subject, predicate, object, and modifiers. &
\end{tabular}

43. For skilled readers, listening and reading comprehension are usually $\quad 25 \quad 71$ about equal for readers in K-3, it is true that:

Reading comprehension is better than listening comprehension.

Listening comprehension is better than reading comprehension.

Reading and listening comprehension was comparable, about the same.

The relation between reading and listening is idiosyncratic.

44. The following are ways to increase reading fluency:

Extra practice writing and reading complex phonic elements.

Repeated readings of easy text.

Both of the above.

Neither of the above.

45. If a student spells the word "electricity" as "elektrisuty" which of the

$15 \quad 43$ following is most likely true?

The student does not know sound-symbol correspondence.

The student has a poor ear for the sounds in our language.

The student does not know the base word and suffix from which the word "electricity" was constructed.

The student has a poor visual memory.

All of the above.

46. The / $\mathrm{k} /$ sounds in lake and lack are spelled differently. Why is lack spelled with ck?

The $/ \mathrm{k} /$ sound ends the word.

The word is a verb.

$\underline{c k}$ is used immediately after a short vowel.

$\underline{\mathrm{c}}$ and $\underline{\mathrm{k}}$ produce the same sound.

There is no principle or rule to explain this.

For each word, determine the number of morphemes:

$\begin{array}{llllllllll}\text { 48. salamander: } & 1 & 2 & 3 & 4 & 5 & 11 & 31 \\ \text { 49. crocodile: } & 1 & 2 & 3 & 4 & 5 & & 11 & 31 \\ \text { 50. attached: } & 1 & 2 & 3 & 4 & 5 & & 10 & 29 \\ \text { 51. unbelievable: } & 1 & 2 & 3 & 4 & 5 & 13 & 37 \\ \text { 52. finger: } 1 & 2 & 3 & 4 & 5 & & & 13 & 37 \\ & & & & & & & \text { (continued) }\end{array}$




\begin{tabular}{lll} 
& $\mathrm{n}$ & $\%$ \\
\hline 53. Which of the following is a feature of English spelling? & 4 & 11
\end{tabular}

53. Which of the following is a feature of English spelling?

$4 \quad 11$

A silent $\mathrm{e}$ at the end of a word always makes the vowel long. Words never end in the letters " $j$ " and "v."

When two vowels go walking, the first one does the talking.

A closed syllable must begin with a consonant.

All of the above.

54. Student must be able to orally segment and blend the phonemes in

$17 \quad 49$

complex syllables before they can benefit from instruction in letter-

sound correspondence.

True False

55. If a student is "glued to print," reading slowly word-by-word, the student should be told to read faster and to stop spending so much effort to decode.

True False

56. Screening at the end of kindergarten can be efficient, reliable, and valid for predicting a child's silent passage reading comprehension at the end of $3^{\text {rd }}$ grade.

True False

57. The best remedy for a weakness in nonsense word reading is lots of practice in reading nonsense words.

True False

58. Timed letter naming on DIBELS is a good risk-indicator for later

reading comprehension.

True False

59. Phonological awareness exercises should always include letters or

1851 print.

True False

60. A closed syllable always begins with a consonant. 


\section{AMY CONNER LOVE}

\section{OBJECTIVE:}

To pursue a career as an ASSISTANT PROFESSOR, SPECIAL EDUCATION in which I may contribute developed skills in a challenging position.

\section{EDUCATION:}

West Virginia University, Morgantown, WV

Ed. D., Special Education, Personnel Preparation, May 2010

Dissertation: "Literacy Knowledge Among Teachers: Considerations for Implementation of the RtI Initiative"

Minor: Educational Psychology

Mount Saint Mary’s College, Emmitsburg, MD

Master of Education, May 2002

Concentrations: Special Education, Elementary Education, and Reading

Western Maryland College, Westminster, MD

Graduate course work concentrated in Secondary Special Education, 2001

Clarion University of Pennsylvania, Clarion, PA

Bachelor of Science, Business Administration, May 1994

Majors: Finance and Accounting Minor: Economics

\section{PROFESSIONAL EXPERIENCE:}

Clarion University of Pennsylvania, Clarion, PA

2007 - 2008,

Instructor, Special Education and Rehabilitative Sciences

2009 - present

Courses: Applied Behavioral Analysis, Social and Emotional Disturbances,

Direct Instruction Reading, Exceptionalities in the General Education

Classroom

Prepared and delivered lectures, study sessions, and exams.

Clarion Area School District, Clarion, PA

Learning Support Teacher at Clarion Elementary School

$2006-2007$

Taught/developed/modified curricula and lesson plans in Reading and

Mathematics in a self-contained classroom. Determined educational requirements and ensured implementation of individualized educational plans.

Brookville Area School District, Brookville, PA

$2005-2006$

Learning Support Teacher at Brookville High School

Taught Direct Instruction Reading, Written Expression, and Mathematics in a self-contained classroom. Taught Life Skills curriculum to students with moderate/severe disabilities. 


\section{PROFESSIONAL EXPERIENCE, continued}

Conewago Valley School District, New Oxford, PA

Learning Support Teacher at New Oxford Middle School $2004-2005$

Taught/developed/modified curricula and lesson plans in the Language Arts, Mathematics, Social Studies, and Science co-taught inclusion and self-contained classrooms. Conducted educational testing, interpreted results, and designed/implemented individualized plans for students. Established close working relationships with general education staff to modify and implement curriculum through differentiated instruction

Frederick County Public Schools, Frederick, MD

Special Education Teacher at Walkersville Middle School $2002-2004$

Special Education Teacher at Governor Thomas Johnson Middle School $1999-2002$

Summer School Teacher at Governor Thomas Johnson Middle School $2000-2002$

Special Education Assistant at New Market Middle School

Taught/developed/modified curricula and lesson plans in the Language Arts, Mathematics, Social Studies, and Science co-taught inclusion and self-contained classrooms. Conducted educational testing; interpreted results and designed/implemented individualized plans for students; determined educational requirements and ensured implementation of individualized educational plans. Organized professional development sessions on implementing accommodations and modifications in the inclusive classroom. Observed and assessed classroom behavior and performance and developed behavioral strategies.

\section{PRESENTATION(S):}

Peer-Reviewed and Accepted Presentations

ter Haseborg, H., Hubler-Larimore, L., Love, A., Lynch, S., Moore, T., Roth, M., \& Curtis, R. (2010, May). Perception of professional development schools partnership at West Virginia University. Poster presented at the annual meeting of the American Education Research Association Conference. Denver, CO.

Love, A. (2010, April). Literacy knowledge among teachers: What the statistics could mean for RTI, Poster presented at the annual meeting of the Council for Exceptional Children Annual Conference, Nashville, TN.

Smith, J. J., Hubler-Larimore, L., Love, A., \& Wu, C. H. (2010). Analysis of the 2009 Benedum Collaborative Review. Report prepared for the Benedum Collaborative, West Virginia University.

Love, A., Moore, T., \& Kohlmeyer, C., \& Hoppey, D. (2009, November). The impact of response to intervention (RtI) implementation on special education teachers' roles and responsibilities: Perceptions from the field. Poster presented at the annual meeting of the Teacher Education Division Conference, Council for Exceptional Children. Charlotte, NC.

Servilio, K., Moore, T., \& Love, A. (2009, April). Differentiating in the new millennium. Poster presented at the annual meeting of theCouncil for Exceptional Children Annual Conference. Seattle, WA.

\section{AWARD(S) AND CERTIFICATION(S):}

Scholarship Recipient at West Virginia University for Project FastTrack: A federally funded intensive Special Education Doctoral Program to Prepare Teacher Educators in Special Education, Awarded 2008 


\section{AWARD(S) AND CERTIFICATION(S), continued}

Pennsylvania - Instructional Level I Certification, Special Education (Grades K - 12)

Instructional Level I Certification, Business/Computer/Information Technology (Grades K-12)

Instructional Level I Certification, Middle Level Mathematics

Instructional Level I Certification, Middle Level English

Maryland - Advanced Professional Certification, Special Education (Grades 1 - 8)

\section{PROFESSIONAL SERVICE:}

Manuscript Review for Teacher Education and Special Education

\section{COMMITTEES/PROFESSIONAL AFFILIATION(S):}

WVU HR\&E's Outstanding Teacher Selection Committee, 2009

Council for Exceptional Children, Member

Teacher Educator Division, Council for Exceptional Children, Member

International Reading Association, Member

Pi Lambda Theta, International Honor Society/Professional Association in Education, Member

\section{REFERENCES:}

Available upon request. 